\title{
Title: A Microtubule Mechanostat Enables Cells to Navigate Confined Environments
}

Authors: Robert J. Ju${ }^{1,2}$, Alistair D. Falconer ${ }^{8}$, Caitlyn K.X. Tang ${ }^{1}$, Kevin M. Dean ${ }^{3,4}$, Reto P. Fiolka $^{3,4}$, David P. Sester, Max Nobis ${ }^{5}$, Paul Timpson ${ }^{5}$, Alexis J. Lomakin ${ }^{6}$, Melanie D. White ${ }^{1}$, Dietmar B. Oelz ${ }^{8}$, Nikolas K. Haass ${ }^{2}$ and Samantha J. Stehbens ${ }^{1,2 *+}$.

\section{Affiliations:}

${ }^{1}$ The University of Queensland, Institute for Molecular Bioscience; St Lucia Brisbane,

${ }^{2}$ The University of Queensland, The University of Queensland Diamantina Institute, Translational Research Institute; Woolloongabba, Brisbane, Queensland 4102, Australia.

${ }^{3}$ Lyda Hill Department of Cell Biology, University of Texas Southwestern Medical Center; Dallas, TX, USA.

${ }^{4}$ Department of Bioinformatics, University of Texas Southwestern Medical Center; Dallas, TX, USA.

${ }^{5}$ The Garvan Institute of Medical Research and The Kinghorn Cancer Centre, Cancer Division, St. Vincent's Clinical School, Faculty of Medicine; University of New South Wales, Sydney, NSW 2010

${ }^{6}$ Medical University of Vienna, Center for Pathobiochemistry and Genetics, Institute of Medical Genetics; Vienna, Austria

${ }^{7}$ Medical University of Vienna, Center for Pathobiochemistry and Genetics, Institute of Medical Chemistry and Pathobiochemistry; Vienna, Austria

${ }^{8}$ The University of Queensland, School of Mathematics and Physics; St Lucia Brisbane, Queensland, Australia.

*Correspondence to: Samantha Stehbens, Email: s.stehbens@uq.edu.au

Abstract: Cells migrating through complex 3D environments face considerable mechanical challenges. Cortical contractility must be highly coordinated to drive both cell movement and squeeze the large nucleus through confined regions. How cells protect themselves against mechanical forces and achieve nuclear transmigration in this context is largely unknown. Here, we demonstrate that cells experiencing confinement form a microtubule-dependent mechanostat in response to compressive forces. The mechanostat is an adaptive feedback mechanism whereby compressive loading of microtubules recruits CLASPs (cytoplasmic linker-associated proteins) to dynamically tune and repair the lattice. These reinforced microtubules allow the cell to withstand force and spatiotemporally organize contractility signaling pathways. Disruption of the mechanostat imbalances cortical contractility, stalling migration and ultimately resulting in catastrophic cell rupture. 
Main Text: Cells exist in highly crowded 3D environments where they need to migrate under physical confinement. Cells navigating 3D environments experience variable physical forces and respond by modulating their behavior and shape to exert forces on the surrounding microenvironment. Importantly, movement in 3D settings not only requires active force generation but active force resistance. Microtubules are required for cell migration through mechanically confined 3D environments (1) - yet the reason for this remains unknown (2). Confinement restrains cell shape, crowding microtubule organization and inducing high curvature of polymers that physically damages the microtubule lattice (3). Microtubules are mechano-adaptive structuresexhibiting self-repair behaviors (4) by modifying the physical properties of polymers through the local incorporation of GTP tubulin dimers at damage sites. Repaired polymers are more resistant to bending-induced breakage- resulting in longer lived, more stable microtubules. Mechanical forces are transmitted across the microtubule lattice, effectively communicating the biophysical forces of the surroundings to intracellular structures physically linked to microtubules- including the nucleus $(5,6)$. Microtubules also sequester key upstream actomyosin regulatory factors (7), to ensure appropriate timing of release and activation of contractile forces to facilitate cell shape changes and movement. Thus, localized mechanoreponsive tuning mechanisms are necessary to ensure that microtubules are repaired and reinforced in areas of high mechanical load This facilitates both positioning and protection of organelles, as well as spatiotemporal regulation of the microtubule-contractility axis that controls migration. How the mechanochemical tuning of microtubule properties is locally regulated to drive cell motility in $3 \mathrm{D}$ environments is not well understood.

\section{A microtubule cage in confined cells}

To understand microtubule organization and function in various 3D environments, we applied Light Sheet Fluorescence Microscopy (LSFM) (8) and volumetrically imaged endogenously tagged microtubules ( $\alpha$-tubulin-eGFP) in a highly migratory cell line, $1205 \mathrm{Lu}$ melanoma cells, embedded deep in reticulated collagen hydrogels (Fig. 1A). We observed that microtubules in these conditions were organized in a highly curved and dynamic cage-like structure enclosing the nucleus and lining the cell cortex Fig. 1B, fig. S1 and movie S1, S2). As the cell routed between reticulated collagen constrictions, the cage dynamically reorganized, the nucleus constantly repositioned and microtubules accumulated at points of cellular constriction (Fig. 1C). Microtubules that exhibit high curvature are prone to lattice fractures and depolymerization (3). Thus, we hypothesized that the maintenance of this highly curved cage-like structure may require mechanical reinforcement through dynamic repair mechanisms.

\section{CLASP-mediated reinforcement of the microtubule cage allows cells to withstand confinement}

To investigate the stability of the microtubule cage, we examined mechanisms that repair damaged microtubules in response to mechanical insult. Cytoplasmic linker associated proteins (CLASPs) are a family of plus-end tracking proteins (+TIPs) that act as microtubule rescue or anticatastrophe factors, spatio-temporally regulating microtubule growth (9). +TIPs such as CLASP, support the continual growth of microtubules, which enhances acetylation of the intraluminal Lysine 40 residue of $\alpha$-tubulin (AcK40)- stabilizing microtubules (10) and making polymers more flexible in response to mechanical force (11). CLASPs also assist repair of mechanical damage to polymers by locally exchanging tubulin dimers at fracture sites $(12,13)$. Strikingly, when CLASPs are depleted, cells navigate tight spaces in 3D collagen more slowly and eventually rupture and die (Fig. 1D-E, movie S3 and fig. S2A-D). Cell death was confirmed by annexin positivity (Fig. S2E-F). Furthermore, microtubule acetylation was lost in CLASP-depleted cells in 3D collagen (Fig. 1F and fig. S3A) consistent with reports in 2D (14) (Fig. S3B, S2A), with no detectable 
change in total tubulin levels (Fig. S3C). To more accurately control the spatial and mechanical constraints experienced by cells as they navigate complex 3D environments, we microfabricated confinement channels with constrictions consisting of cylindrical pillars $(2.5-2 \mu \mathrm{m} \times 4 \mu \mathrm{m})$ representing pore sizes cells navigate through in 3D collagen gels (Fig. 1G, fig. S4A) (15, 16). Using 3D Structured Illumination Microscopy (3D-SIM) to volumetrically image cells in microchannels we confirmed the presence of the microtubule cage (Movie S4). As in 3D collagen, CLASP-depleted cells rupture in confinement (Fig. 1H-I, fig. S4C-E and movie S5, movie S6). This behavior was consistent across melanoma, medulloblastoma and fibroblast cell lines (Fig. 1I). Again, CLASP-depletion caused microtubule depolymerization specifically when cells experienced confinement (Fig. 1J, and fig. 2A-B), preceding annexin V positivity (Fig. 1J) suggesting microtubules are required to resist cell death induced by mechanical forces. These data demonstrate that in the absence of CLASPs, microtubules are unable to resist mechanical compression and depolymerize, resulting in cell rupture and death.

\section{Mechanoresponsive CLASP localization confers spatiotemporal microtubule stability}

Microtubule repair factors such as CLASPs and AcK40, act as proxy signals to label sites of microtubule lattice damage and repair $(17,18)$. We hypothesized that CLASPs and enzymes acetylating $\alpha$-tubulin at Lysine 40 (AcK40) would be recruited to cellular regions correlating with high microtubule curvature and mechanical stress to locally repair and reinforce the microtubule lattice. First, we examined the localization of CLASPs (2xmNeonGreen-CLASP1) as cells passed through constrictions. After the front of the cell enters a constriction, the nucleus becomes occluded and must deform to transmigrate through the confined region (Fig. S4B). We found that once nuclear occlusion occurred, CLASPs were spatially regulated localizing to two distinct pools: 1) a stable rear pool in the cellular compartment behind the nucleus, and 2) a dynamic pool associating with growing plus-ends in the compartment in front of the nucleus (Fig. 2C-D, fig. S5). Acute compression of $2 \mathrm{xmNeonGreen-CLASP1}$ expressing cells induced a shift in CLASP localization from microtubule plus-ends to along the lattice, demonstrating that CLASP1 is mechanoresponsive (Fig. 2E; 3 microns axial confinement). As microtubule acetylation cannot be visualized in real time, we assessed the relative distribution of AcK40 and tyrosinated (Tyr) $\alpha-$ tubulin, to identify stable and dynamic pools of microtubules, respectively (Fig. 2F-G; fig. S6A-B and movie S7) (10, 19). Like CLASP, AcK40 localization became polarized upon nuclear transmigration between pillars, predominantly labeling microtubules in the rear cytoplasmic compartment (Fig. 2G; early). As cells progressed further through constrictions, the rear AcK40 re-localized to parallel microtubule bundles enveloping the nucleus (Fig. 2G; mid) - a similar location to where Arp2/3-dependent actin nucleation generates lateral pressure on the nucleus to deform it (20). Once the nucleus progressed through a constriction, the AcK40 polarization of the front and rear microtubule pools was lost (Fig. 2G; post/pre). In CLASP-depleted cells, AcK40 failed to accumulate in the rear compartment (Fig. 2H, fig. S6C), and nuclei were uncaged and mispositioned.

\section{CLASP-reinforced microtubules are required for nuclear positioning during confinement}

Control cells entering constrictions position their nucleus with the long axis aligned with the axis of migration (Fig. 3A-B). However, CLASP-depleted cells fail to reorient their nuclei (Fig. 3B) and spend significantly longer in highly constricted states of non-productive migration (Fig. 3CD, and fig. S7A-B) with nuclear deformation (Fig. 3E and fig. S7D) and aberrant nuclei positioning (Fig. 3B-F). CLASP-depleted cells showed an increase in nuclear rupture events (Fig. 3F and fig. S7C) compared to control cells, indicating that the loss of the microtubule cage also results in nuclear damage. 
CLASP-stabilized microtubules are required to balance cortical contractility and hydrostatic pressure.

CLASP-depleted cells undergoing constricted migration display persistent, abnormal cortical blebbing (Fig. 1J, Movie S6). Blebs are membrane protrusions that form when actomyosin contraction generates hydrostatic pressure that causes detachment of the membrane from the underlying cortical actin. Influx of cytosolic content enlarges the membrane protrusion, which can retract once the pressure is re-equilibrated and balanced by repair of the cortex $(21,22)$. In constricted control cells with fluorescently labeled membranes (LCK-mScarlet-i) and F-actin (Lifeact-eGFP), we observed occasional small blebs at the rear membrane, indicating higher cortical contractility and hydrostatic pressure in the rear compartment than in the front compartment (Fig. 4A). This polarized rear blebbing quickly resolved once cells progressed through constrictions (Movie S8). In comparison, constricted CLASP-depleted cells (Fig. 4B) exhibited significantly larger, more persistent blebs with faster protrusion velocities, in both the front and rear of cells (Fig.4C-F, Fig. S8). This unpolarized blebbing behavior persisted for prolonged periods during which cells could not progress through constrictions (Movie S8). Whilst the blebs in CLASP-depleted cells protruded with a greater velocity than control cells, they resolved at the same retraction velocity (Fig. 4F) indicating that cortical repair mechanisms were intact. These data suggest that mechanically reinforced microtubules are required to locally harmonize cortical contractility and hydrostatic pressure.

Mechanically reinforced microtubules allow spatiotemporal control of contractility

We then sought to understand how CLASP-dependent microtubule reinforcement might locally control actomyosin contractility. First, we investigated the spatiotemporal relationship between microtubules and myosin during nuclear transmigration. As control cells labelled for microtubules (eGFP- $\alpha$-tubulin), myosin light chain (MYL9, MLC-mTurquoise2) and nuclei (Snaptag-H2B) entered constrictions and the nucleus became occluded, myosin accumulated proximal to the rear plasma membrane (Fig. 4G) consistent with previous studies $(20,23-26)$. The myosin signal increased in intensity as the nuclear constriction progressed and the rear compartment membrane contracted maximally. Cells maintained a cytoplasmic compartment between the nucleus and rear membrane, filled with highly curved microtubules (Fig. 4I; movie S9) coincident with those decorated with static CLASPs (Fig. 2C) and AcK40 (Fig. 2F, and fig. $\mathrm{S} 6 \mathrm{~B})$. Although the microtubules in the front cellular compartment maintained a polymer structure, the rear pool of microtubules disassembled immediately prior to nuclear propulsion through the constriction (Fig. 4I, arrowheads, and Fig. 4K, movie S9). This rear pool of mechanically reinforced microtubules was noticeably absent in CLASP1-depleted cells (Fig. 4H and J, and movie S9). We propose that increasing hydrostatic pressure in the rear compartment forms a cushion of CLASP-reinforced microtubules. This cushion allows the cytosolic pressure behind the nucleus to reach a critical threshold to overcome the resistance to nuclear translocation $(25,26)$.

Microtubules regulate the spatial and temporal activation of Rho-dependent actomyosin contractility of cells (27) - a phenomena recently named the 'microtubule-contractility axis' (28). The RhoA activating protein GEF-H1 (ARHGEF2), is a microtubule-bound GEF which locally integrates microtubule and actin dynamics $(29,30)$. GEF-H1 is held in a catalytically inactive state on microtubule polymers(31), and activated upon release from depolymerizing microtubules. To investigate if mechanically reinforced microtubules control myosin localization through sequestration and release of GEFH1, we imaged cells expressing a GEFH1 activity biosensor (GEF-H1 FLARE212) (30) (Fig. 5, A-C, and movie S10). Following nuclear occlusion in constrictions, there was a rapid increase in GEFH1 activity in the rear compartment (Fig. 5A, high 
FRET, yellow; and 5C), likely due to release of inactive GEF-H1 from the depolymerizing microtubule cushion (Fig. 5B). The cell nucleus then rapidly passed through the constriction. Consistent with our observations of myosin localization, CLASP-depleted cells which lack the microtubule cushion were unable to concentrate GEFH1 activity to the rear of cells (Fig. 5, A-C; CLASP1shRNA). Furthermore, cells undergoing nuclear transmigration revealed a burst of Rho (eGFP-RhoA) (32) behind the nucleus (Fig. 5E and Movie S11) correlating with the timing of microtubule depolymerization (Fig. 4I) and GEF release (Fig. 5A-C) in the rear compartment (Fig. $5 \mathrm{~F}$ ) immediately prior to nuclear translocation. This coordinated Rho accumulation was absent in CLASP-depleted cells (Fig. 5, E-F, CLASP1shRNA). Instead, Rho accumulation fluctuated at various locations across the cell membrane in both the front and rear compartment over many hours $(>8 \mathrm{~h})$. These unpolarized Rho dynamics were coincident with non-productive migration where cells would oscillate back and forth in a constricted state (movie S11). Thus, mechanical reinforcement of microtubules by CLASPs enables spatiotemporal control of the microtubulecontractility axis, allowing cells to efficiently navigate through confinement.

\section{Theoretical model of mechanostat function in confined cell migration}

We formulated a mathematical model for single-cell transmigration between two micropillars to understand how microtubules spatiotemporally control contractility during nuclear transmigration (Fig 6B). In this model, both the cell cortex and the nuclear envelope are represented by closed 2D contour lines (fig. S9A). When the nucleus is occluded it establishes front and rear cytoplasmic compartments. The mechanical component of the model relies on the balance of a constant migratory force, friction, viscous and elastic forces of nuclear centering, cortical tension, cytoplasmic pressure as well as nuclear envelope tension and nuclear pressure (Fig. 6A). The mechanical model is complemented by rearward cortical myosin flow, leading to an increase in contractility and rear-to-front flux of cytoplasm in response to the increase in rear pressure. We also involve a dense network of mechanically reinforced microtubules in the rear cytoplasmic compartment acting as the 'cushion' - preventing the rear compartment from reaching a zero volume (blue area in Fig. 6B). When the rear pressure exceeds the cushion's resistance to compression we model the disassembly of microtubules (fig. S9B). This results in a burst of Rho activity which increases cortical tension in the rear compartment (Fig 6C).

Our simulations reveal that transmigration is initially prevented by the elastic resistance of the nucleus. Once occlusion occurs, myosin accumulates in the rear cortex, triggering a difference in cortical tension and a subsequent imbalance in cytoplasmic pressure between the front and the rear compartments (Fig. 6C). During this process the microtubule cushion is compressedpreventing close physical contact between the cortex and the nucleus- allowing for pressure to build in the rear. The microtubule cushion then disassembles, releasing a burst of Rho activity (Fig. 6C graph) that accelerates the build-up of tension in the rear cortex and increases the velocity of nuclear transmigration (fig. S9C, movie S12). In simulations lacking the rear microtubule cushion and subsequent myosin up-regulation in response to microtubule disassembly, the nucleus fails to pass the constriction (Fig 6D-E, S9D; movie S13). If sufficient pulling forces remain the nucleus passes at a much later time point - spending longer in a constricted state (movie S13).

\section{Discussion}

Cells live in confined environments where they must squeeze through narrow spaces, such as matrix pores, along tissue tracks and intercellular spaces, which presents a significant mechanical challenge. As the largest and stiffest organelle, the cell nucleus is a major impediment 
to migrating through a confinement. To successfully transmigrate constrictions, cells must correctly position and protect the nucleus, and spatiotemporally coordinate actomyosin contractility to efficiently squeeze through confinement. We have established that a CLASPdependent feedback mechanism reinforces microtubules in response to compressive forces in cells undergoing confined migration. These mechanically tuned microtubules act as a mechanostat that is dynamically repaired and required to coordinate cortical contractility and nuclear positioning for migration.

Nuclear deformation and occlusion within tight pores divide the cell into front and rear compartments. It has been proposed that nuclear occlusion can generate a gradient of intracellular pressure; low at the rear and high at the front (33). However, more recent chemico-mechanical models suggest that cells overcome the resistance of nuclear constriction by a combination of actin contraction and cytosolic pressure from the rear (34). The importance of a rear cytosolic pressure gradient has been shown to be integral in compressing the nucleus to promote constricted nuclear transmigration $(20,24,25,34,35)$. While we know that this cytosolic back pressure requires locally focused actomyosin contractility, how this force-producing machinery is actively controlled at the rear within complex geometries is unclear. Our data demonstrates the local reinforcement of microtubules by CLASPs comprises a mechanostat that enables cells to 1) correctly position the nucleus and 2) spatiotemporally coordinate the actomyosin contractility that generates the cytosolic pressure required to overcome the nuclear occlusion. We propose that upon reaching a threshold of hydrostatic pressure in the rear cellular compartment, the microtubule cushion disassembles and releases GEFH1. This activates a final burst of RhoA-mediated contractility at the rear membrane which increases nuclear velocity, enabling the nucleus to escape the constriction.

The exact mechanism that causes the microtubule disassembly remains to be determined. Increasing hydrostatic pressure may directly induce microtubule depolymerization as has been shown previously (36). However, we cannot exclude that hydrostatic pressure indirectly affects microtubule stability, potentially downstream of mechanosensitive ion channels (37). In the absence of reinforcement by CLASPs, microtubules may be less able to withstand the effects of increasing hydrostatic pressure, causing inappropriate disassembly, release of GEFH1 and uncoordinated actomyosin contractility. The inability to repair lattice damage and resist mechanical stress, likely drives a switch- from a tightly regulated microtubule-contractility axis to an induction of global contractility. This results in a loss of front-rear polarity and an imbalance of the forces required for nuclear translocation.

Our findings demonstrate that the mechanostat is crucial for maintaining cellular mechanical integrity in confinement. We demonstrate a requirement for mechanoresponsive reinforcement of the microtubule lattice in response to compressive forces during constriction. Failure to efficiently repair and reinforce spatially distinct pools of microtubules during mechanical challenges promotes catastrophic cell rupture and death in confined 3D environments. 
bioRxiv preprint doi: https://doi.org/10.1101/2022.02.08.479516; this version posted February 9, 2022. The copyright holder for this preprint (which was not certified by peer review) is the author/funder. All rights reserved. No reuse allowed without permission.

Fig 1
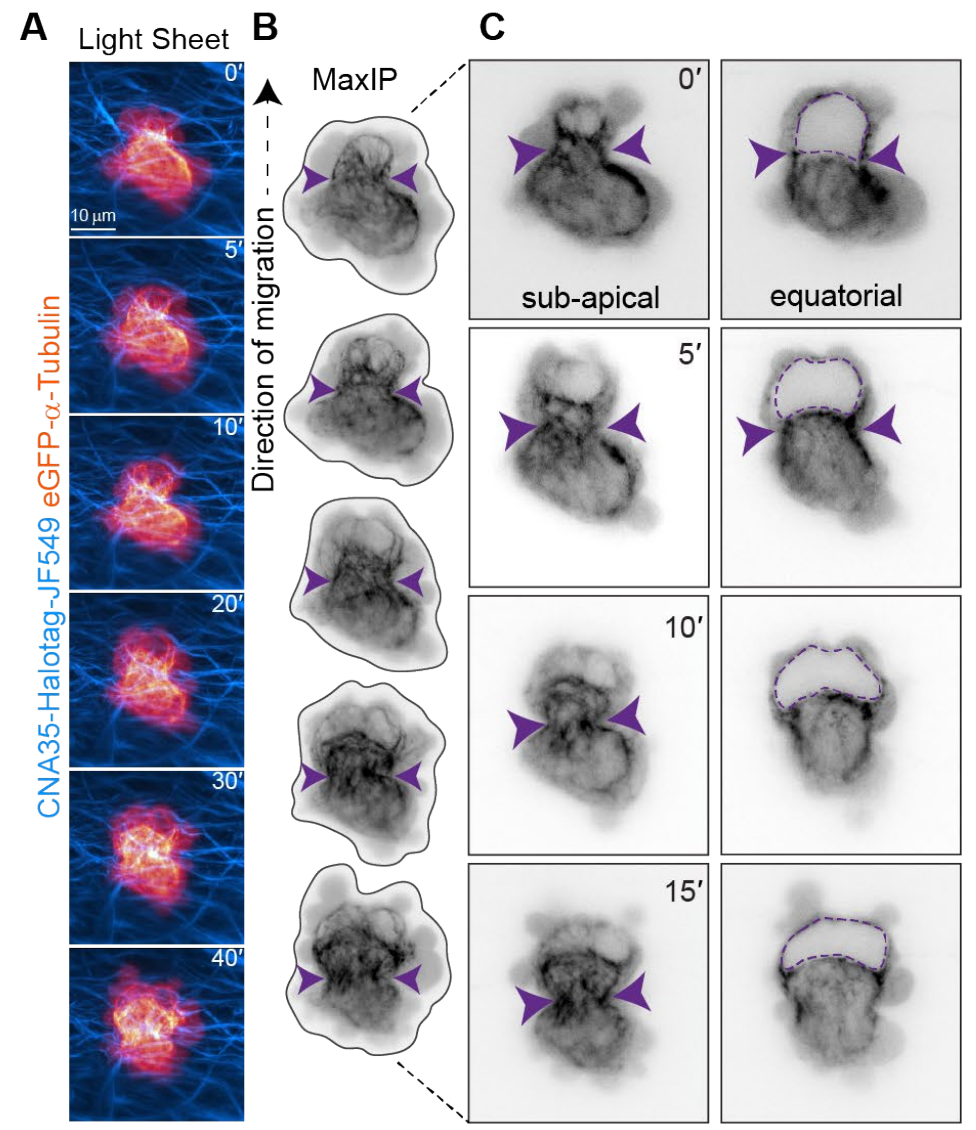

D
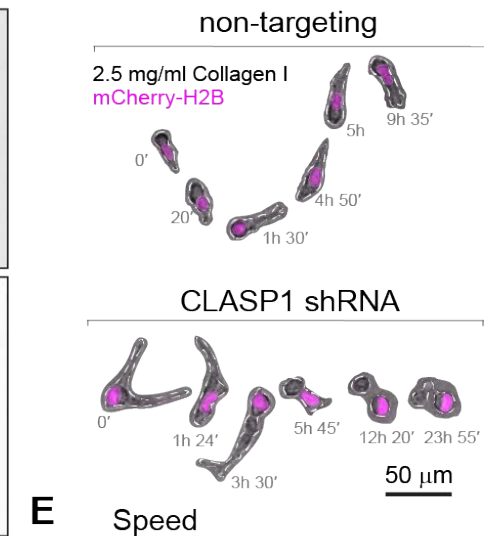

E Speed
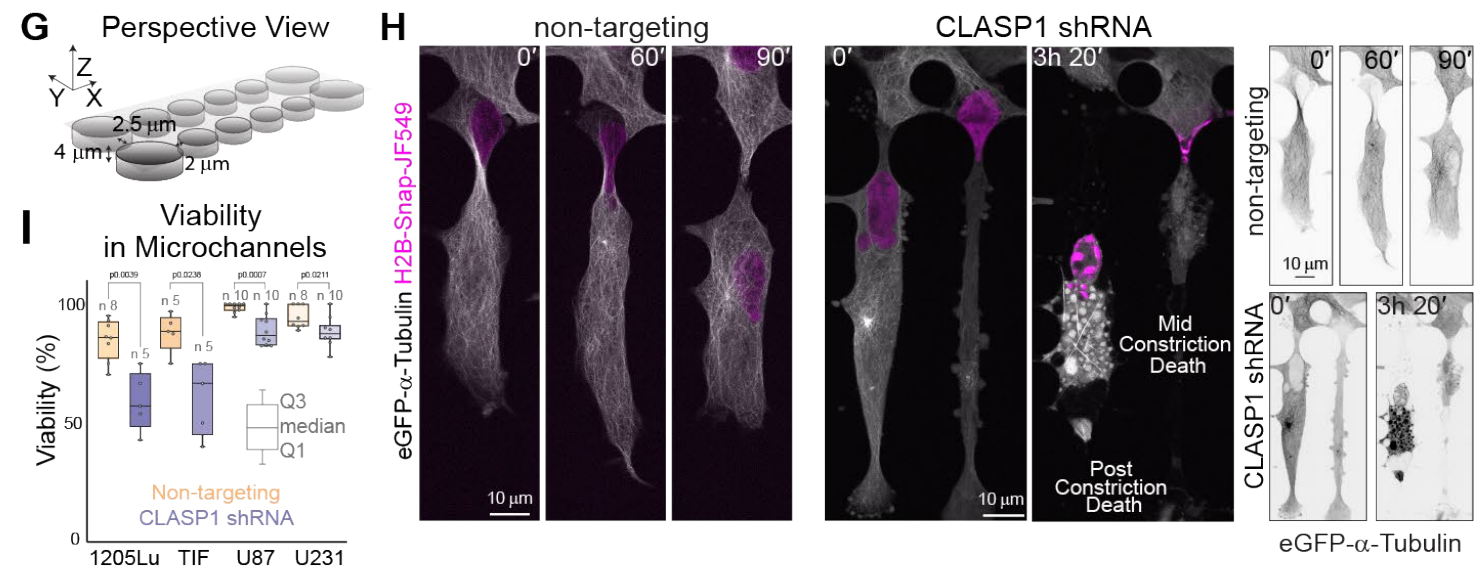

J CLASP2-Depleted Cell in Confinement

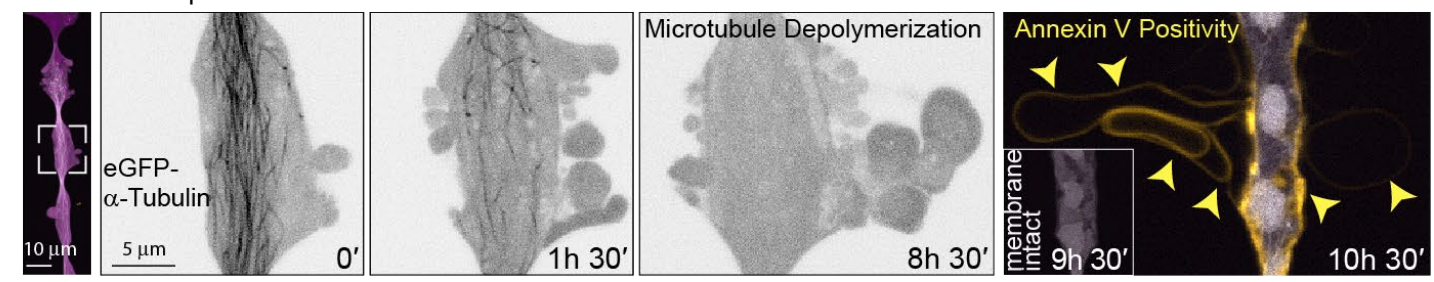


Fig.1. A CLASP1-dependent dynamic microtubule cage is required for cell migration in complex 3D environments. (A) 1205Lu cells endogenously expressing eGFP- $\alpha$-tubulin migrating through reticulated 3D collagen I hydrogel. LSFM volumetric imaging reveals microtubule dynamics as cells squeeze between matrix fibers. (B) Microtubule organization (eGFP- $\alpha$-tubulin) during constriction (purple arrowheads). (C) Sub-apical and equatorial Z sections of cell in B. Purple dotted line defines nucleus. (D) CLASP1 depletion causes cell death during 3D migration. Representative time-lapse of control (non-targeting shRNA) and CLASP1-depleted nuclear labeled (mCherry-H2B) 1205Lu cells navigating 3D collagen I hydrogels. (E) 3D migration speed of control and CLASP1-depleted cells embedded in Collagen I. (F) Immunofluorescence of acetylated alpha-tubulin (AcK40) reveals CLASP1-depleted cells in collagen I hydrogels lose microtubule acetylation. (G) PDMS Constriction microchannels design. Cylinders represent PDMS pillars forming constrictions at defined spacings. (H) Spinning disk confocal microscopy time-lapse of 1205Lu cells with fluorescently labeled microtubules (eGFP- $\alpha$-tubulin) and nuclei (SnapTag-H2B-JF549) in constriction microchannels. CLASP1 depletion results in cell rupture. Contrast inverted images highlight microtubule architecture. (I) CLASP1 depletion results in significantly more cell death in microchannels over 12 hours. (1205lu melanoma, TIFF telomerase-immortalized normal fibroblasts, U87 and U231 medulloblastoma). (J) CLASP2depleted $1205 \mathrm{Lu}$ cell endogenously expressing eGFP- $\alpha$-tubulin and nuclear marker, $3 \mathrm{X}$ NLS mScarlet-I (magenta) incubated with Annexin V-647 (yellow). Magnified region from left panel: microtubule depolymerization coincides with excessive membrane blebbing (1h 30'-8h 30') and precedes annexin positivity (9h-30'-10h 30'). 
bioRxiv preprint doi: https://doi.org/10.1101/2022.02.08.479516; this version posted February 9, 2022. The copyright holder for this preprint (which was not certified by peer review) is the author/funder. All rights reserved. No reuse allowed without permission.

Fig 2

A
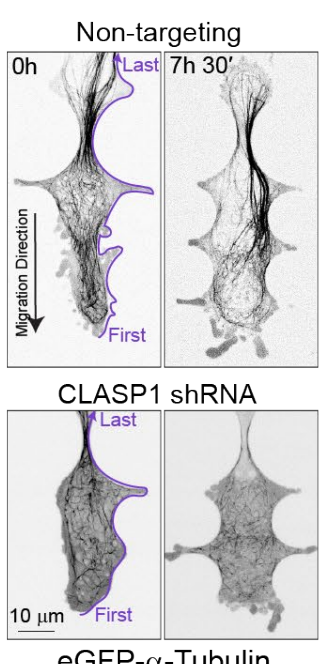

$\mathbf{E}$

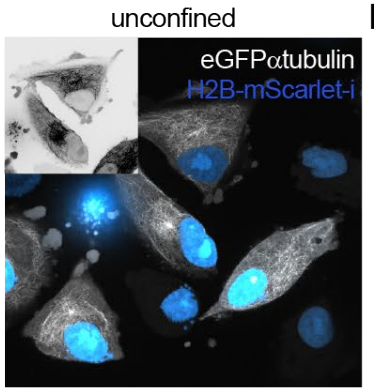

confined

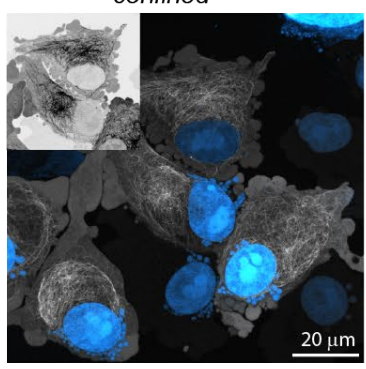

B Signal Intensity

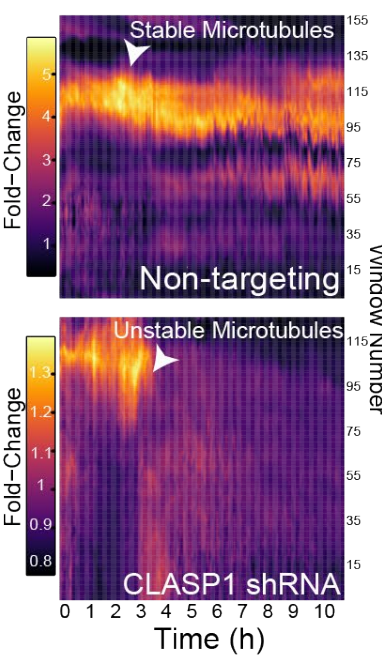

C $2 \times m$ Neongreen
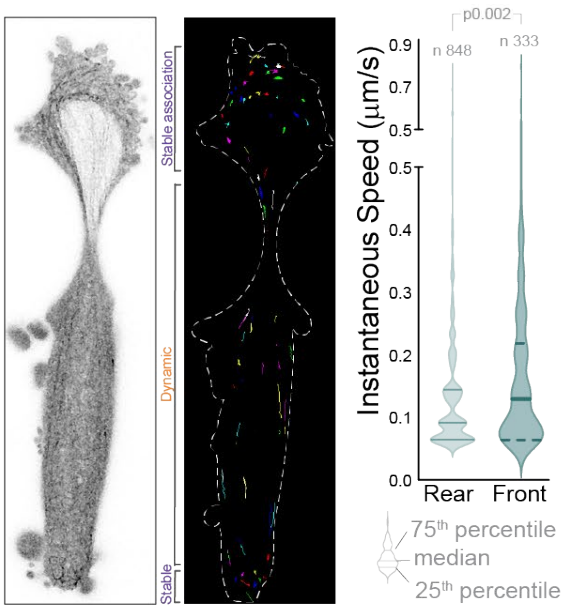

$\mathbf{F}$
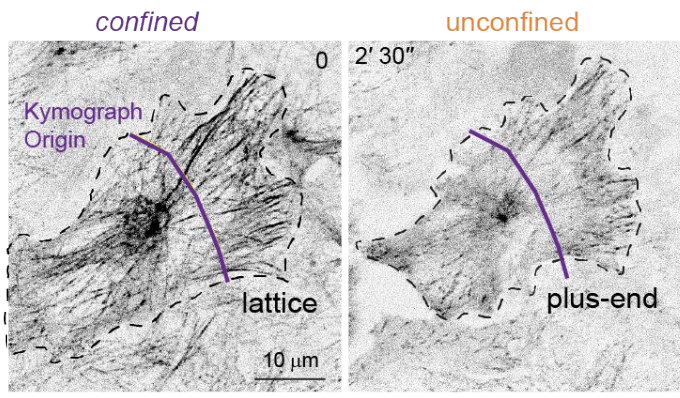

Re-confined

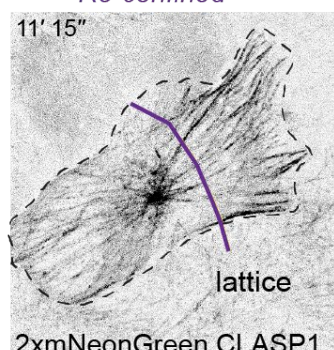

unconfined

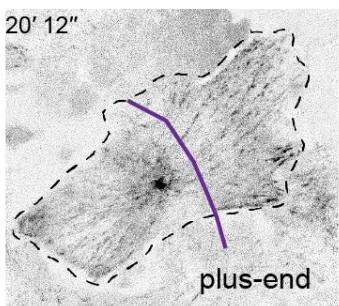

$\stackrel{2}{10 \mathrm{~m}}$

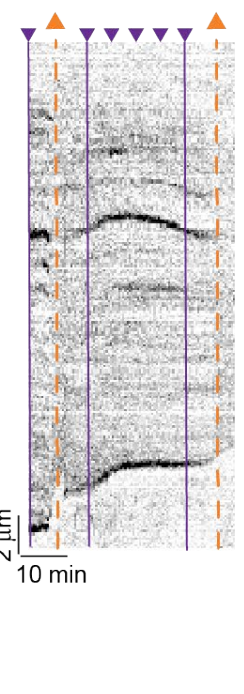

2xmNeonGreen CLASP1

G

Non-targeting
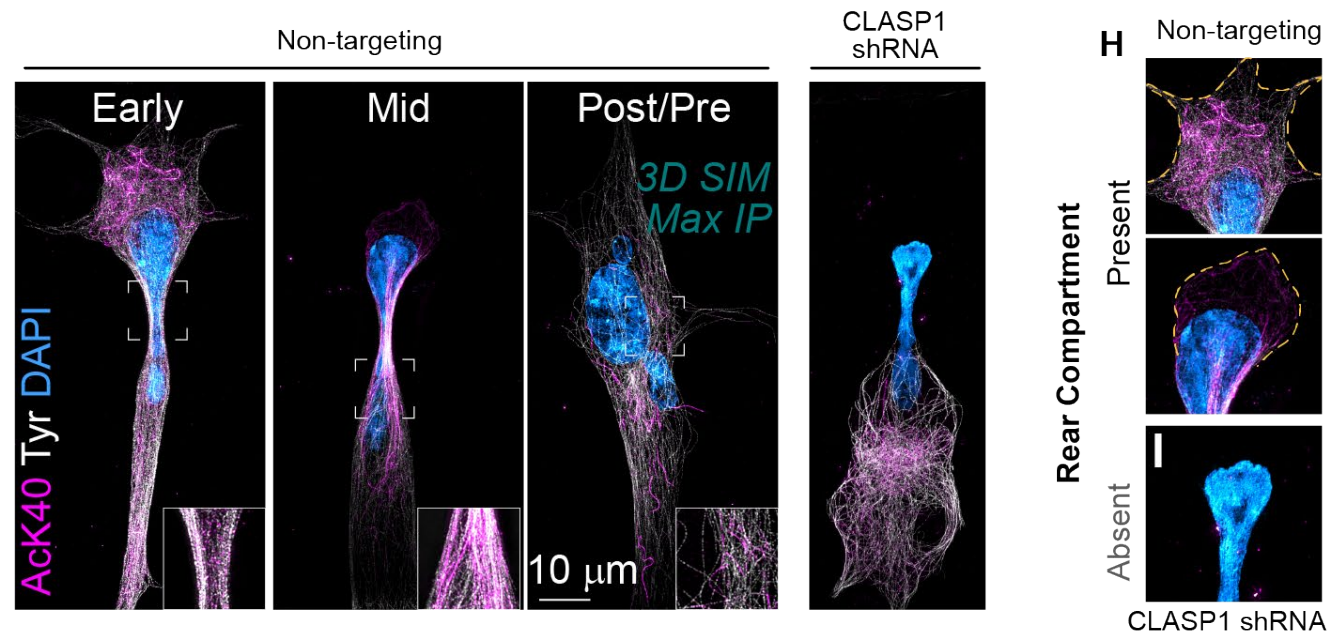
Fig.2. CLASPs spatiotemporally regulate microtubule mechanical stability in confined environments. (A) CLASP1-depleted microtubules destabilize upon mechanical constriction in microchannels. Representative time-lapse of control (non-targeting shRNA) and CLASP1depleted 1205lu cells endogenously expressing eGFP- $\alpha$-tubulin. Quantitation windows dynamically wrap with cellular edge over 11-hours (purple line shows window placement). (B) Kymographs of quantitation windows in A demonstrate abrupt microtubule loss in CLASP1depleted cells $\sim 2.8$ hours into constriction. (C) 1205lu cell expressing 2xmNeongreen-CLASP1 migrating through a microchannel constriction. CLASP 1 dynamics over 45 seconds reveal stable association with microtubules in the cell's rear compartment but dynamic association in the front. (D) CLASP1 instantaneous speed in rear and front cellular compartments during constriction. (E) 12051 cells endogenously expressing eGFP- $\alpha$-tubulin and nuclear marker, H2B-mScarlet-i before and during axial confinement. (F) 2xmNeonGreen-CLASP1 switches localization from microtubule plus-ends to the lattice upon axial confinement. Kymograph of CLASP lattice and plus-end localization dynamics in cells undergoing confinement and release cycles. (G) 3DStructured Illumination microscopy of control (non-targeting shRNA) 1205Lu cells early, mid and post/pre-constriction. Acetylated (AcK40) and tyrosinated a-tubulin (Tyr) immunolabelled 1205lu cells, nuclei labelled with DAPI. (H) Magnified regions from control and (I) CLASP1-depleted cells undergoing confinement. CLASP1-depleted cells lack microtubules in the rear compartment. 
bioRxiv preprint doi: https://doi.org/10.1101/2022.02.08.479516; this version posted February 9, 2022. The copyright holder for this preprint (which was not certified by peer review) is the author/funder. All rights reserved. No reuse allowed without permission.

Fig 3

A Temporal Projection of Nuclear Outline

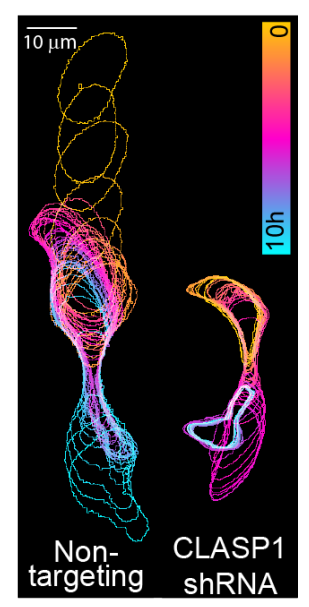

B $\begin{gathered}\text { Nuclear } \\ \text { Approach Angle }\end{gathered}$

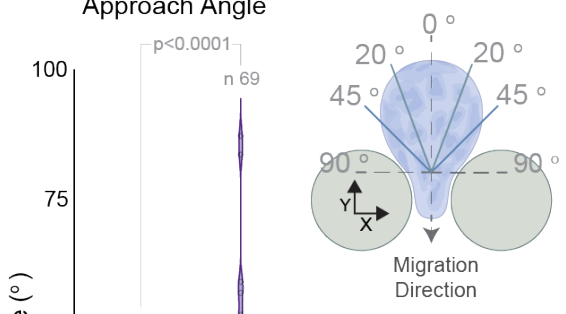

ฮ

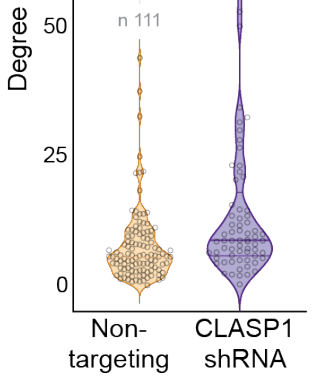

$\mathbf{F}$

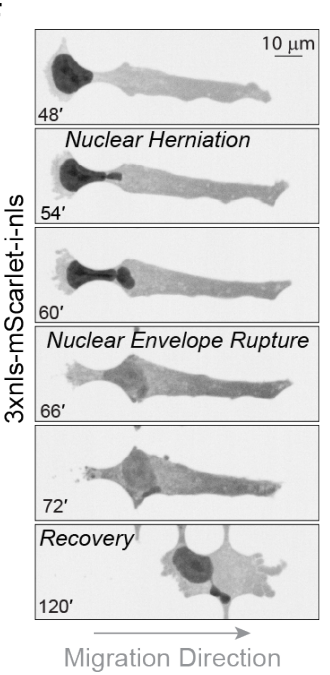

$75^{\text {th }}$ percentile median

$25^{\text {th }}$ percentile
C Nuclear Passage Time

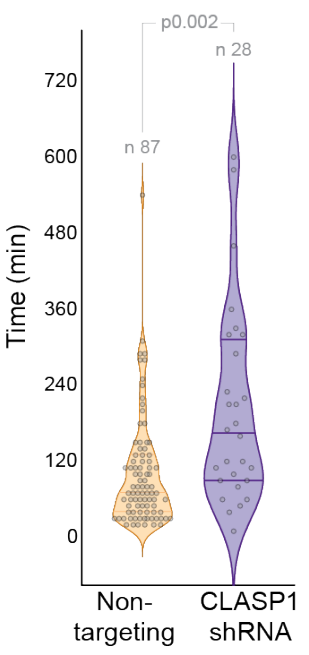

Nuclear Rupture
D

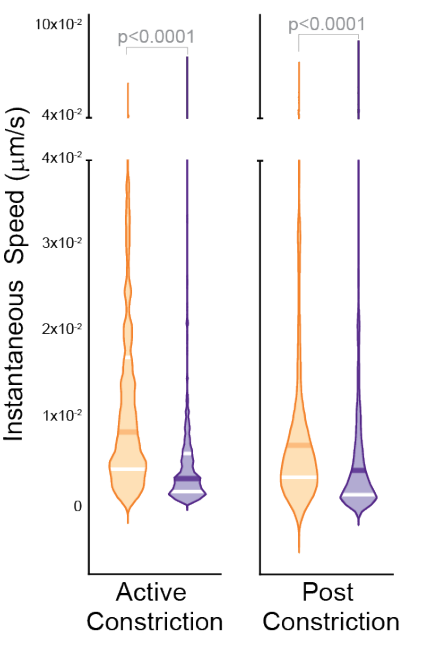

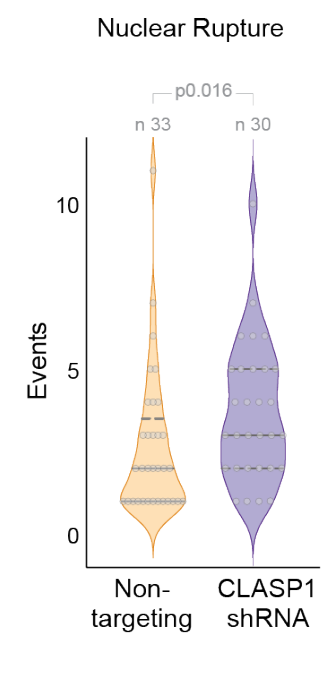

Nuclear Curvature

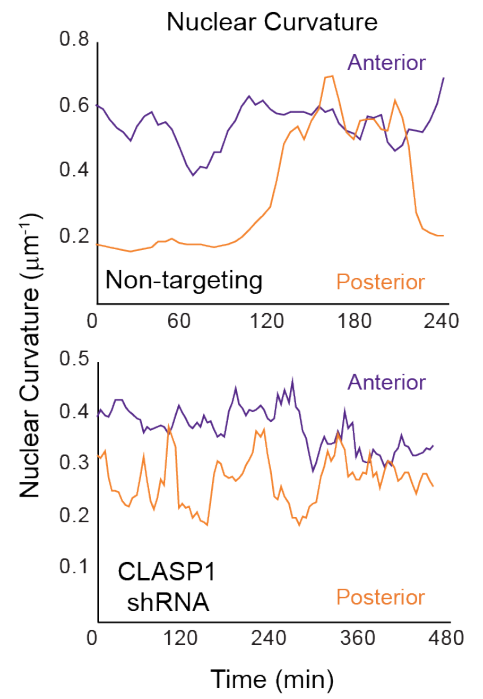


Fig.3. CLASP1-reinforced microtubules are required to position and protect the nucleus in confined cells. (A) Temporal color-coded projection of nuclear outlines of control (non-targeting shRNA) and CLASP1-depleted cells undergoing constriction in microchannels. (B) Quantitation and schematic of nuclear approach angle in control and CLASP-depleted cells. Analysis of (C) nuclear passage time in control and CLASP-depleted cells, and (D) instantaneous cell speeds during active and post nuclear constriction phases. (E) Representative time-lapse images of nuclear envelope rupture and recovery (3xNLS-mScarlet-I-nucleoplasmin-NLS) as cell passes through a constriction. Quantitation of nuclear rupture events in control and CLASP-depleted cells. (F) Representative time-lapse images of H2B-mScarlet-I labelled nuclei, control and CLASP1depleted cells. Graph of nuclear curvature of anterior and posterior surfaces in cells undergoing constriction. Anterior nuclear curvature remains stable, whereas posterior nuclear curvature increases only as nucleus progresses through constriction. CLASP1 depletion alters nuclear curvature dynamics. 
bioRxiv preprint doi: https://doi.org/10.1101/2022.02.08.479516; this version posted February 9, 2022. The copyright holder for this preprint (which was not certified by peer review) is the author/funder. All rights reserved. No reuse allowed without permission.

Fig 4

A

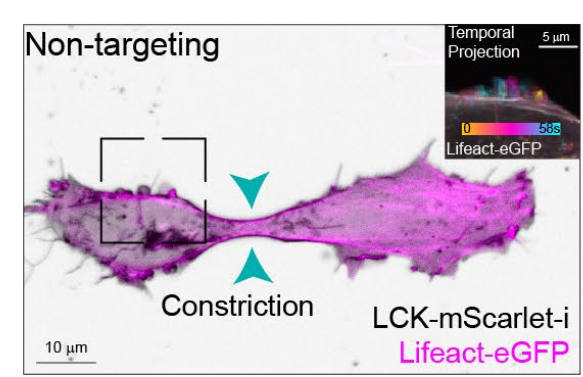

B

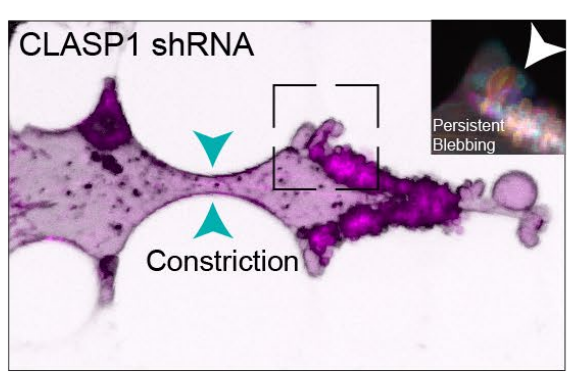

C

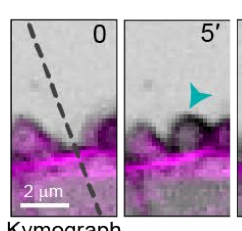

Kymograph

Origin

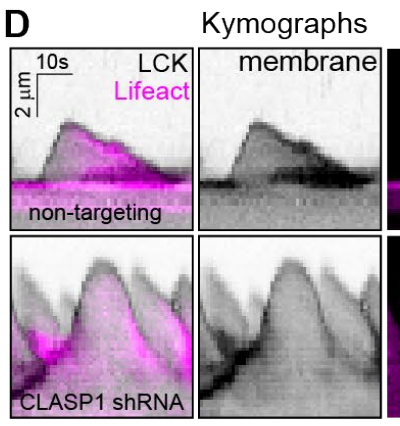

G

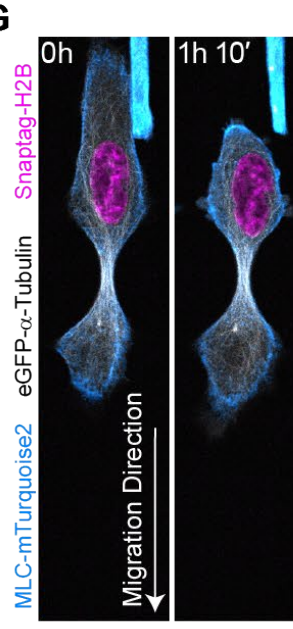

Non-targeting
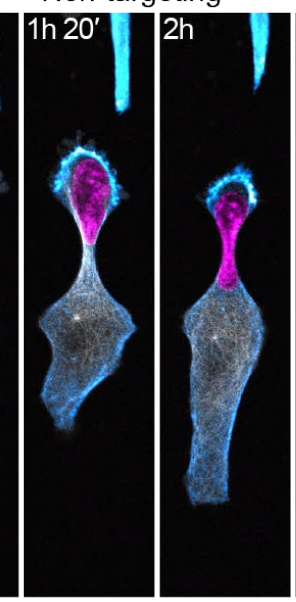

I

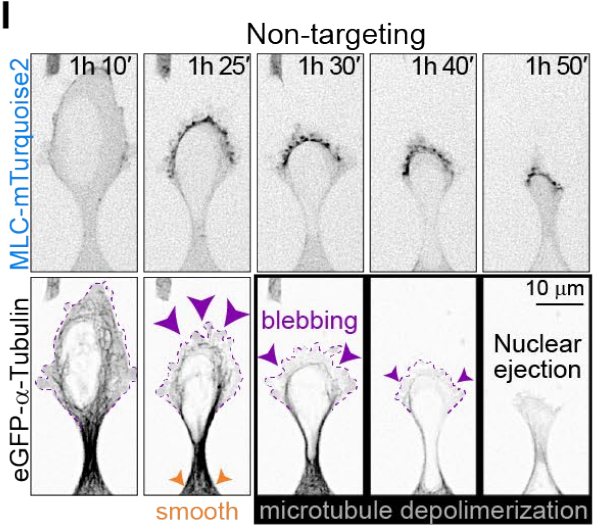

H
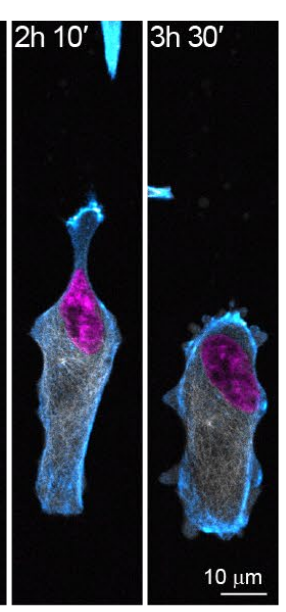

J

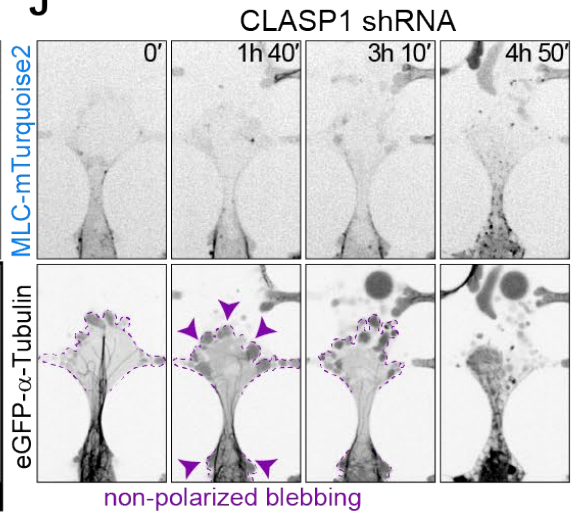

K

CLASP1 shRNA
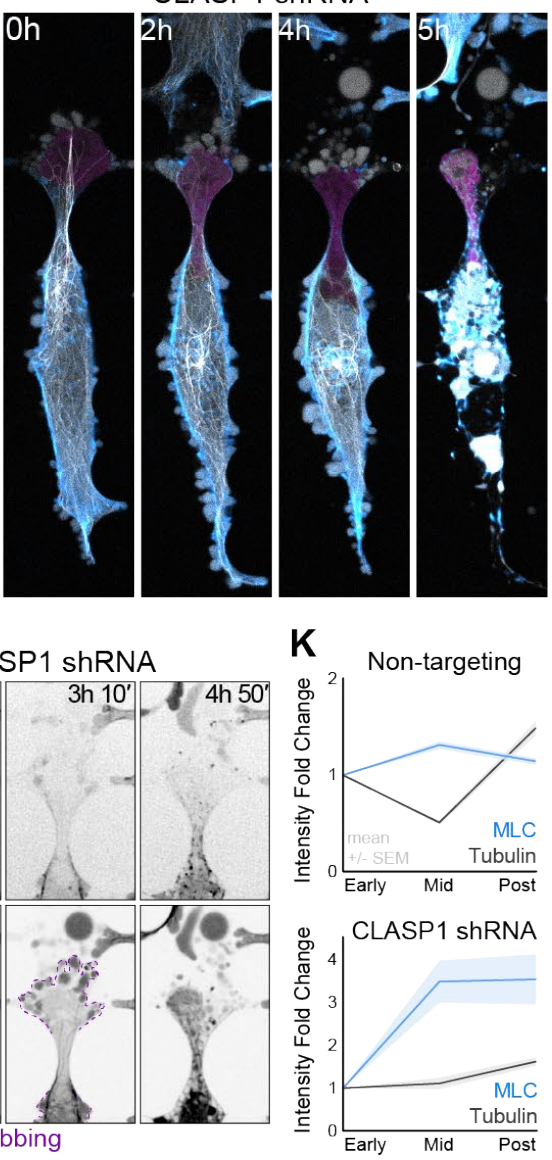
Fig.4. CLASP1-reinforced microtubules are required to coordinate contractility in confined cells. (A) Time-lapse images of control (non-targeting shRNA) and (B) CLASP1-depleted cells co-expressing membrane (LCK-mScarlet-i) and cortical (eGFP-Lifeact) markers undergoing nuclear constriction in microchannels. Insets are temporal color-coded projections ( 1 frame/sec for $1 \mathrm{~min}$ ) of actin bleb dynamics at the cell surface. CLASP depletion results in persistent pericellular blebbing during cellular constriction (temporal projection inset). (C) Enlarged inset of time-lapse imaging of bleb formation and recovery in control cell. Membrane blebs (black) form from breaks in the actomyosin cortex $(5 \mathrm{~s})$ and are recovered by subsequent cortical repair (magenta; 10-20 seconds). (D) Kymograph of membrane (black) and cortical (magenta) dynamics in control and CLASP1-depleted cells. CLASP1-depletion increases bleb size (E), and bleb protrusion and retraction velocity (F) compared to control. (G) Time-lapse images of control and CLASP1depleted $(\mathrm{H})$ 1205lu cells with fluorescently labeled microtubules (eGFP- $\alpha$-tubulin), nucleus (SnapTag-H2B-JF549) and myosin light chain (MYL9, MLC-mTurquoise2) undergoing constricted migration. (I) Myosin concentrates on the rear membrane, proximal to the microtubule filled compartment (eGFP- $\alpha$-Tubulin; microtubule 'cushion') and correlates with an increase in membrane blebbing (purple line and arrowheads) as microtubules disassemble. (J) Myosin does not polarize to the rear compartment of CLASP-depleted cells. (K) Dynamics of myosin and microtubule intensities in the rear cellular compartment during nuclear translocation in control and CLASP1-depleted cells. 
bioRxiv preprint doi: https://doi.org/10.1101/2022.02.08.479516; this version posted February 9, 2022. The copyright holder for this preprint (which was not certified by peer review) is the author/funder. All rights reserved. No reuse allowed without permission.

Fig 5
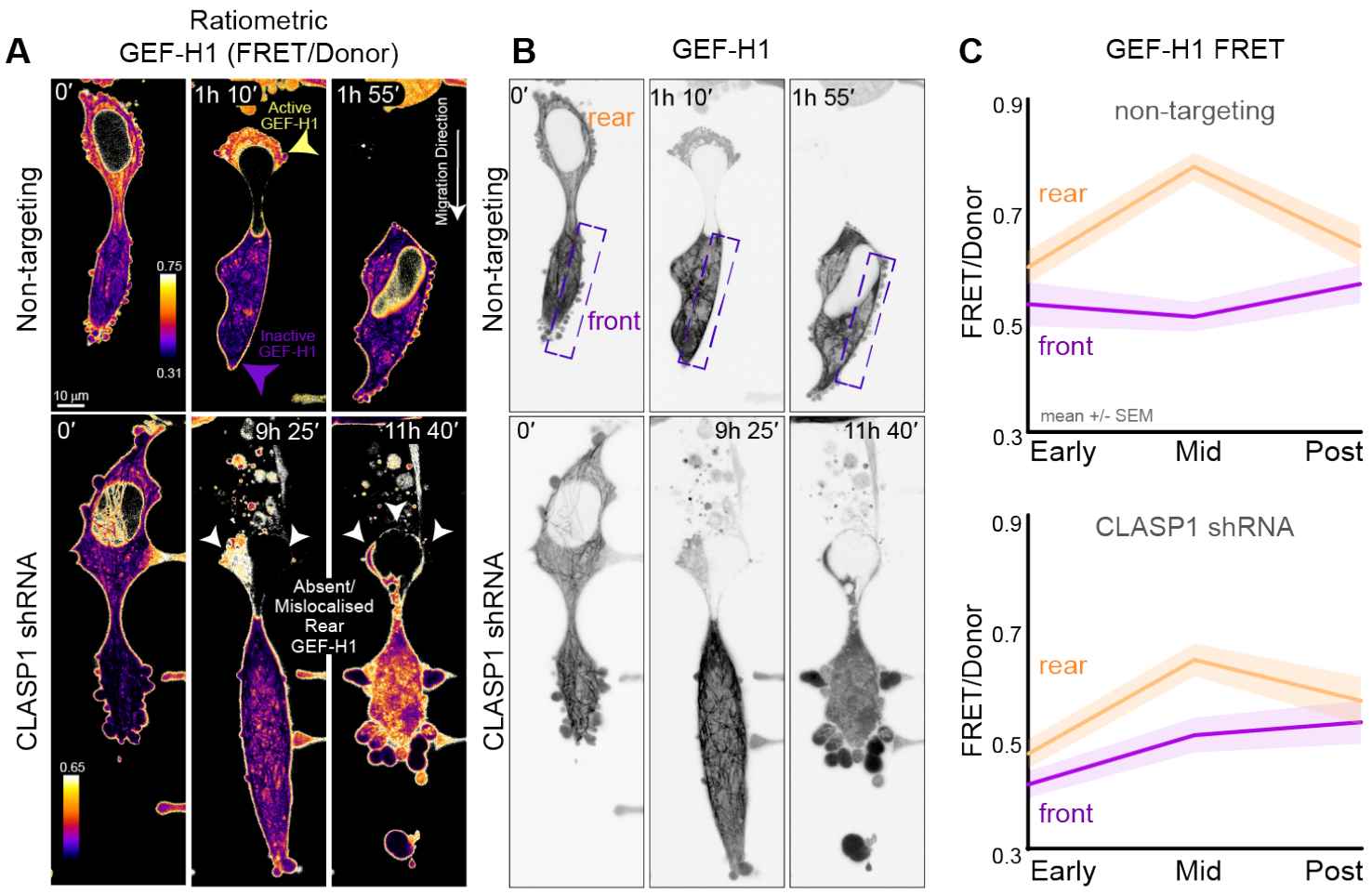

$E$

eGFP-RhoA
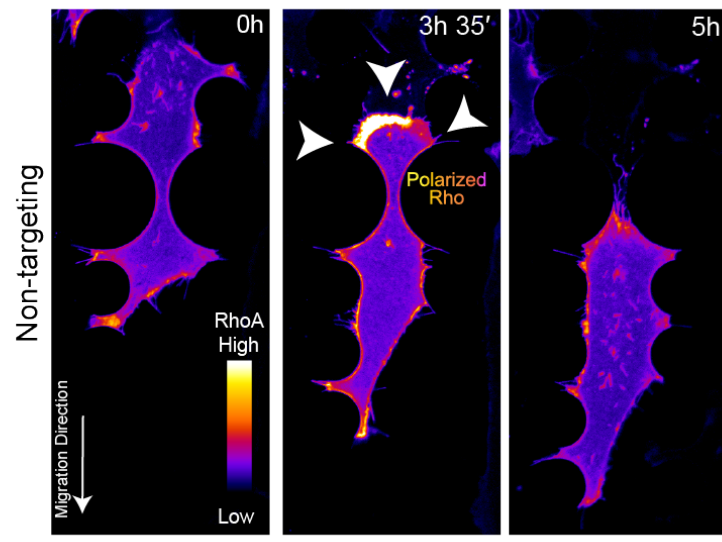

F
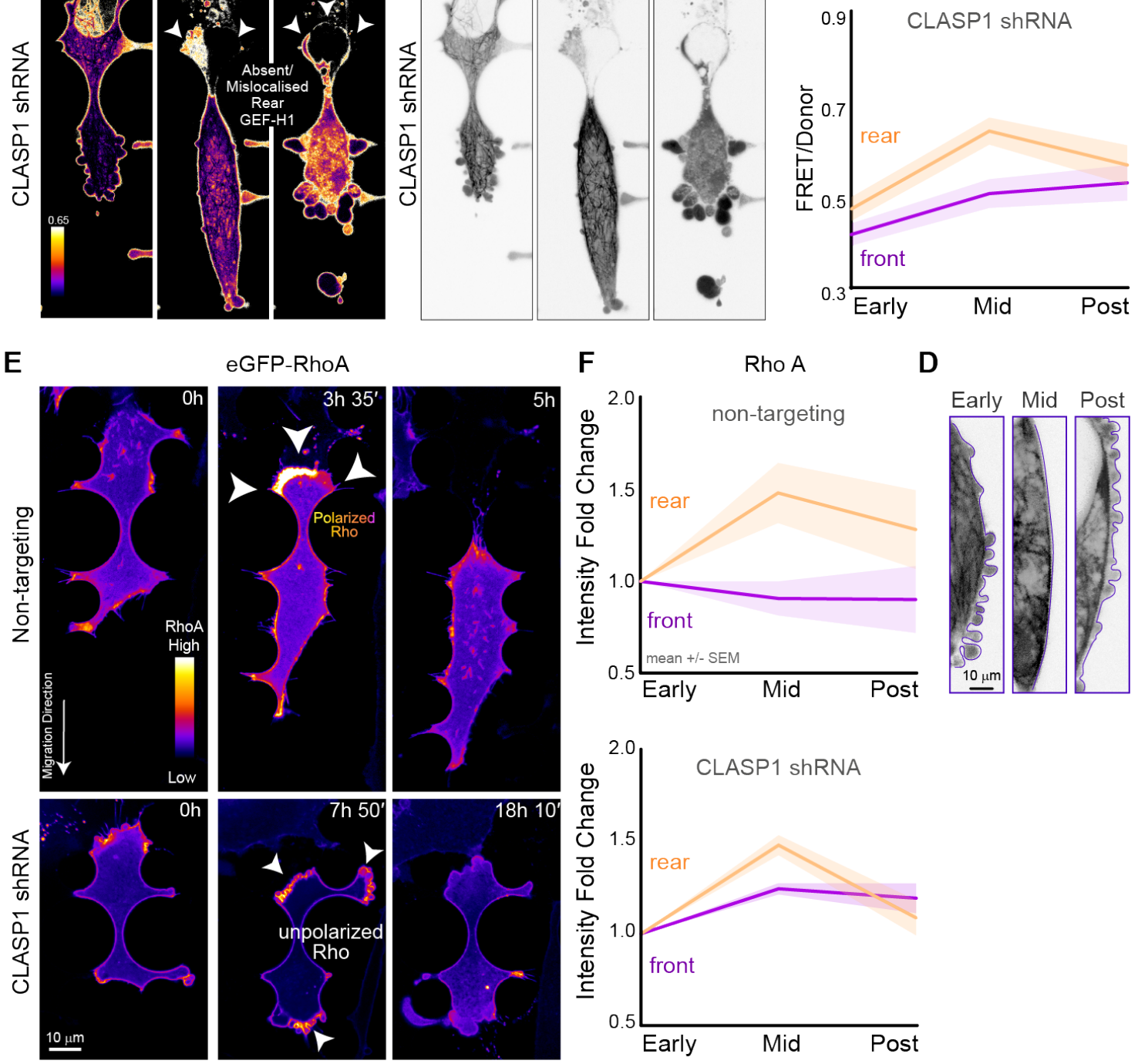

D
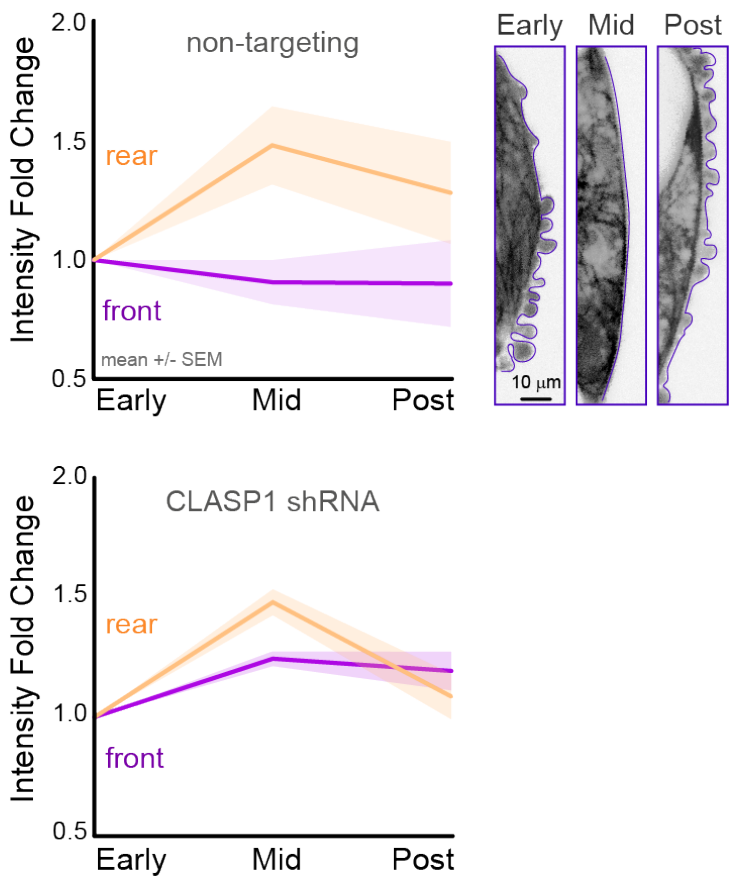
Fig.5. Controlled Microtubule Depolymerization is Required to Spatially Restrict the Microtubule Contractility Axis. (A) Time lapse images of GEF-H1 FLARE212 localization in control (non-targeting shRNA) and CLASP1-depleted cells undergoing constriction. GEF-H1 activation (yellow, high FRET/donor ratio) arising from microtubule depolymerization is polarized posterior to the nucleus during nuclear translocation $(1 \mathrm{~h} 10 \mathrm{~min})$. The polarization of active GEF-H1 equilibrates after cells translocate through constrictions ( $1 \mathrm{~h} 55 \mathrm{~min}$ ), shown by inactive (purple, low FRET/donor ratio) GEF-H1 association with microtubules. GEF-H1 activation is aberrantly localized in CLASP-depleted cells. Cells subsequently spend longer in constricted states $(0-9 \mathrm{~h} 25 \mathrm{~min})$, resulting in cell rupture (11h 40min). (B) GEF-H1 localization on microtubules. (C) Dynamics of GEF-H1 FRET activity as a function of nuclear constriction phases- in front (purple) and rear (orange) compartments of control and CLASP-depleted cells. (D) Enlarged insets from areas outlined in control cell front compartments in B (purple boxes) demonstrating changes in membrane blebbing during nuclear occlusion (mid). (E) Rho-A accumulates posteriorly prior to a Rho-burst ( $3 \mathrm{~h} 35 \mathrm{~min}$; arrowheads) which completes nuclear ejection through translocation $(5 \mathrm{~h}$ ). In CLASP-depleted cells Rho-A no longer concentrates at the rear and occurs both posteriorly and anteriorly (arrowheads) with erratic localization at large blebs. (F) Dynamics of Rho-A intensity as a function of nuclear constriction phases- in front (purple) and rear (orange) compartments of control and CLASP-depleted cells. 
bioRxiv preprint doi: https://doi.org/10.1101/2022.02.08.479516; this version posted February 9, 2022. The copyright holder for this preprint (which was not certified by peer review) is the author/funder. All rights reserved. No reuse allowed without permission.

\section{Fig 6}

A
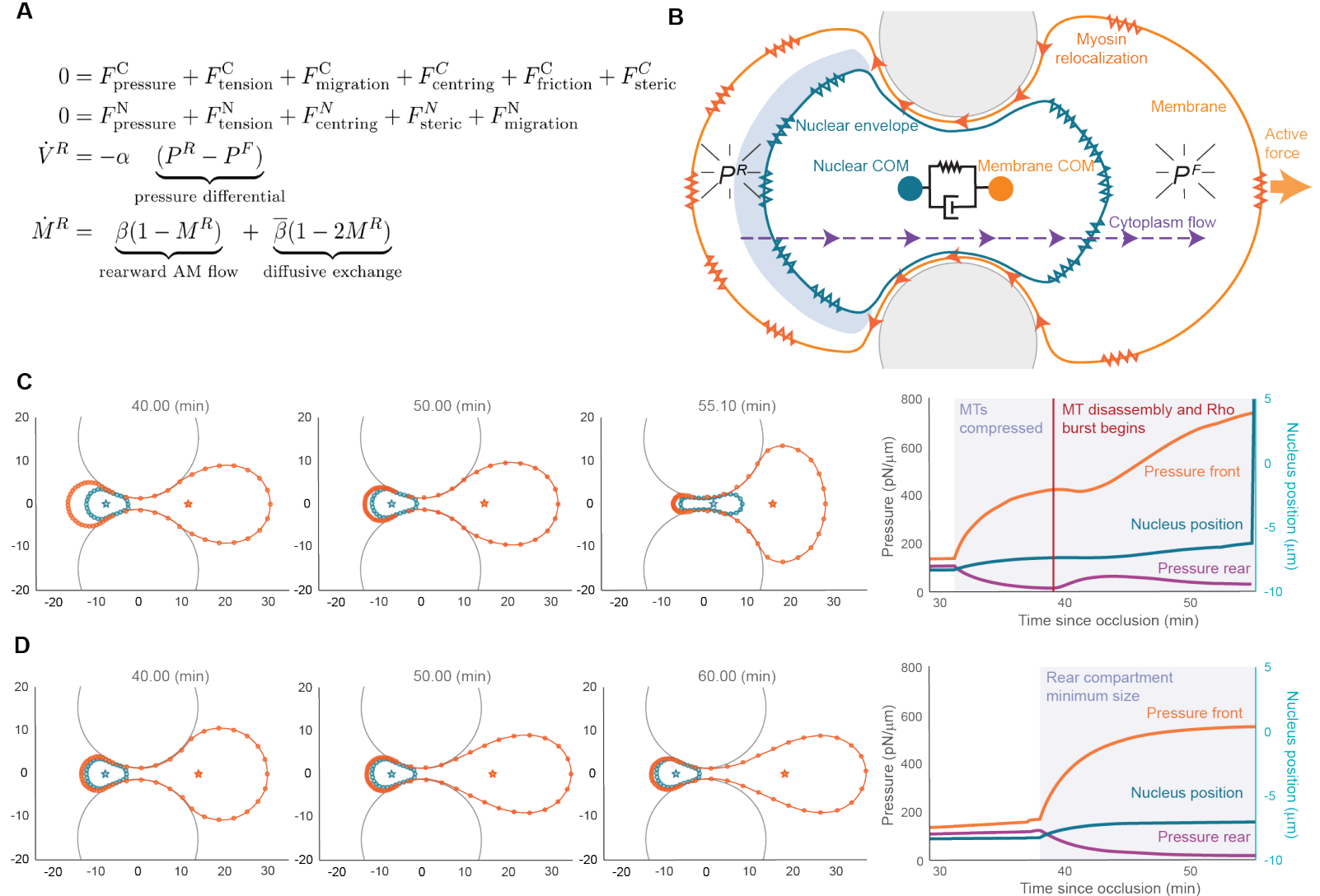

E
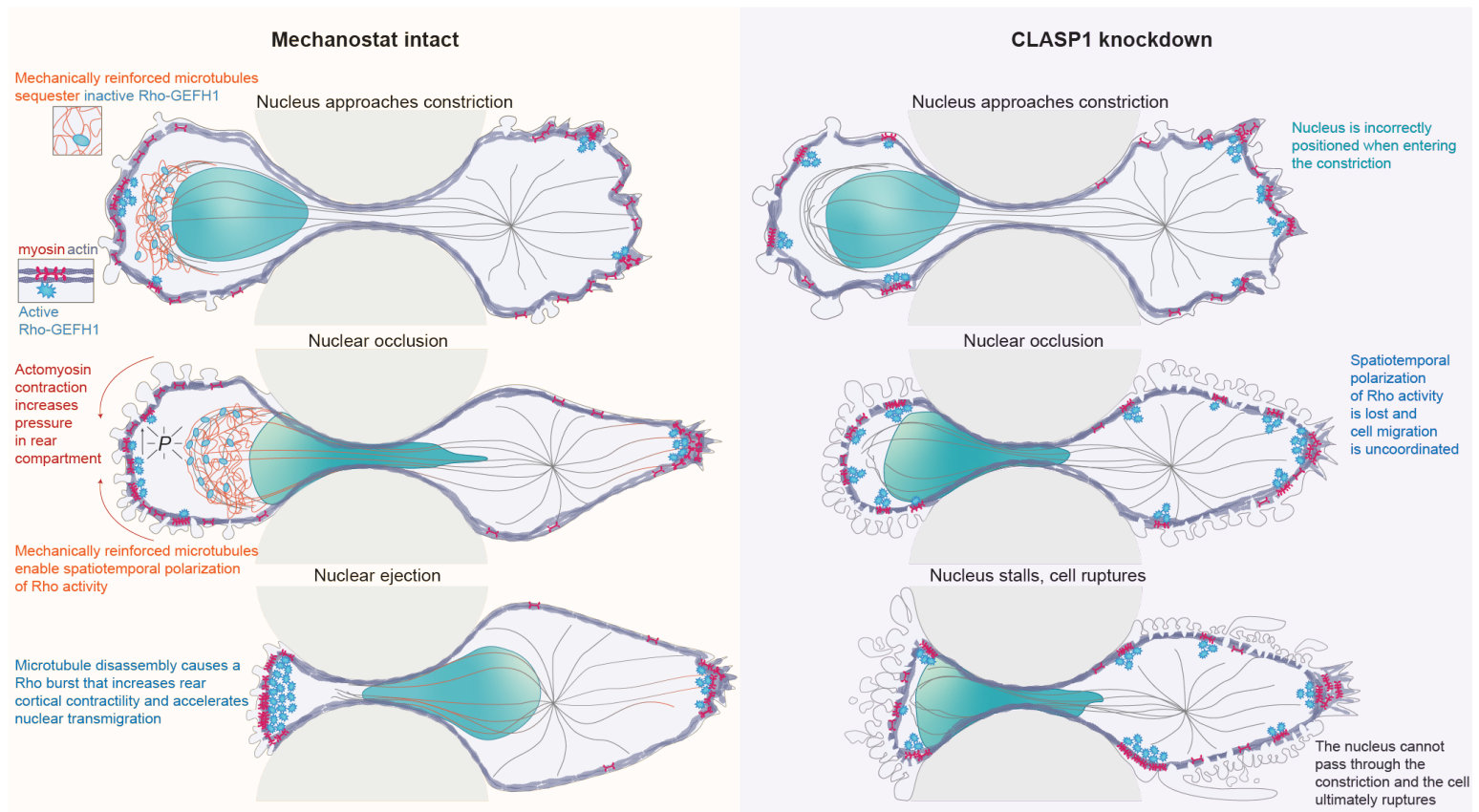
Fig.6. Theoretical model of mechanostat function in confined cell migration. (AB) A system of force balance equations governs the shape and motion of cell and nucleus. Rate equations describe myosin aggregation in the rear due to the rearward actomyosin flux and diffusive exchange, as well as forward flux of cytoplasm during occlusion. (B) Tension in the actomyosin cortex and the nuclear envelope increase the rear pressure $\mathrm{P}^{\mathrm{R}}$ and front pressure $\mathrm{P}^{\mathrm{F}}$ in the associated compartments. A Kelvin-Voigt element (elastic spring and viscous dash-pot in parallel) between the centers of mass of the cell and the nucleus, models nuclear positioning. (C) The simulated progression of a cell through the constriction: The pressure graph shows an initial pressure differential upon first entering the occlusion which increases once the volume of the rear cytosolic compartment is stabilized by the microtubule cushion (shaded area). Gradual up-regulation of rear cortical tension in response to a burst of Rho activity following microtubule disassociation accelerates the buildup of pressure and of the velocity of the nucleus and leads to the passage of the nucleus past the pillars within minutes. (D) In the absence of a rear microtubule cushion and of myosin up-regulation, the rear cortex physically contacts the nuclear envelope during the attempted transmigration. The nucleus does not progress through the constriction within the simulated period of time. (E) Schematic summarizing the role of the microtubule mechanostat in confined migration. 


\section{Acknowledgments:}

We thank A.Yap, D.Bryant, T.Wittmann, A.Molines and members of the Haass, Collins and Stehbens laboratories for discussion and comments on the manuscript. We also thank TRI (and IMB facility staff and L.Lavis for Janelia Fluorophores. Research was conducted in a facility constructed with support from Australian Cancer Research Foundation (ACRF)/Institute for Molecular Bioscience Cancer Biology Imaging Facility, which was established with the support of the ACRF.

\section{References}

1. H. Jayatilaka et al., EB1 and cytoplasmic dynein mediate protrusion dynamics for efficient 3-dimensional cell migration. FASEB J 32, 1207-1221 (2018).

2. E. M. Balzer et al., Physical confinement alters tumor cell adhesion and migration phenotypes. FASEB J 26, 4045-4056 (2012).

3. D. J. Odde, L. Ma, A. H. Briggs, A. DeMarco, M. W. Kirschner, Microtubule bending and breaking in living fibroblast cells. J Cell Sci 112 ( Pt 19), 3283-3288 (1999).

4. L. Schaedel et al., Microtubules self-repair in response to mechanical stress. Nat Mater 14, 1156-1163 (2015).

5. B. A. Sosa, A. Rothballer, U. Kutay, T. U. Schwartz, LINC complexes form by binding of three KASH peptides to domain interfaces of trimeric SUN proteins. Cell 149, 10351047 (2012).

6. K. J. Roux et al., Nesprin 4 is an outer nuclear membrane protein that can induce kinesinmediated cell polarization. Proc Natl Acad Sci U S A 106, 2194-2199 (2009).

7. M. Krendel, F. T. Zenke, G. M. Bokoch, Nucleotide exchange factor GEF-H1 mediates cross-talk between microtubules and the actin cytoskeleton. Nat Cell Biol 4, 294-301 (2002).

8. K. M. Dean, P. Roudot, E. S. Welf, G. Danuser, R. Fiolka, Deconvolution-free Subcellular Imaging with Axially Swept Light Sheet Microscopy. Biophys $J$ 108, 28072815 (2015).

9. A. Akhmanova et al., Clasps are CLIP-115 and -170 associating proteins involved in the regional regulation of microtubule dynamics in motile fibroblasts. Cell 104, 923-935 (2001).

10. L. Eshun-Wilson et al., Effects of alpha-tubulin acetylation on microtubule structure and stability. Proc Natl Acad Sci U S A 116, 10366-10371 (2019).

11. Z. Xu et al., Microtubules acquire resistance from mechanical breakage through intralumenal acetylation. Science 356, 328-332 (2017).

12. C. Tropini, E. A. Roth, M. Zanic, M. K. Gardner, J. Howard, Islands containing slowly hydrolyzable GTP analogs promote microtubule rescues. PLoS One 7, e30103 (2012).

13. H. de Forges et al., Localized Mechanical Stress Promotes Microtubule Rescue. Curr Biol 26, 3399-3406 (2016).

14. Y. Mimori-Kiyosue et al., CLASP1 and CLASP2 bind to EB1 and regulate microtubule plus-end dynamics at the cell cortex. J Cell Biol 168, 141-153 (2005).

15. P. M. Davidson, J. Sliz, P. Isermann, C. Denais, J. Lammerding, Design of a microfluidic device to quantify dynamic intra-nuclear deformation during cell migration through confining environments. Integr Biol (Camb) 7, 1534-1546 (2015). 
16. C. M. Denais et al., Nuclear envelope rupture and repair during cancer cell migration. Science 352, 353-358 (2016).

17. D. Portran, L. Schaedel, Z. Xu, M. Thery, M. V. Nachury, Tubulin acetylation protects long-lived microtubules against mechanical ageing. Nat Cell Biol 19, 391-398 (2017).

18. A. Aher et al., CLASP Mediates Microtubule Repair by Restricting Lattice Damage and Regulating Tubulin Incorporation. Curr Biol 30, 2175-2183 e2176 (2020).

19. T. E. Kreis, Microtubules containing detyrosinated tubulin are less dynamic. EMBO J 6, 2597-2606 (1987).

20. H.-R. Thiam et al., Perinuclear Arp2/3-driven actin polymerization enables nuclear deformation to facilitate cell migration through complex environments. Nature Communications 7, 10997 (2016).

21. G. T. Charras, J. C. Yarrow, M. A. Horton, L. Mahadevan, T. J. Mitchison, Nonequilibration of hydrostatic pressure in blebbing cells. Nature 435, 365-369 (2005).

22. E. Paluch, M. Piel, J. Prost, M. Bornens, C. Sykes, Cortical actomyosin breakage triggers shape oscillations in cells and cell fragments. Biophys $J$ 89, 724-733 (2005).

23. A. J. Lomakin et al., The nucleus acts as a ruler tailoring cell responses to spatial constraints. Science 370, (2020).

24. K. Wolf et al., Physical limits of cell migration: control by ECM space and nuclear deformation and tuning by proteolysis and traction force. J Cell Biol 201, 1069-1084 (2013).

25. P. Mistriotis et al., Confinement hinders motility by inducing RhoA-mediated nuclear influx, volume expansion, and blebbing. J Cell Biol 218, 4093-4111 (2019).

26. H. P. Lee et al., The nuclear piston activates mechanosensitive ion channels to generate cell migration paths in confining microenvironments. Sci Adv 7, (2021).

27. A. Kopf et al., Microtubules control cellular shape and coherence in amoeboid migrating cells. J Cell Biol 219, (2020).

28. E. D. Tabdanov et al., Engineering T cells to enhance 3D migration through structurally and mechanically complex tumor microenvironments. Nat Commun 12, 2815 (2021).

29. P. Nalbant, Y. C. Chang, J. Birkenfeld, Z. F. Chang, G. M. Bokoch, Guanine nucleotide exchange factor-H1 regulates cell migration via localized activation of RhoA at the leading edge. Mol Biol Cell 20, 4070-4082 (2009).

30. M. L. Azoitei et al., Spatiotemporal dynamics of GEF-H1 activation controlled by microtubule- and Src-mediated pathways. J Cell Biol 218, 3077-3097 (2019).

31. D. Meiri et al., Mechanistic insight into the microtubule and actin cytoskeleton coupling through dynein-dependent RhoGEF inhibition. Mol Cell 45, 642-655 (2012).

32. P. Timpson et al., Spatial regulation of RhoA activity during pancreatic cancer cell invasion driven by mutant p53. Cancer Res 71, 747-757 (2011).

33. R. J. Petrie, H. Koo, K. M. Yamada, Generation of compartmentalized pressure by a nuclear piston governs cell motility in a 3D matrix. Science 345, 1062-1065 (2014).

34. X. Cao et al., A Chemomechanical Model for Nuclear Morphology and Stresses during Cell Transendothelial Migration. Biophys J 111, 1541-1552 (2016).

35. D. G. Thomas et al., Non-muscle myosin IIB is critical for nuclear translocation during 3D invasion. Journal of Cell Biology 210, 583-594 (2015).

36. M. Gao et al., On the Origin of Microtubules' High-Pressure Sensitivity. Biophys J 114, 1080-1090 (2018).

37. R. Zhao et al., Cell sensing and decision-making in confinement: The role of TRPM7 in a tug of war between hydraulic pressure and cross-sectional area. Sci Adv 5, eaaw7243 (2019). 
bioRxiv preprint doi: https://doi.org/10.1101/2022.02.08.479516; this version posted February 9, 2022. The copyright holder for this preprint (which was not certified by peer review) is the author/funder. All rights reserved. No reuse allowed without permission. 
A meGFP- $\alpha-$ Tubulin
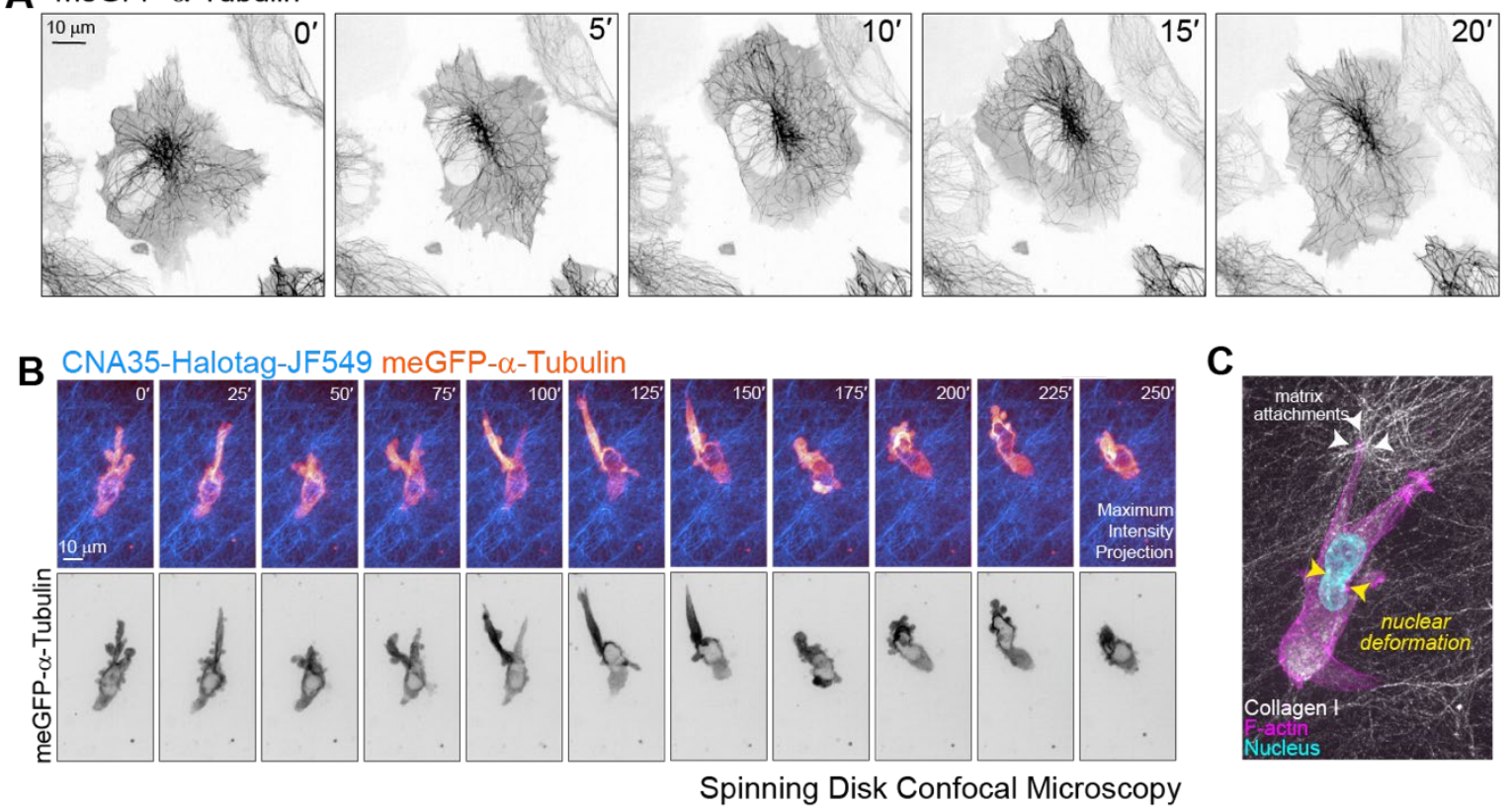

Fig.S1. Microtubule morphology in 2D and 3D collagen hydrogel models. (A) $1205 \mathrm{Lu}$ melanoma cell CRISPR edited to express meGFP- $\alpha$-tubulin migrating in 2D. LUT inverted to enhance visibility of microtubule organisation. (B) $1205 \mathrm{Lu}-\mathrm{eGFP}-\alpha$-tubulin (orange heatmap) expressing cell migrating through a CNA35-Halo JF549 labelled collagen I hydrogel (2.5 $\mathrm{mg} / \mathrm{ml}$; cyan heatmap) imaged by spinning disc confocal microscopy (SDCM). Visible distention of the cell body and nucleus can be observed where microtubules are seen to outline. (C) $1205 \mathrm{Lu}$ melanoma cell invading through a collagen hydrogel (DQ Collagen; white) labelled for F-actin (phalloidin, magenta) and nucleus (DAPI, cyan). Collagen aligns at cellmatrix attachment points (white arrowheads). The nucleus deforms as the cell invades (yellow arrowheads). 
bioRxiv preprint doi: https://doi.org/10.1101/2022.02.08.479516; this version posted February 9, 2022. The copyright holder for this preprint

A

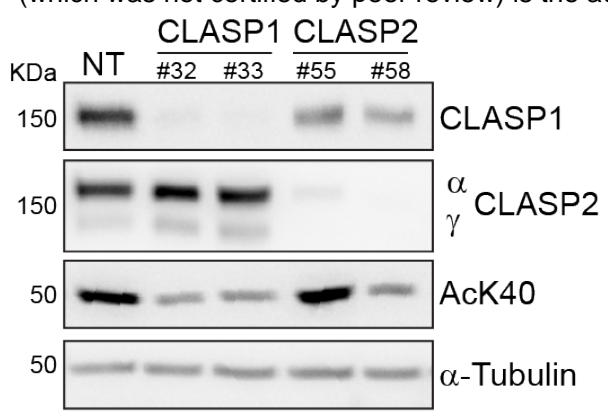

C

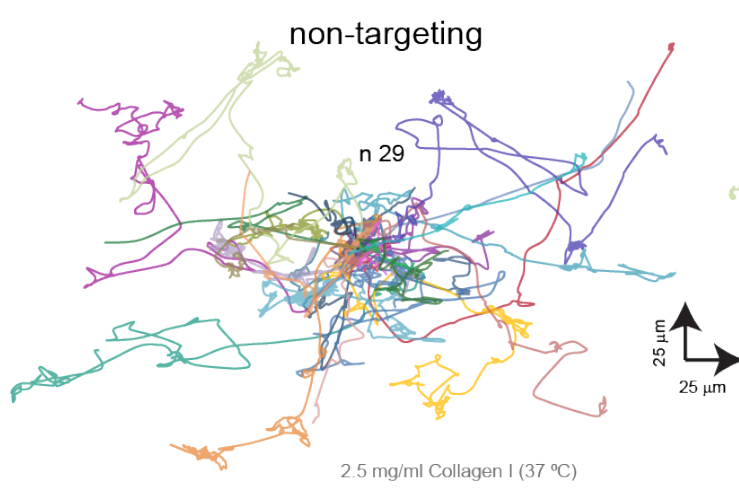

$\mathbf{E}$

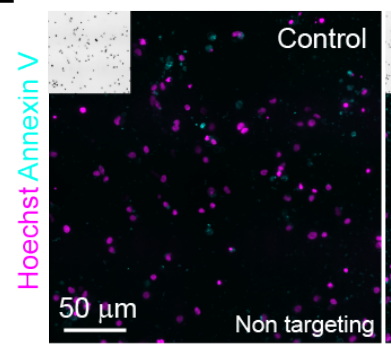

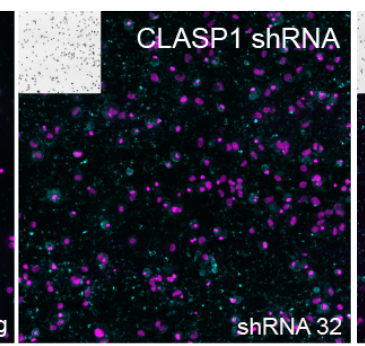

$2.5 \mathrm{mg} / \mathrm{ml}$ Collagen I $\left(37^{\circ} \mathrm{C}\right)$
B

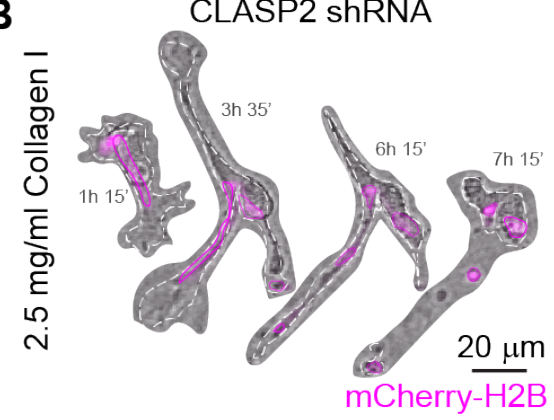

CLASP1

ShRNA (33)

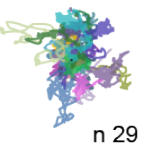

29

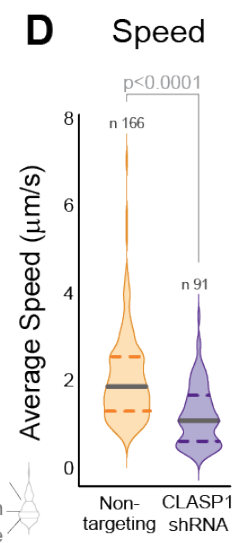

Displacement

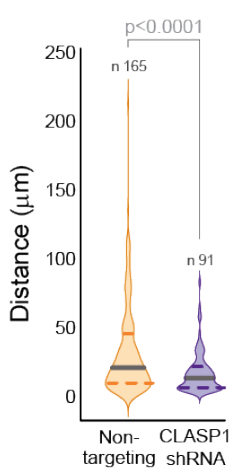

Fig. S2. Validation of CLASP Migration Phenotype in 3D Collagen Hydrogels. (A) Immunoblot of lysates from 1205Lu melanoma cells expressing different shRNA constructs after seven days of puromycin selection. Tubulin was used as a loading control. Blots were probed with paralog specific antibodies to either CLASP1 or CLASP2. (B) CLASP2-depleted cells (shRNA \#58) rupture when migrating in collagen hydrogels. Representative frames of time-lapse images of $1205 \mathrm{Lu}$ melanoma cells expressing mCherry-H2B (nuclei, magenta) depleted of CLASP2, embedded in a collagen I hydrogel $(2.5 \mathrm{mg} / \mathrm{ml})$. (C) Cell migration tracks (spider plots) of control (non-targeting shRNA) and CLASP-depleted (CLASP1 shRNA) cells. (D) Speed and Displacement measurements cells migrating in collagen hydrogels. (E) Immunofluorescence of control (non-targeting shRNA) and CLASP1- and CLASP2 depleted 1205Lu melanoma cells labelled for annexin V (cyan) and nuclei (Hoechst; magenta). (F) Quantitation of percentage of Annexin v positive cells in control and CLASP-depleted cells. 
bioRxiv preprint doi: https://doi.org/10.1101/2022.02.08.479516; this version posted February 9, 2022. The copyright holder for this preprint

A (which was not certified by peer review) is the author/funder. All rights reserved. No reuse allowed without permission.
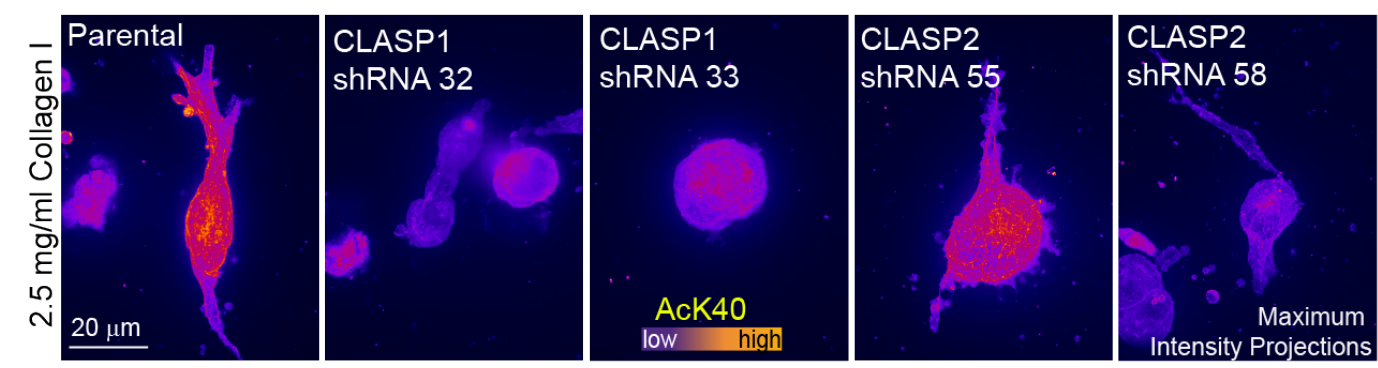

B

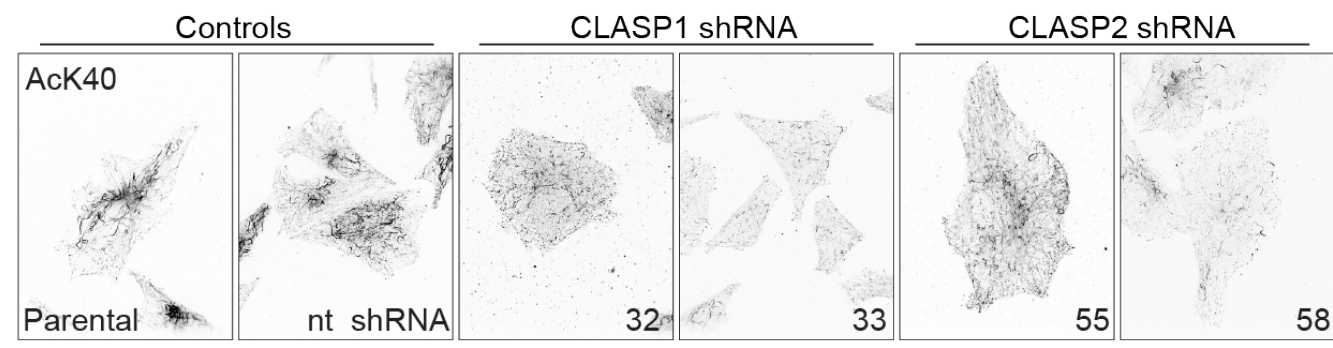

C

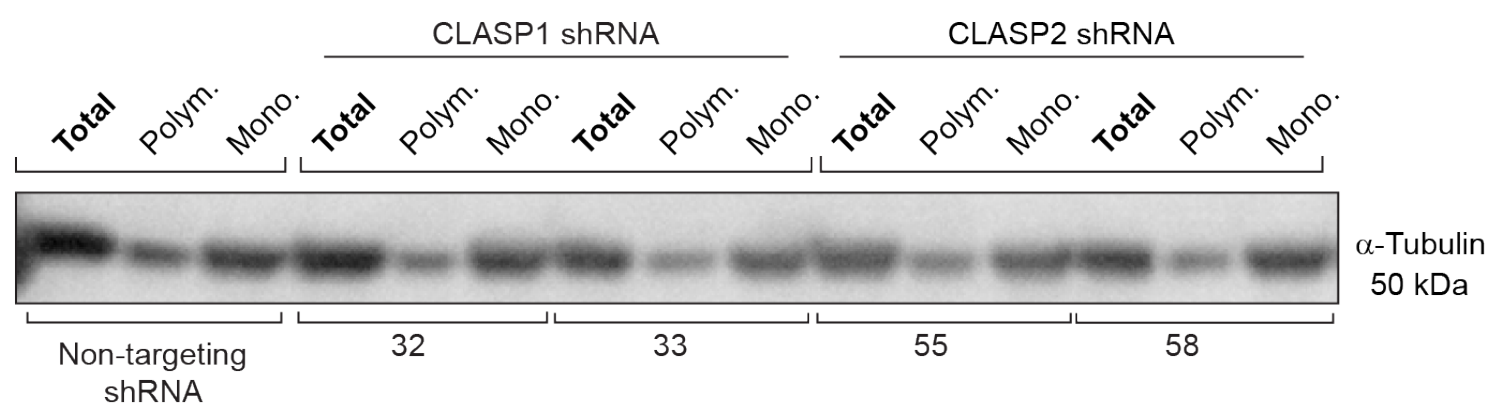

Fig.S3. Tubulin acetylation is decreased in CLASP-depleted cells. (A) Control (parental), and alternative CLASP1 and 2 hairpins from figure 2F (shRNA \#33 and \#55, 58, respectively), 1205Lu melanoma cells embedded in collagen I hydrogels (collagen, $2.5 \mathrm{mg} / \mathrm{ml}$ ) labelled for acetylated $\alpha$-tubulin (AcK40). AcK40 fluorescence intensity displayed as a LUT heatmap; purple indicating low with yellow-red indicating high. Scalebar $=20 \mu \mathrm{m}$. (B) Immunofluorescence of control (parental, non-targeting shRNA), CLASP1-(shRNA\#32, \#33) and CLASP2-depleted (\#55, \#58) 1205Lu melanoma cells labelled for acetylated a-tubulin (AcK40, contrast inverted). (C) Immunoblot of tubulin pelleting assay lysates of $1205 \mathrm{Lu}$ melanoma cells expressing non-targeting, CLASP1 or 2 shRNA constructs. CLASP-depletion does not alter the levels of polymerized microtubules. 
bioRxiv preprint doi: https://doi.org/10.1101/2022.02.08.479516; this version posted February 9, 2022. The copyright holder for this preprint (which was not certified by peer review) is the author/funder. All rights reserved. No reuse allowed without permission.

A
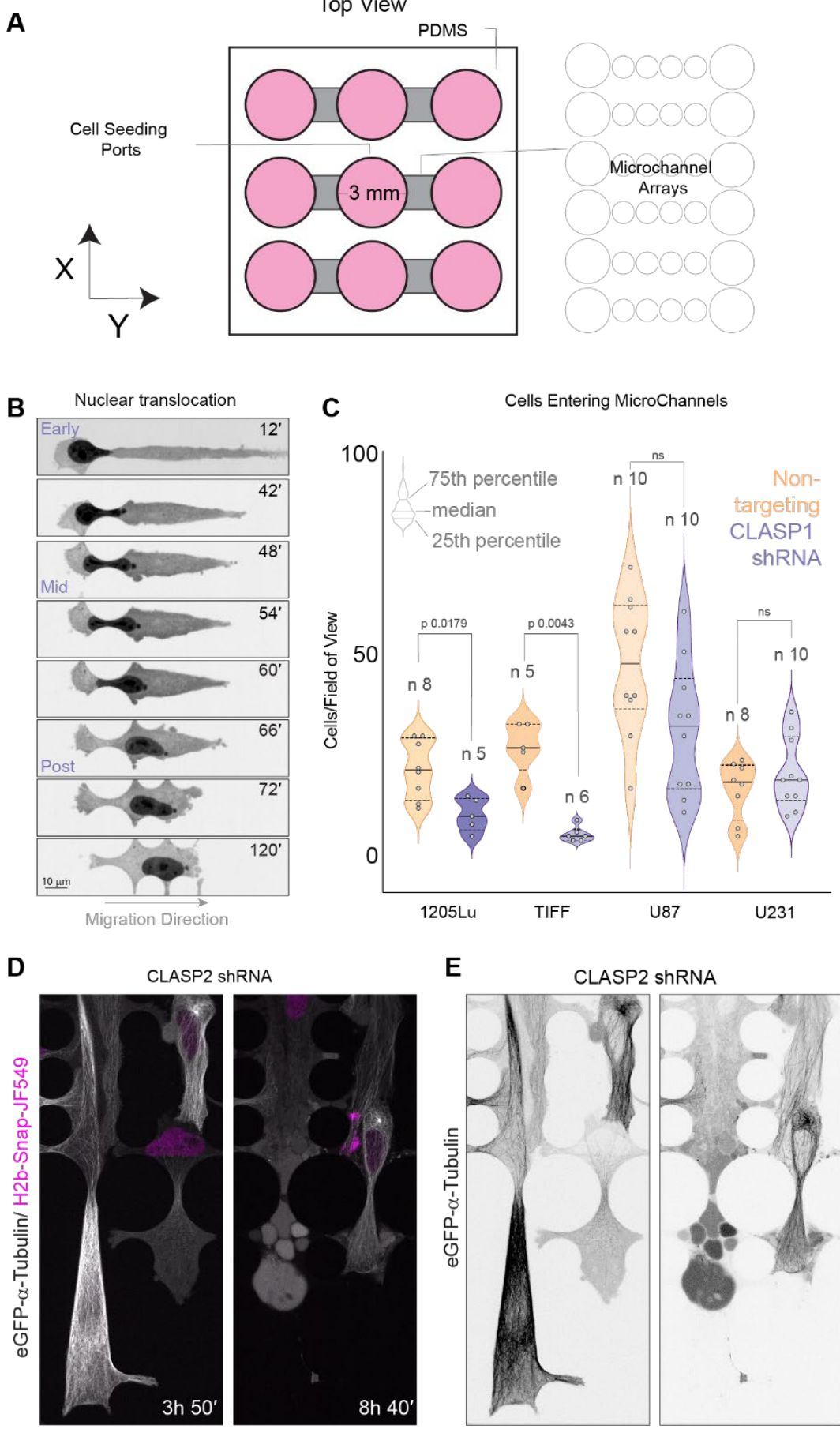

Fig.S4. Validation of CLASP Migration Phenotype in PDMS constriction channels. (A) Simplified graphical schematic of constriction microchannel design. (B) Example of a nuclear translocation event- showing early, mid and post constriction phases. (C) CLASP depletion decreases the number of cells entering constriction microchannels (12 h of live imaging). (nt; non-targeting shRNA, KD; CLASP1 shRNA \#. 1205lu melanoma, TIFF telomeraseimmortalized normal fibroblasts, U87 and U231 medulloblastoma). (D) Timelapse sequence of cells undergoing nuclear constriction in microchannels. Spinning disk confocal microscopy of CLASP2-depleted 1205Lu cells endogenously expressing microtubules (eGFP- $\alpha$-tubulin; white) and co-expressing a nuclear marker (SNAPtag-H2B; magenta). (E) LUT inverted timelapse images of microtubules from D. 
bioRxiv preprint doi: https://doi.org/10.1101/2022.02.08.479516; this version posted February 9, 2022. The copyright holder for this preprint (which was not certified by peer review) is the author/funder. All rights reserved. No reuse allowed without permission.

2xmNeongreen CLASP1

Mid- Confinement Tracks

$0-45$ seconds

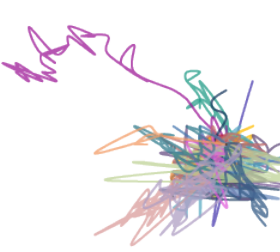

Rear Tracks

n 26

Fig.S5. CLASP1 exhibits polarized Spatio-Temporal dynamics. Spider plots of CLASP1 (2xmNeonGreen-CLASP1) tracks in front and rear cell compartments during mid-nuclear occlusion. 45 seconds duration. 
bioRxiv preprint doi: https://doi.org/10.1101/2022.02.08.479516; this version posted February 9, 2022. The copyright holder for this preprint

A

Microchannel Array Patterns

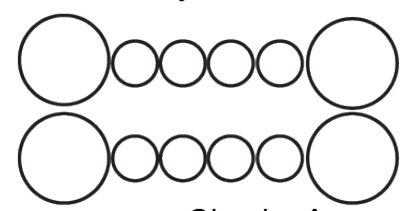

Circular Array

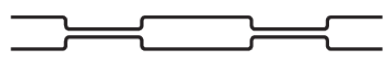

Continuous Confinement

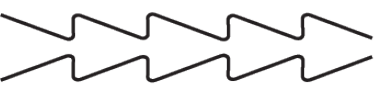

Ratcheting Confinement

C

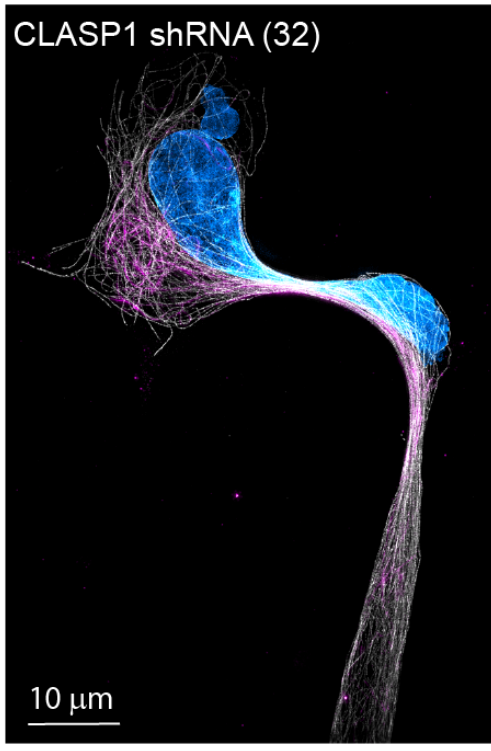

B
Acetylated- $\alpha$-tubulin Tyrosinated- $\alpha$-tubulin DAP
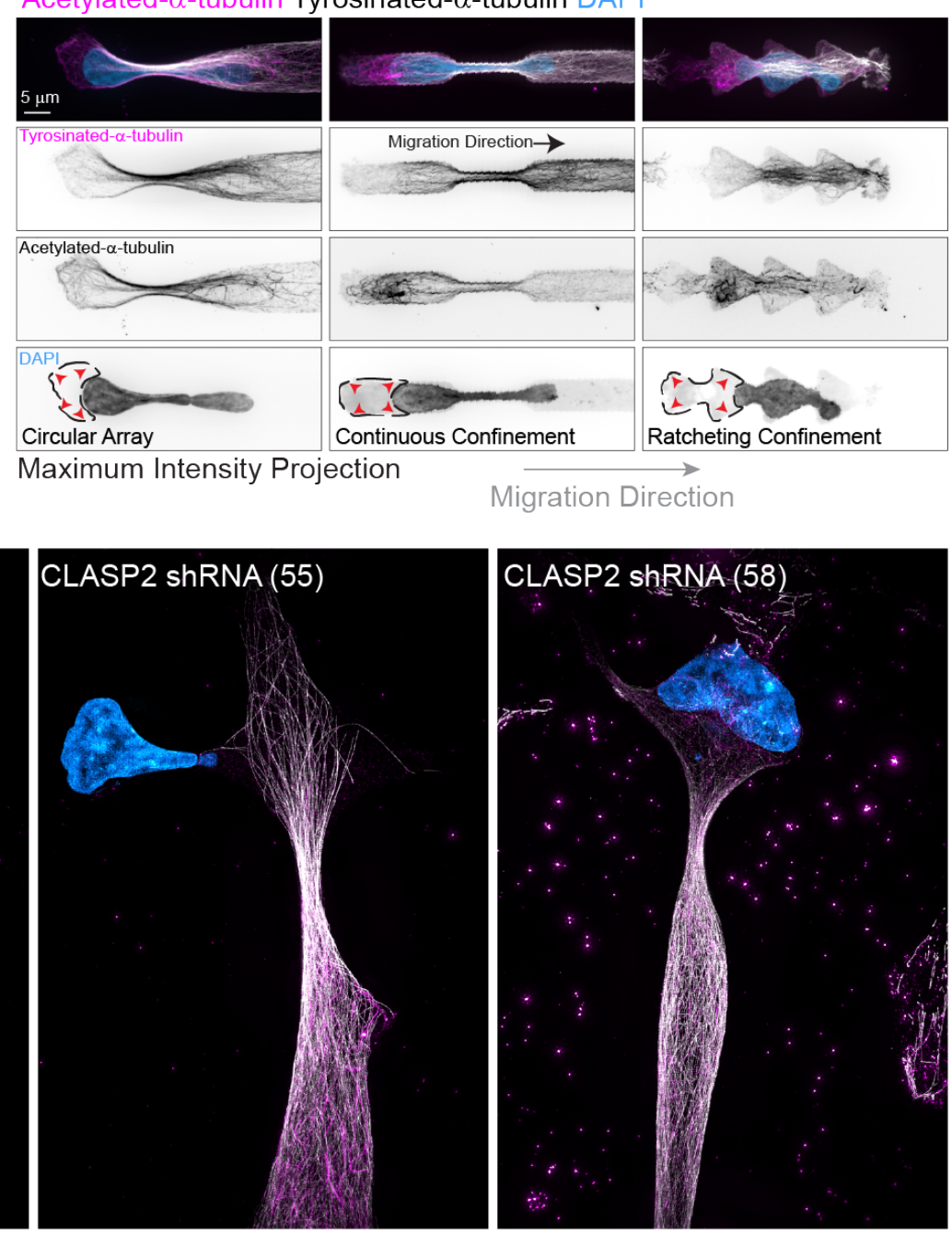

Fig.S6. Microtubule Acetylation Patterns in Cells in Confinement. (A) Simplified graphical schematic of constriction microchannel patterns; Circular, continuous and ratcheting. (B) Immunofluorescence of $1205 \mathrm{Lu}$ melanoma cells labelled for acetylated a-tubulin (AcK40, magenta), tyrosinated a-tubulin (white) and nuclei (DAPI, cyan) navigating through indicated microchannel designs. Scale bar $5 \mu \mathrm{m}$. Images are displayed as maximum intensity projections of z-stacks. Single channels are displayed as contrast inverted images, demonstrating regardless of design, acetylated-a-tubulin forms a polarized network that contrasts tyrosinated-a-tubulin. A rear cytoplasmic compartment can be seen which flanks the rear of the nucleus (dotted line), predominantly filled with flexible acetylated tubulin (red arrow heads). 
A

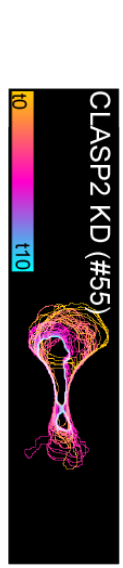

\section{B}

Constriction Speed

Active Constriction Post Constriction
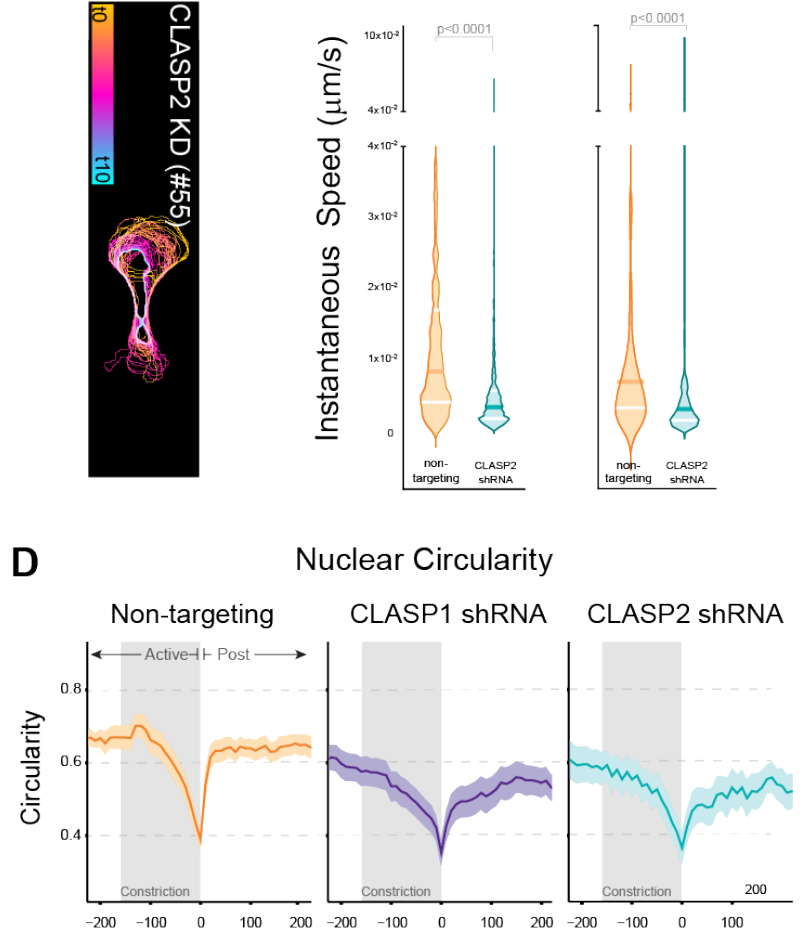

C

Nuclear

Envelope Rupture

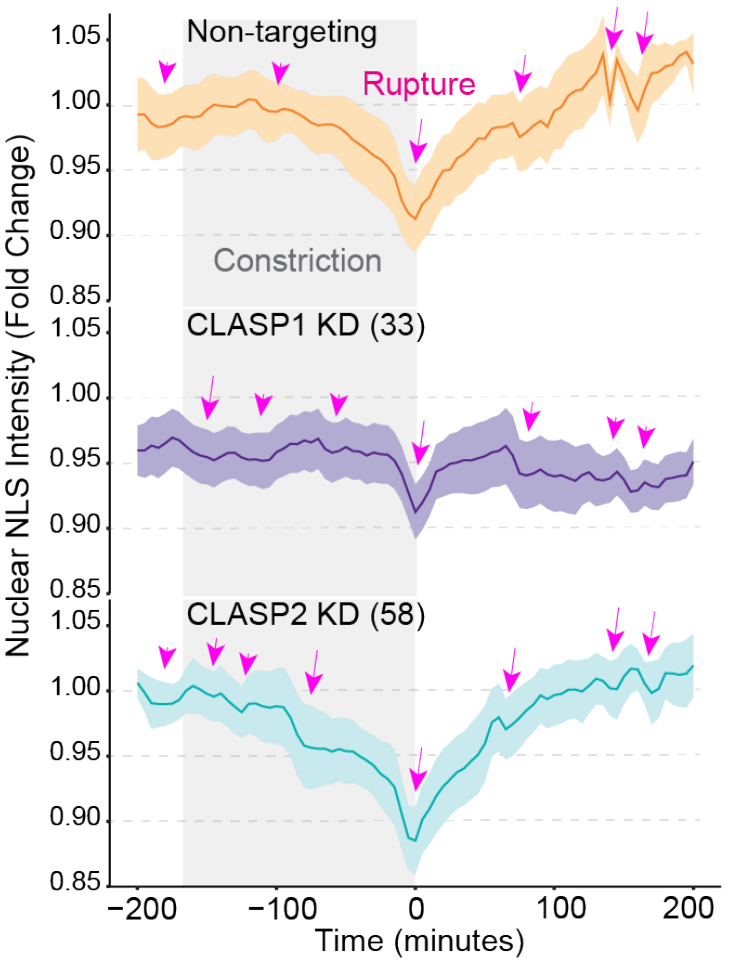

Fig.S7. CLASP-depleted cells exhibit aberrant nuclear positioning and morphologies. (A) Temporal color-coded projection of nuclear outlines of a CLASP2-depleted cell undergoing nuclear constriction. (B) Instantaneous cell speeds during active and post nuclear constriction phases; comparing control (non-targeting shRNA and CLASP2-depleted cells (CLASP2shRNA). (C) Nuclear circularity traces of control (non-targeting shRNA) and CLASP depleted cells (CLASP1 and CLASP2 shRNA) showing lower nuclear circularity values as cells enter and exit constrictions. Graph shows mean circularity values with shaded 95\% C.I. Nontargeting shRNA $n=61$, CLASP1-shRNA $n=55$, CLASP2 shRNA $n=43$, data is representative of two independent repeats. (D) Representative 1205lu cells expressing 3xnls-mScarlet-i demonstrating nuclear herniation (cell 1; teal outline) vs., nuclear rupture and recovery (cell 2; orange outline). The loss of nuclear fluorescence intensity (3xNLS-mScarlet-i) during constriction, demonstrating nuclear signal loss associated with nuclear envelope rupture. (E). Nuclear NLS intensity quantitation demonstrating major and minor rupture events (magenta arrows) during constriction. Graph shows mean with shaded $95 \%$ C.I. Non-targeting $n=37$, CLASP1 KD n=23, CLASP2 KD n=25, data is representative of two independent repeats. 
bioRxiv preprint doi: https://doi.org/10.1101/2022.02.08.479516; this version posted February 9, 2022. The copyright holder for this preprint (which was not certified by peer review) is the author/funder. All rights reserved. No reuse allowed without permission.
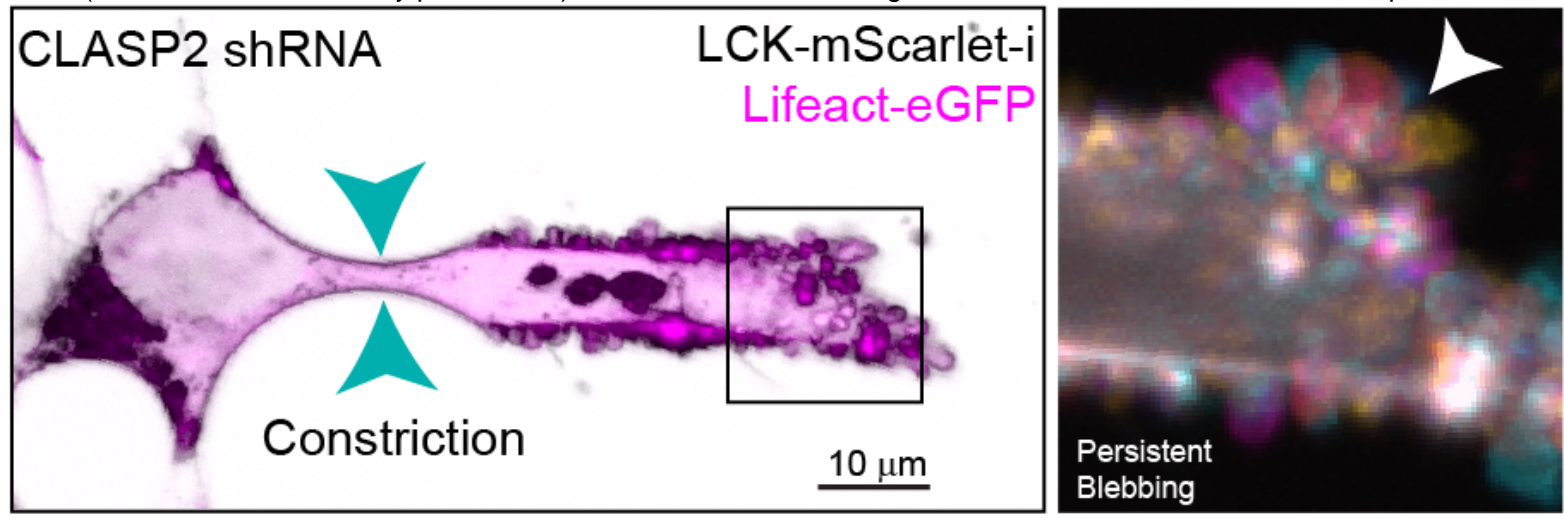

Fig.S8. CLASP2-reinforced microtubules are required to coordinate contractility in confined cells. Time-lapse images of control CLASP2-depleted cells co-expressing membrane (LCK-mScarlet-i) and cortical (eGFP-Lifeact) markers undergoing nuclear constriction in microchannels. Insets are temporal color-coded projections (1 frame/sec for $1 \mathrm{~min}$ ) of actin bleb dynamics at the cell surface. 
A (which was not certified by peer review) is the author/funder. All rights reserved. No reuse allowed without permission.

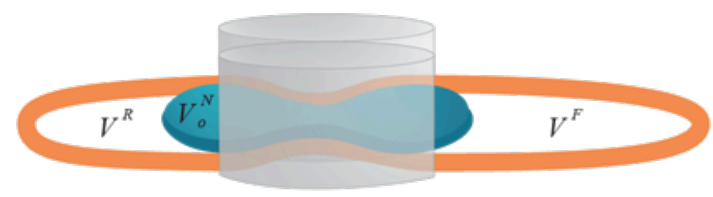

C

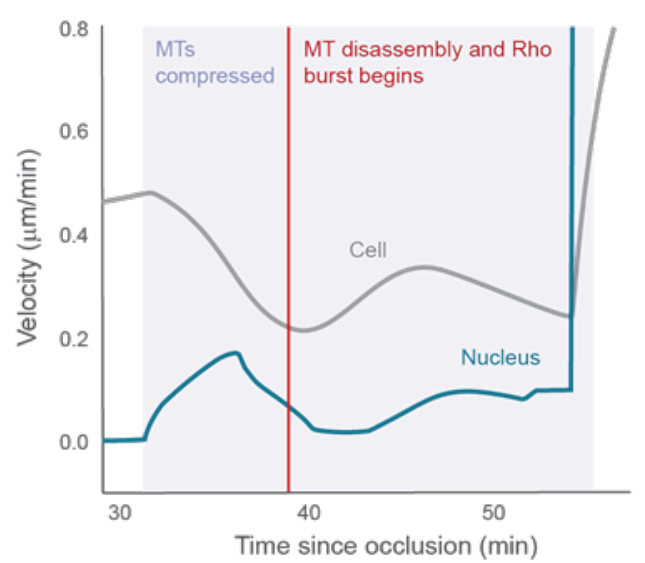

B

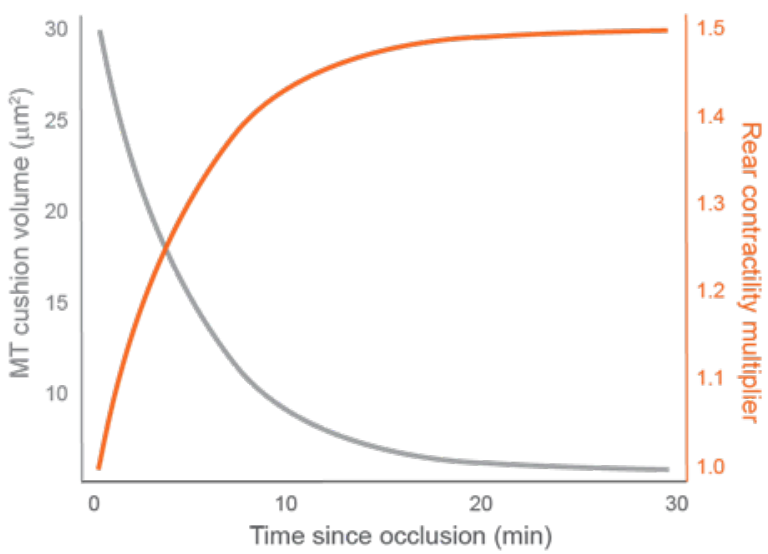

D

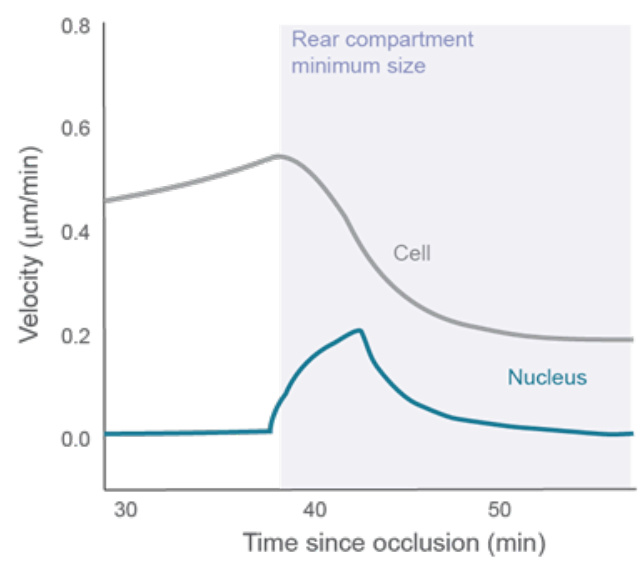

Fig.S9. (A) Sketch of the 2D cross sections of a cell and its nucleus during occlusion. The front and rear cytosolic compartments as well as the nucleus have volumes $\mathrm{V}^{\mathrm{R}}, \mathrm{V}^{\mathrm{F}}$ and $\mathrm{V}_{0} \mathrm{~N}$. . (B) Gradual shrinking of the rear microtubule cushion (grey) and simultaneous increase of the Rho up-regulation factor (rear contractility multiplier (orange) after initiation of microtubule cushion disassembly. (C) Velocity of cell (grey) and nucleus (blue) for the simulation in Fig. 6C and SM12 depicting a control cell. The initiation of the Rho burst (red line) accelerates both cell and nucleus which finally leads to the sudden passage of the nucleus through the constriction. (D) Velocity of cell (grey) and nucleus (blue) for the simulation without the microtubule cushion in Fig. 6D and movie S13 
bioRxiv preprint doi: https://doi.org/10.1101/2022.02.08.479516; this version posted February 9, 2022. The copyright holder for this preprint (which was not certified by peer review) is the author/funder. All rights reserved. No reuse allowed without permission.

\section{Materials and Methods}

\section{Cell Culture}

1205Lu human melanoma cells (Meenhard Herlyn, Wistar), Telomerase-immortalised fibroblasts (TIFs) (Paul Timpson, Garvan Institute of Medical Research), glioblastoma astrocytoma cell lines U-251 MG (Merck, SKU09063001-1VL) and U-87 MG (Merck, SKU 89081402-1VL), HEK293FT cells (ThermoFisher Scientific , R70007) were all maintained in high glucose DMEM (Gibco, 11965092), 10\% foetal bovine serum (Gibco, 10100147), 0.1 $\mathrm{mM}$ MEM non-essential amino acids (11140050, Gibco) and 100 i.u. $\mathrm{ml}^{-1}$ penicillin, $100 \mu \mathrm{g}$ $\mathrm{ml}^{-1}$ streptomycin (Gibco, 15070063). 293FT cells were maintained in $0.5 \mathrm{mg} \mathrm{ml}^{-1} \mathrm{G} 418$ (Gibco, 10131-035). Cells were routinely subjected to PCR mycoplasma testing $[1,2]$ and confirmed negative.

3D Atelo Bovine collagen I (Advanced Biomatrix, \#5133, FibriCol) hydrogels were prepared by diluting collagen I stock to a final concentration of $2.5 \mathrm{mg} / \mathrm{ml}$ with $10 \% \mathrm{v} / \mathrm{v} 10 \mathrm{x}$ MEM- $\alpha$ (BE12-684F, Lonza), 10\% v/v foetal bovine serum, $2 \mathrm{mM}$ L-glutamine (Gibco, 25030) and sterile water. Hydrogel solutions were titrated to $\sim \mathrm{pH} 7$ using sodium bicarbonate (Gibco, 25080094) with $\mathrm{pH}$ indicator strips (Merck, 109535). Collagen I solution preparation was performed on ice with all reagents pre-chilled to $4{ }^{\circ} \mathrm{C}$, polymerization was induced by incubation at $37{ }^{\circ} \mathrm{C}, 5 \% \mathrm{CO}_{2}$ in a tissue culture incubator for 30-60 minutes after cell embedding, before imaging. Recombinant CNA35-Halotag collagen I binding peptide was purified and used as previously described [3], endotoxin levels were reduced using spin columns (Thermo Fisher Scientific, 88274,). DQ ${ }^{\mathrm{TM}_{-}}$-collagen was used as per manufacturer's instructions (Invitrogen, D12060).

\section{DNA constructs and lentiviral vectors}

All plasmids will be made available on Addgene and upon reasonable request. To generate stable fluorescent protein expressing 12051 cell lines, proteins of interest were subcloned into entry vectors and recombined into lentiviral destination vectors- except for the eGFP-RhoA expressing cells. Stable 1205Lu-RhoA FRET cells were generated as described previously [4]. The RhoA-FRET biosensor [5, 6], was cloned into the pPB-CAG.EBNXN vector [7] by NdeI/SalI excision from its pcDNA3.1 backbone. pPB-CAG.EBNXN-RhoA-FRET was then co-transfected with pCMV-hyPBase [8] into 1205Lu cells. Changes in RhoA localisation during constricted migration were calculated using eGFP fluorescence alone.

Entry vectors were created as follows. pENTR-SNAPf-H2B was created by restriction digest of pENTR1a-GFP-N2 (FR1) (Addgene, \#19364 Eric Campeau and Paul Kaufman) and pSNAPf-H2B control plasmid (Addgene \#101124, New England Biolabs and Ana Egana) using KpnI and NotI, and ligated together using T4 DNA ligase (New England Biolabs, M0202). The following constructs were created using HiFi assembly (New England Biolabs, E2521L) Compatible fragments were combined as per manufacturer's instructions.

pENTR-3xNLS-mScarlet-I-nucleoplasmin-NLS was created using HiFi assembly (New England Biolabs). The $3 \times$ NLS-mScarlet-I insert was synthesised as a gblock (Genewiz) and PCR amplified (New England Biolabs, M0515, Q5 Hot start) with primers FW 5'CCACCGGCCGGTCGCATGCCAAAAAAGAAGAGAAAGGTAGACC -3' and RV 5'TCGAGTGCGGCCGCTTTATTTCTTTTTCTTAGCTTGACCAGCTTTCTT -3' to create overhanging microhomologies. A microhomology compatible vector was created by PCR 
bioRxiv preprint doi: https://doi.org/10.1101/2022.02.08.479516; this version posted February 9, 2022. The copyright holder for this preprint (which was not certified by peer review) is the author/funder. All rights reserved. No reuse allowed without permission.

amplification of pENTR1a-eGFP-N2 (FR1) [9], (Addgene, \#19364 Eric Campeau and Paul Kaufman) using the primers ENTR-FW 5'-AGCGGCCGCACTCGAGA-3' and ENTR-RV primer 5'- GCGACCGGCCGGTGGAT-3'. The compatible fragments were combined using HiFi DNA assembly (New England Biolabs, E2521L).

pENTR H2B mScarlet-I was created by PCR amplification of mScarlet-I from plasmid EB3mScarlet-I [10] (Addgene \#98826, Dorus Gadella), using the primers FW 5'ACCGGTGAATTCACCATGGTGAGCAAGGGCG-3' and RV 5'GGATCCGCCTGCAGGTTACTTGTACAGCTCGTCCATG-3'. A microhomology compatible vector was created by PCR amplification of pENTR-SNAPf-H2B using primers FW 5'- CCTGCAGGCGGATCC-3' and RV 5'- GGTGAATTCACCGGTCTGTAC-3'.

pENTR LCK-mScarlet-I was created by PCR amplification of LCK-mScarlet-I [10], (\#98821, Addgene, Dorus Gadella), with the primers FW 5'CCACCGGCCGGTCGCGTGAACCGTCAGATCCGCTAG-3' and RV 5'TCGAGTGCGGCCGCTTTATCTAGATCCGGTGGATCCCG-3'. Compatible overhanging microhomologies of pENTR1a GFP N2 (FR1) were created using primers FW 5'AGCGGCCGCACTCGAGA-3' and RV 5'- GCGACCGGCCGGTGGAT-3'.

pENTR-GEF-H1-FLARE212-sGFP2-mScarlet-I-FRET was derived from the original GEFH1-FLARE212 biosensor as described previously [11] with the following modifications. The CFP-YFP FRET donor-acceptor fluorophore module was replaced with sGFP2 and mScarlet$\mathrm{I}$, retaining all the original linker regions. The entire coding sequence was synthesised as a gene block (Gene Universal) and ligated into the PUC57 plasmid. PUC57-GEF-H1-FLARE212sGFP2-mScarlet-I-FRET was then subcloned into an entry vector by restriction digest of pENTR1a-eGFP2-N2 (FR1) and PUC57-GEF-H1-FLARE212-sGFP2-mScarlet-I-FRET with KpnI and XbaI. DNA fragments were ligated together using T4 DNA ligase. All entry plasmids were propagated in XL2-blue ultracompetent E. coli (200150, Agilent) and sequence verified via sanger sequencing (Australian Genome Research Facility, St Lucia).

Lentiviral expression vectors were created by Gateway Gene Cloning (Invitrogen, 11791-020) with Gateway LR Clonase II (Invitrogen, 11791) into either of the following destination vectors: pLX_TRC311 (Addgene, \#113668, John Doench), pLenti CMV Hygro DEST (W1171) [9], (Addgene, \#17454, Eric Campeau and Paul Kaufman), pLIX_403 (Addgene, \#41395, David Root). Lentiviral plasmids were propagated in One Shot Stbl3 chemically competent $E$. coli (ThermoFisher Scientific, C737393). Plasmids were sequence verified with Sanger sequencing using vector specific primers. pLIX_403 fusion gene expression was induced using $5 \mu \mathrm{g} / \mathrm{ml}$ Doxycycline hyclate (Merck, D9891) for $12 \mathrm{~h}$ prior to any performed experiment and withdrawn during the experiment. pLenti LifeAct-eGFP BlastR (Addgene \#84383, Ghassan Mouneimme).

\section{Lentiviral Production and Cell Transduction}

Human pseudo-typed lentivirus particles were produced in low passage HEK293FT cells, cotransfected with lentiviral packaging plasmids (pCEP4-tat, pHEF-VSVG and pNHP) and lentiviral expression plasmids using Lipofectamine 2000 (Invitrogen, 11668019) as previously described [12] with the following modifications. $24 \mathrm{~h}$ after transfection, the media was replaced with media supplemented with $30 \% \mathrm{v} / \mathrm{v}$ foetal bovine serum. Media containing high titer pseudo virus was collected at $4 \mathrm{~h}$ intervals after the first media exchange and continuously for $48 \mathrm{~h}$ thereafter and filtered through a $0.45 \mu \mathrm{m}$ PES filter (Merck, SLHP033RS) to remove cell 
bioRxiv preprint doi: https://doi.org/10.1101/2022.02.08.479516; this version posted February 9, 2022. The copyright holder for this preprint (which was not certified by peer review) is the author/funder. All rights reserved. No reuse allowed without permission.

debris. Media containing viral particles was supplemented with $8 \mu \mathrm{g} / \mathrm{ml}$ Hexadimethrine bromide (Sigma-Aldrich, 107689) to transduce target cells. Infected cells were selected $48 \mathrm{~h}$ after transduction with antibiotic supplemented media containing either $0.1 \mathrm{mg} / \mathrm{ml}$ Hygromycin B (H3274, Roche), $5 \mu \mathrm{g} / \mathrm{ml}$ Blasticidin S Hydrochloride (Gibco, A1113903), 500 $\mu \mathrm{g} / \mathrm{ml}$ Geneticin/G418 (Santacruz, 108321-42-2) or $2.5 \mu \mathrm{g} / \mathrm{ml}$ Puromycin dihydrochloride (A1113803, Gibco), depending on the lentiviral expression plasmid transduced. Stable cell lines were made following lentiviral transduction and selection as described previously [13, 14]. Cell sorting was conducted using either a Beckman Coulter MoFlo Astrios EQ or BD FACSAria Fusion (SORP) (TRI flow cytometry suite, Translation Research Institute). Cells were sorted to isolate 2-6 populations simultaneously, using gating strategies that identified target populations based upon both the combination of fluorophores expressed and the desired level of expression for the given fluorophores.

Lentivirus-mediated shRNA was performed as above, using the lentiviral shRNA plasmid pLKO.1 expressing CLASP targeting shRNA sequences. Validated shRNA pLK0.1 target sequences were used as previously described [15]. A non-targeting shRNA sequence that has no known target in the mammalian genome was used as a control (non-targeting shRNA) [15]. Transduced cells were maintained in $2.5 \mu \mathrm{g} / \mathrm{ml}$ Puromycin dihydrochloride (A1113803, Gibco) selection media for 5 days before experimental use. CLASP-depletion was validated by immunoblot.

Full-length 2xmNeonGreen-CLASP1 was generated using RNA isolated from 1205Lu cells. RNA was extracted using the Nucleospin RNA mini kit (Macheryl-Nagel, 740955.50). FirstStrand cDNA was synthesised using the Superscript III First-Strand Synthesis System (Invitrogen, 18080051) using oligoDT primers. The CLASP1 isoform was amplified using Q5 Hot Start High-Fidelity DNA Polymerase (New England BioLabs, M0493) with gene specific primers (FW 5'-TCTGGATTTGAATTCCACTATGGAGCCTCGCATGGAG-3' and RV 5'TACTGCCATTAGCTGTGCGTGGAGACATCGGAGGA-3') from synthesized cDNA. The correct target amplicon was identified by agarose gel electrophoresis and purified using a NucleoSpin gel and PCR Clean-up kit (Macheryl-Nagel, 740609). Purified DNA was ligated into the pMiniT 2.0 vector using the New England Biolabs PCR cloning kit (E1203S) and transformed into XL2-blue ultracompetent E. coli (Agilent, 200150). Sequences were validated using sanger sequencing with CLASP1 specific primers (CLASP1-1 FW 5'GTGCTGCTGAGTATGATAACTTCT- $3^{\prime}$ and CLASP1-1 RV 5'CTGATGACAGATGCCCCAAC-3') designed against reference the CLASP1NM_001142273.1 reference sequences using Snapgene software (GSL Biotech LLC). pENTR$2 \mathrm{xmNeonGreen-CLASP1}$ was created by HiFi assembly of the following PCR fragments pENTR1a-GFP-N2 using the primers FW 5'- AGCGGCCGCACTCGAGA - 3' and RV 5'GCGACCGGCCGGTGGAT-3', mNeonGreen-H2B-C10 using the primers FW 5'CCACCGGCCGGTCGCATGGTGAGCAAGGGCG-3', RV 5'GCCCTTGCTCACCATCTTGTACAGCTCGTCCATGC-3', mNeonGreen-H2B-C10 using the primers FW 5'-ATGGTGAGCAAGGGCG-3', FW 5'CATGGCGGTACCGGACTTGTACAGCTCGTCCATGCCC-3' and pMiniT 2.0 CLASP1 using the primers FW 5'-TCCGGTACCGCCATGGAGCCTCGCATGGAG-3' and 5'TCGAGTGCGGCCGCTTTAGCTGTGCGTGGAGACATCG-3'. pENTR1a-2xmNeonGreeCLASP1 was recombined into $\mathrm{pLX}$-TRC311 to create $\mathrm{pLX}-2 \mathrm{xmNeonGreen-CLASP1.}$

2xmNeonGreen-CLASP1 stably expressing $1205 \mathrm{Lu}$ cells were created by first transducing cells with $\mathrm{pLX}-2 \mathrm{xmNeonGreen-CLASP} 1$ lentiviral particles followed by Blasticidin selection. Cells were then transduced with CLASP1 shRNA targeting the 3' UTR of CLASP1 RNA and 
bioRxiv preprint doi: https://doi.org/10.1101/2022.02.08.479516; this version posted February 9, 2022. The copyright holder for this preprint (which was not certified by peer review) is the author/funder. All rights reserved. No reuse allowed without permission.

grown in selection in Puromycin and Blasticidin S selection for 2 weeks, before cell sorting based on $\mathrm{mNeonGreen} \mathrm{fluorescence} \mathrm{intensity.}$

pET28a-Halotag-CNA35 was created using InFusion HD Assembly (Takara) by replacement of the eGFP coding sequence within pET28a-eGFP-CNA35 [3], (Addgene, \#61603, Maarten Merkx; primers FW 5'-TCCGGAGAATTCCACGGATCCG-3' and RV 5'GCTAGCCATATGGCTGCCGC-3'), with a Halotag coding sequence from pENTR4-Halotag (Addgene, \#29644, Eric Campeau; primers FW 5'AGCCATATGGCTAGCATGGCAGAAATCGGTACTGGC-3' and RV 5'GTGGAATTCTCCGGAGCCGGAAATCTCGAGCGTC-3'). The construct was sequence validated before expression and purification as previously described [3].

JF549 and JF646 Halotag and SnapTag ligands [16] were a generous gift from Luke Lavis (Janella Research Campus, HHMI). Hoechst 33342, (Invitrogen, H1399) Annexin V 647 (Invitrogen, A23204) were used as live cell dyes.

\section{CRISPR Knock-in of eGFP- $\alpha$-Tubulin}

CRISPR-CAS9 endogenous eGFP tagging of the TUB1AB in 1205Lu cells was performed as previously described $[17,18]$. To create a uniform fluorescent population of cells, cells were sorted using a MoFlo Astrios EQ cell sorter (Beckman Coulter) using a two-round sort strategy. Cells were first sorted using an enrichment mode to sort cells expressing high levels of eGFP. These enriched cells were immediately subjected to a second round of sorting, employing a purity sort mode (and gating strategy that defined a narrow window of eGFP expression), resulting in a purified population with uniform eGFP and post-sort purity of $>98 \%$.

\section{Antibodies, immunofluorescence and immunoblotting}

Immunofluorescence was performed using protocols previously described [13, 15]. Acetylated $\alpha$-tubulin (Merck, T7451), tyrosinated $\alpha$-tubulin (Merck, MAB1864-I) were detected using protein specific antibodies. Goat anti-Mouse Alexa-488 (Thermo Fisher Scientific, A32723) and Goat anti-Rabbit Alex Fluor 594 (Thermo Fisher Scientific, A-11012) conjugated secondary antibodies were used for immunofluorescence. F-actin and nuclei were labelled with Alexa Fluor 647 phalloidin (Thermo Fisher Scientific, A22287) and DAPI (Invitrogen, D1306). For 3D immunofluorescence samples in Collagen, 1205Lu cells were embedded for 24 hours before being fixed with $0.25 \%$ Glutaradehyde, $4 \% \mathrm{v} / \mathrm{v}$ Paraformaldehyde, $0.1 \%$ Trixton-X 100 in cytoskeleton stabilisation buffer and stained with CNA35 fusion proteins with the exception of fig S1 which was DQ collagen (XX). For immunofluorescence in microchannels, cells were first fixed in 4\% PFA in BRB80 before removal of the PDMS device.

Immunoblotting and primary antibody dilutions were performed as previously described [13, 15]. Acetylated $\alpha$-tubulin (Merck, T7451), $\alpha$-tubulin (Merck, T5168), CLASP1 and CLASP2 (Absea 050801A06, and 032012H02) were detected using protein specific antibodies. Rabbit, Mouse or Rat specific HRP conjugated secondary antibodies (7074, 7076, 7077, Cell Signaling Technology) were used to detect primary antibodies for immunoblotting and detected using Luminata Forte ECL reagent (WBLUF0100, Merck Milipore). Membranes were imaged using a BioRad gel documentation system, and assembled in Adobe Illustrator CC. Images were adjusted linearly to enable comparison of protein of interest to loading controls

Tubulin Pelleting Assay 
bioRxiv preprint doi: https://doi.org/10.1101/2022.02.08.479516; this version posted February 9, 2022. The copyright holder for this preprint (which was not certified by peer review) is the author/funder. All rights reserved. No reuse allowed without permission.

$12051 \mathrm{u}$ cells $\left(4 \times 10^{6}\right)$ were seeded onto $10 \mathrm{~cm}$ tissue culture dishes and allowed to adhere for 5 h. All subsequent steps were performed on ice and with reagents chilled to $4^{\circ} \mathrm{C}$. Samples were washed twice with ice cold PBS containing $4 \mu \mathrm{M}$ Taxol. Cells were scraped and lysed into 400 $\mu 1$ Microtubule-stabilizing buffer containing 0.1 M PIPES, pH 6.9, $2 \mathrm{M}$ glycerol, $5 \mathrm{mM} \mathrm{MgCl}$, $2 \mathrm{mM}$ EGTA, $0.5 \%$ Triton X-100, 1x cOmplete Protease inhibitor cocktail (Merck, 04693159001) and supplemented with $4 \mu \mathrm{M}$ Taxol to maintain microtubule stability during isolation. Cell lysates were vortexed and protein concentration was determined (Pierce BCA Protein Assay Kit, 23225). $100 \mu \mathrm{g}$ of each sample was transferred to a new microfuge tube and centrifuged for 45 minutes at $20,000 \mathrm{RCF}$ at $4^{\circ} \mathrm{C}$ before separating the supernatant containing monomeric tubulin from the polymerized microtubule pellet. Each pellet was then resuspended into $100 \mu \mathrm{l}$ of $1 \mathrm{x}$ Laemmli buffer containing $0.5 \% \mathrm{w} / \mathrm{v}$ Bromophenol blue, $0.5 \mathrm{M}$ Dithiothreitol, $5 \% \mathrm{w} / \mathrm{v}$ SDS in $0.5 \mathrm{M}$ Tris- $\mathrm{Cl} \mathrm{pH} 6.8$ and incubated at $95^{\circ} \mathrm{C}$ for 5 minutes. 20 $\mu \mathrm{g}$ of each cell protein lysate sample was separated using a hand-cast $5-15 \%$ gradient Tris glycine gel (BioRad, Protocol Bulletin 6201) using a custom made 25-well comb.

\section{Microchannel Fabrication}

Fabrication of moulds for microchannel experiments was performed at the Australian National Fabrication Facility - Queensland at the Australian Institute for Bioengineering and Nanotechnology, The University of Queensland. Fabrication was performed in either a class 1000 or 10,000 clean room with generous assistance from ANFF-Q professional staff.

\section{Chrome Mask Printing}

Microchannel designs were created using L-Edit (Tanner Tools) or AutoCAD 2021 and printed using a Heidelberg uPG 101 using the high-resolution print head ( $>2 \mu \mathrm{m}$ features). Designed were etched onto 5 Inch square soda-lime chrome masks. After chrome photomask etching, each mask was subjected to one cycle of post baking on a dry hot plate at $95^{\circ} \mathrm{C}$ for one minute. Each chrome mask was developed in AZ726 developer (MicroChemicals) for 45 seconds with gentle agitation, then rinsed thoroughly with de-ionized water and dried with nitrogen gas. Chrome etching of each photomask was performed using Chromium etchant (Merck, 651826). Timing varied between 1-10 minutes, notably the termination of the process was finalized after the following steps were observed: 1. Chrome appearance of features 2. Chrome disappearance 3 . Feature transparency at locations originally seen in chrome in step 1. Once progression through steps was visualized, each mask was rinsed with deionized water and dried with nitrogen gas. To complete chrome photomask development, each mask was submerged in acetone and sonicated in an ultrasonic cleaner at $30 \%$ power at $75^{\circ} \mathrm{C}$. Post sonication, each mask was washed several times with acetone, then placed into another beaker filled with $100 \%$ isopropanol and sonicated under the same conditions. After sonication, masks were washed one final time with $100 \%$ isopropanol and each mask was gently wiped clean with a low lint towel wetted with $100 \%$ isopropanol.

\section{SU-8 2000 Mould Fabrication and Silanization}

To ensure SU-8 2000 adhesion to silicon wafers, 5 inch round silicon wafers were etched using $48 \%$ hydrofluoric acid (Sigma, 695068). The etched wafer was then washed with water, dried using a nitrogen gas and used immediately for SU-8 2000 (Kayaku Advanced Materials, MicroChem) spin coating. To achieve a $\sim 4 \mu \mathrm{m}$ thickness, SU-8 2000 was spin coated as per manufacturer's instructions. The subsequent SU-8 2000 was then soft baked as per manufacturer's instructions. Chrome masks were then overlayed onto SU-8 2000 spin-coated 
bioRxiv preprint doi: https://doi.org/10.1101/2022.02.08.479516; this version posted February 9, 2022. The copyright holder for this preprint (which was not certified by peer review) is the author/funder. All rights reserved. No reuse allowed without permission.

silicon wafers. The resulting chrome mask SU-8 2000 sandwich was exposed on an EVG620 (EV Group) mask aligner using $360 \mathrm{~nm}$ UV light, exposure time and power was tailored depending on mask thickness (typically UV dose ranged from $120 \mathrm{~mJ} / \mathrm{cm}^{2}-140 \mathrm{~mJ} / \mathrm{cm}^{2}$ ). SU82000 regions exposed to UV were then developed using manufacturer instructions.

After SU-8 2000 moulds were developed, each mask was silanzed to create an anti-stiction layer for easy PDMS demolding from SU-8 2000 silicon wafers. Silanization was performed by applying two drops of Trichloro $(1 \mathrm{H}, 1 \mathrm{H}, 2 \mathrm{H}, 2 \mathrm{H}$-perfluorooctyl) silane (Merck, 44893) onto a sheet of aluminium foil, then placed into a vacuum desiccator alongside the SU-8 2000 mould. Air was evacuated using a vacuum tap for 5 minutes, after which the vacuum line was clamped. The vacuum was held for an hour or until the silane had completely vaporized. Successful silanization of the mask was observed by a faint opaque layer on the surface of the SU-8 2000 mould. This step was performed once for every new mould developed.

\section{Polydimethylsiloxane (PDMS) Casting}

PDMS (Slygard 184, Dow Corning) was mixed at a ratio of 10:1 (w/w) base to catalyst-cross linker and poured on top of SU-8 2000 moulds, then baked at $60 \mathrm{C}$ for 2 hours. Seeding ports were created using a $3 \mathrm{~mm}$ biopsy punch (T983-30, ProSciTech). PDMS microchannels were permanently bonded to glass using a Corona discharge tool as previously described [19]. Microchannel devices were functionalized with $50 \mu \mathrm{g} / \mathrm{ml}$ collagen I in PBS and incubated overnight at $37^{\circ} \mathrm{C}$ before replacing with media. To perform experiments, between $1.0 \mathrm{e}^{4}-5.0 \mathrm{e}^{4}$ cells were resuspended in $10 \mu \mathrm{l}$ and seeded into each $3 \mathrm{~mm}$ port. Cells were allowed to attach for 6-12 hours before subsequent imaging.

\section{Axial Confinement of Cells}

Axial cell confinement was performed using a 1-well dynamic confinement device (4D cell), confinement height was controlled using a coverslip containing 3 um height PDMS micropillars passivated with non-adhesive pLL-PEG (SuSoS).

\section{Microscopy, image processing and data analysis}

Fixed and live imaging was performed on a custom-built spinning disk confocal microscope as previously described [14] or an Andor Dragonfly spinning disk confocal equipped with dual Andor Zyla 4.2 sCMOS cameras, controlled by Fusion Software (Andor). 3D-SIM was performed using a GE-OMX-V4 Blaze (Applied Precision, GE Healthcare). LSFM was performed on a custom built high numerical aperture variant of Axially Swept Light Sheet Microscope without utilising remote focusing or rolling shutter readout, details of this system are published elsewhere [20, 21]. Brightfield and epifluorescence live cell microscopy was performed on a Nikon Ti-E inverted microscopy equipped with a Hammamatsu Flash 4.0 sCMOS camera, controlled by NIS Elements software (Nikon) or an Olympus IX81 live cell microscope equipped with a Hamamatsu Orca Flash 2.8 camera. Subcellular fluorescent protein dynamics were imaged at $37^{\circ} \mathrm{C}$, supplemented with $5 \% \mathrm{CO}_{2}$ (Okolab Cage Incubator Gas Chamber, Bold Line Gas Controller operated by OKO-TOUCH).

Raw images were processed into images and movies in Fiji [22] and NIS elements (Nikon). Tiff stacks were bleach corrected and sharpened using the unsharp mask tool for visualisation purposes only. Quantification was performed only on raw 14-16-bit images. Black-magenta image overlays were generated as described previously [15]. Figures were assembled using 
bioRxiv preprint doi: https://doi.org/10.1101/2022.02.08.479516; this version posted February 9, 2022. The copyright holder for this preprint (which was not certified by peer review) is the author/funder. All rights reserved. No reuse allowed without permission.

Adobe Illustrator CC (Adobe). Statistical analysis was performed in GraphPad Prism 9.0, R Studio, Excel or PlotTwist [23]. For power in statistics, we assumed unequal variance and nonnormal distribution. A Mann-Whitney U test was used for statistical comparison between two groups. A Kruskal-Wallis One-way ANOVA test with a Dunn's correction for false discovery was used for comparisons of two or more groups. Reproducibility was determined based on at least three individual repeats. No predetermined sample sizes were arranged during experimentation.

Object tracking. Cells were embedded in Collagen gels (described above) then recovered in a tissue culture incubator for an hour prior to imaging for $24 \mathrm{~h}$. Images were acquired every 5 min. Cells were tracked based on mCherry-H2B fluorescence using Trackmate [24, 25]. XY tracking data was used to create representative spider-plots, as previously described [13]. CLASP1 tracking was performed using the manual tracking function in Fiji.

Cell viability in microchannels. Nuclei morphology was used to determine cell viability within constriction microchannels. Cells death was deemed to occur once nuclear condensation and fragmentation appeared in the earliest frame (Hoechst 33342 stained or Snaptag-H2B fluorescence).

Microtubule Windowing Analysis. Windowing analysis was performed in MATLAB as previously described [26]. Images of cells expressing eGFP-a-tubulin were first cropped in half along the long axis of the cell in the direction of cell migration. Sampling windows were held constant throughout all frames. Only the first windows adjacent to the defined cell membrane edge was quantitated to derive fluorescence intensity values from microtubules which experienced the most direct mechanical force. Window values were averaged with surrounding nearest neighbour values and normalised to the first sampled window and shown as fold-change. Windows containing $\mathrm{NaN}$ values were excluded and replaced with 0 . Heatmaps were plotted in R studio using ggplot2 [27].

Nuclear approach angle, morphometrics, passage time, rupture and curvature. Nuclear approach angles were measured using the 'angle tool' in Fiji. Angles were created using the first frame where individual nuclei were seen to contact constrictions. Angles were measured by drawing a centre line between the two pillars of constriction in the direction of migration, the second line was drawn to cover the long axis of the nucleus. The angle between the two lines was determined as the nuclear approach angle. Nuclear morphology was quantitated using fluorescent images of Janelia Fluor 549/646 covalent linked Snaptag-H2B nuclei. Images were first gaussian blurred using a sigma of 2.0 then binarized, any holes present within binarized nuclear shapes were filled using the 'Fill Holes' function before using the 'Erode' function. Binary masks were used to derive nuclear circularity measurements and XY positions over time. Extracted values were then used to calculate displacement and instantaneous speed. Duration of nuclear passage time was determined by counting frames between from nuclear constriction pillar first contact to the last frame in which nuclei had completely cleared constriction channels. Nuclear rupture was quantitated based on changes in 3xNLS-mScarletI-NLS signal intensity. The magic wand tool (legacy mode) was used to create ROIs which encompassed at least $90 \%$ of nuclei as cells progressed through constrictions. Fluorescence intensity measurements were normalised to the first measured frame to determine fold-change over time. A cut-off of 0.04-fold reduction was used to determine the presence of nuclear rupture events. Nuclear circularity and nuclear rupture measurements were plotted as a function of normalised time, individual dynamic traces were normalized to each other by aligning the lowest circularity or fold-change values in each trace to timepoint 0 . Nuclear curvature was 
bioRxiv preprint doi: https://doi.org/10.1101/2022.02.08.479516; this version posted February 9, 2022. The copyright holder for this preprint (which was not certified by peer review) is the author/funder. All rights reserved. No reuse allowed without permission.

measured using Kappa $(\kappa)$ [28] in Fiji at the front and rear nuclear contours that were not in direct contact with constriction pillars.

Bleb analysis. To visualise cortex (F-actin) and plasma membrane dynamics, cells were dualtransduced with pLenti eGFP-Lifeact and pLX-LCK-mScarlet-I. Cells were allowed to migrate into channels and imaging acquisition was nested at hourly intervals over a total duration of 24 $\mathrm{h}$, each nested acquisition was acquired at $1 \mathrm{~Hz}$ for 2 mins. Kymographic curves of bleb traces were created in Fiji using a line that only spanned entire blebs from protrusion to retraction. Kymographs were used to measure: bleb formation time (the X-Euclidian-distance from cortical F-actin signal loss - marking cortex rupture- to the maximal membrane bleb height), bleb size (the maximal Y protrusion height from cortex to the peak distention of each bleb) and bleb retraction time (the X-Euclidian distance starting from the base of the maximum curve peak to complete cortex recovery). Individual bleb retraction or formation speeds were calculated using the formula: speed $=\frac{\text { distance }}{\text { time }}$.

Microtubule-Contractility Axis Localisation Dynamics. Quantitation of Microtubule, RhoA and Myosin dynamics during constriction was performed using a 10-point thickness segmented line drawn over the rear and front perimeter of the cell. Nuclei served as demarcation points to create front and rear compartments. Measurements from three specific stages of constricted migration were used. Early constriction - where the cytoplasm but not the nucleus touched constriction pillars, mid constriction - when the nucleus exhibited a 'figure 8' shape and was under peak constriction between pillars, and late constriction - when the nucleus had completely exited and cleared constriction pillars. Individual measurements were background subtracted and mean +/- SEM was graphed.

Ratiometric GEF-H1 FRET images were created in Fiji. sGFP2 timeseries images were first binarized then multiplied, using the 'Image calculator' function, against individual FRET and donor channels to remove spurious FRET signal from the background. Background masked FRET channels were then divided by donor channels to produce ratiometric FRET/Donor images. To quantitate GEF-H1 activation, a polygon ROI was drawn around the rear and front of the cell cytoplasm during the previously defined phases of constricted migration to read out FRET/Donor ratios. 
bioRxiv preprint doi: https://doi.org/10.1101/2022.02.08.479516; this version posted February 9, 2022. The copyright holder for this preprint (which was not certified by peer review) is the author/funder. All rights reserved. No reuse allowed without permission.

\section{Supplementary Text}

\section{Full details of the mathematical model}

\section{Mechanical model for cell and nucleus}

We introduce a mathematical model for single-cell transmigration between two micro-pillars. Our model describes the horizontal $1 \mu \mathrm{m}$ thick cross-section of a cell migrating between two micro-pillars. The nucleus is treated as an elastic object represented by a closed contour line in the two-dimensional plane representing its nuclear envelope $\mathbf{n}(t, s) \in \mathbb{R}^{2}$ (fig. S9A). It is parametrized by $0 \leq s \leq 1$ and $t \geq 0$ represents time. Similarly, the cell cortex is represented by the closed contour line $\mathbf{m}(t, s) \in \mathbb{R}^{2}$. The entire setup is sketched in Figure 1 .

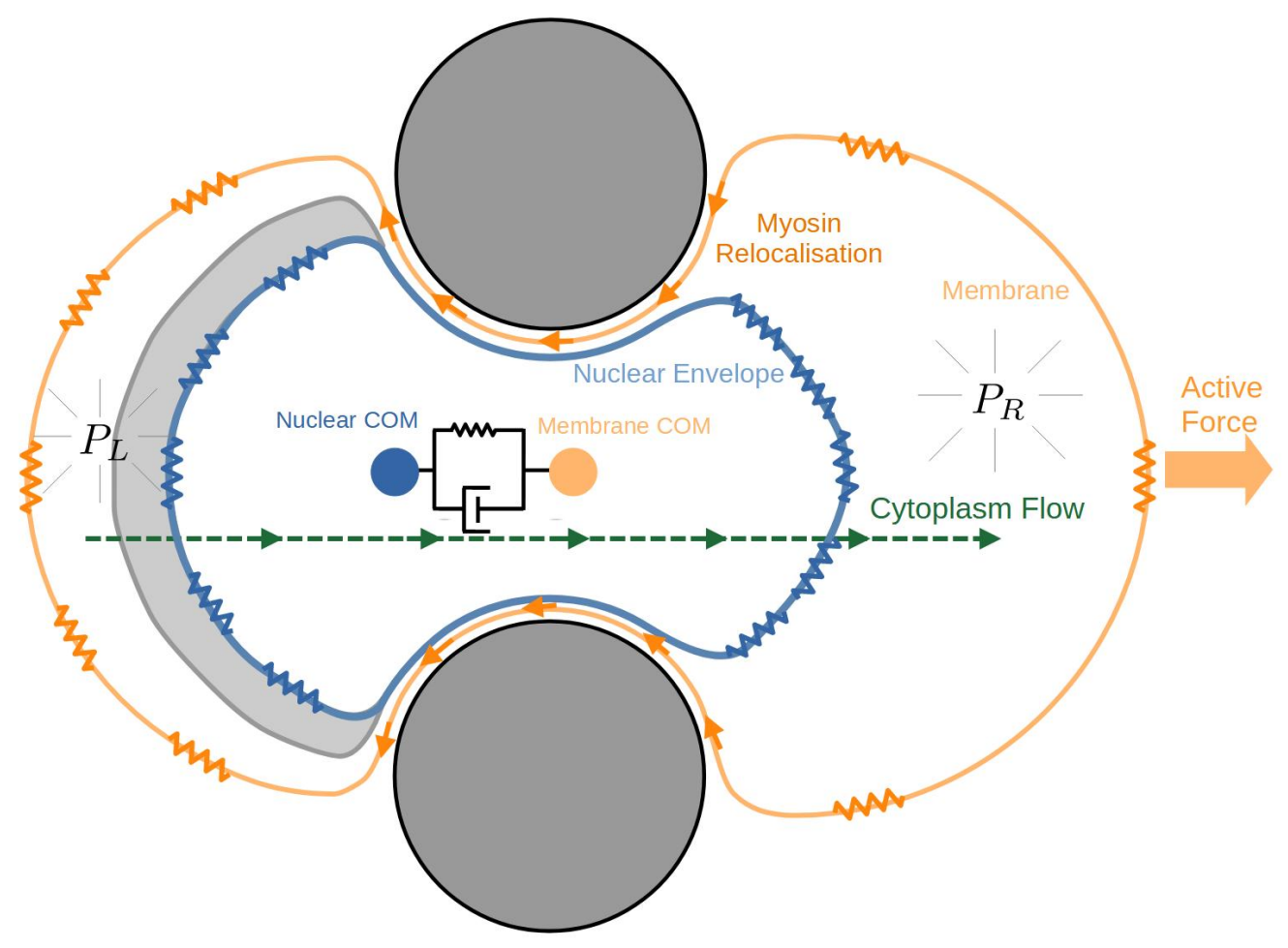

Figure 1: Sketch of the mathematical model during occlusion: The active migratory force acts on both, the centers of mass of the membrane and - mediated by cytoskeleton fibers - of the nucleus. Surface friction is assumed to act on the cell's center of mass. It is coupled to the center of mass of the nucleus through a Kelvin-Voigt element modelling nucleus centering. The cell membrane and the nuclear envelope are under tension. The tension of the cortex adapts locally to the redistribution of myosin due to rearward actomyosin flow and diffusive exchange and pressurizes the front and rear cytoplasm compartments. The resulting pressure differential between rear and front supports the transmigration of the nucleus and induces a flow of cytoplasm between the compartments which is stalled once the volume of the rear compartment reaches the volume associated with the microtubule cushion $V_{0, M T}^{R}$ shown in grey. Upon reaching a threshold pressure the $M T$ cushion disassembles gradually to $\left.V_{0, \text { min }}^{R}\right)$. This triggers a simultaneous increase of Rho activity up-regulating rear tension which ultimately propels the nucleus through the constriction.

We assume that the cell is exposed to a constant active migratory force in the direction of the

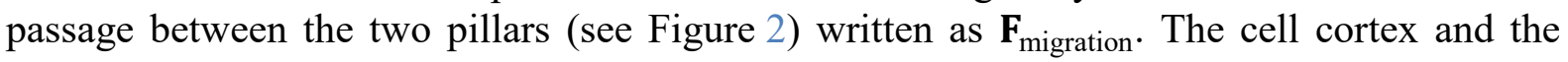


bioRxiv preprint doi: https://doi.org/10.1101/2022.02.08.479516; this version posted February 9, 2022. The copyright holder for this preprint (which was not certified by peer review) is the author/funder. All rights reserved. No reuse allowed without permission.

nuclear envelope are both under tension which gives rise to the following stretching energies and associated forces,

$$
\mathbf{F}_{\text {tension }}^{\mathrm{C}}=\frac{\delta}{\delta \mathbf{m}} E_{\text {tension }}^{\mathrm{C}} \quad \text { where } \quad E_{\text {tension }}^{\mathrm{C}}[\mathbf{m}]=\sigma^{\mathrm{C}} \int_{0}^{1}\left|\mathbf{m}^{\prime}(s)\right| d s
$$

and

$$
\mathbf{F}_{\text {tension }}^{\mathrm{N}}=\frac{\delta}{\delta \mathbf{n}} E_{\text {tension }}^{\mathrm{N}} \quad \text { where } \quad E_{\text {tension }}^{\mathrm{N}}[\mathbf{n}]=\sigma^{\mathrm{N}} \int_{0}^{1}\left|\mathbf{n}^{\prime}(s)\right| d s,
$$

where we model the stiffness of the nuclear envelope $\sigma^{N}$ and of the cell cortex $\sigma^{C}$ as constants and where' represents the derivative with respect to $s$. When the nucleus obstructs the constriction between the two pillars we assume that the cortex is clamped on both sides between the nucleus and the pillars. In this case the rear and the front segment of the cortex are described by curves $\mathbf{m}^{R}=\mathbf{m}^{R}(t, s)$ and $\mathbf{m}^{F}=\mathbf{m}^{F}(t, s)$ and the stretching energy by

$$
E_{\text {tension }}^{\mathrm{M}}\left[\mathbf{m}^{R}, \mathbf{m}^{F}\right]=\sigma^{R} \int_{0}^{1}\left|\left(\mathbf{m}^{R}\right)^{\prime}(s)\right| d s+\sigma^{F} \int_{0}^{1}\left|\left(\mathbf{m}^{F}\right)^{\prime}(s)\right| d s,
$$

where $\sigma^{R}$ and $\sigma^{F}$ are the stiffness of the rear and front cortex.

The volumes (here: the area of the 2D cross-section) of the cytoplasm and of the nucleus are fixed and written as $V_{0}^{C}$ and $V_{0}^{N}$ respectively. When the nucleus occludes the passage the volume of the cytoplasm is divided into the volume of the rear compartment $V^{R}(t)$ and of the front compartment $V^{F}(t)$. In this case the stiffness of the cortex is assumed to vary between rear and front, written as $\sigma^{R}$ and $\sigma^{F}$, in response to the amount of myosin $M^{R}$ and $M^{F}$ in the cortex of the respective compartment. As a consequence, both compartments and also the nucleus are characterised by distinct pressure levels. They are defined by the constraints that the respective volumes are $V^{R}, V^{F}$ and $V_{0}^{N}$. The resulting forces enter the system of force balance equations, namely of forces acting on the cortex

$$
\mathbf{0}=\mathbf{F}_{\text {pressure }}^{\mathrm{C}}+\mathbf{F}_{\text {tension }}^{\mathrm{C}}+\mathbf{F}_{\text {migration }}^{\mathrm{C}}+\mathbf{F}_{\text {centering }}^{\mathrm{C}}+\mathbf{F}_{\text {friction }}^{\mathrm{C}}+\mathbf{F}_{\text {steric }}^{\mathrm{C}},
$$

and of forces acting on the nuclear envelope,

$$
\mathbf{0}=\mathbf{F}_{\text {pressure }}^{\mathrm{N}}+\mathbf{F}_{\text {tension }}^{\mathrm{N}}+\mathbf{F}_{\text {centering }}^{\mathrm{N}}+\mathbf{F}_{\text {steric }}^{\mathrm{N}}+\mathbf{F}_{\text {migration }}^{\mathrm{N}} .
$$

This system of equations also involves forces due to nucleus centering which is modelled by a Kelvin-Voigt element (Hookean attractive force and drag in parallel) between the centers of mass of the nucleus and the cell, as well as repulsive forces ("steric") preventing overlap between the nuclear envelope and plasma membrane/cortex and also between plasma membrane/cortex and micro-pillars. Note also that we assume that the migratory force $\mathbf{F}_{\text {migration }}$ partially acts partially on the cortex $\left(\mathbf{F}_{\text {migration }}^{\mathrm{C}}\right)$ and on the nucleus $\left(\mathbf{F}_{\text {migration }}^{\mathrm{N}}\right)$.

\section{Actomyosin flux}

Once the nucleus occludes the passage between the micro-pillars we model two dynamic phenomena, myosin re-localization due to the rearward flow of actomyosin [29] and diffusive exchange between the compartments as well as the flow of cytoplasm past the nucleus.

The former is well-documented and plays a critical part in establishing a pressure gradient across the nucleus. To model it we introduce the fraction of cortical myosin contained in the 
bioRxiv preprint doi: https://doi.org/10.1101/2022.02.08.479516; this version posted February 9, 2022. The copyright holder for this preprint (which was not certified by peer review) is the author/funder. All rights reserved. No reuse allowed without permission.

rear and front compartments, $M^{R}=M^{R}(t)$ and $M^{F}=M^{F}(t)$, assuming that the total amount of cortical myosin is conserved, i.e. $M^{R}+M^{F}=1$. We formulate a simple rate equation model stating that there is an influx of myosin into the rear compartment due to the rearward actomyosin flux which is proportional to the fraction of cortical myosin in the front compartment. We also include the effect of myosin exchange through the cytoplasm over or beneath the nucleus through an exchange term which is proportional to the difference of myosin fractions and the rate constant $\bar{\beta}$. This amounts to $\dot{M}^{R}=\beta M^{F}+\bar{\beta}\left(M^{F}-M^{R}\right)$ where $\beta>0$ and $\bar{\beta}>0$ are given. As a consequence - using that $M^{R}=1-M^{F}$, the fraction $M^{R}$ follows the simple first order differential equation

$$
\dot{M}^{R}=\beta\left(1-M^{R}\right)+\bar{\beta}\left(1-2 M^{R}\right) .
$$

Finally, we assume that the stiffness of the cortex in the rear and at the front of the cell is given by a multiple of the fraction of cortical myosin,

$$
\sigma^{R}=\gamma \mu M^{R} \text { and } \sigma^{F}=\gamma M^{F},
$$

where $\gamma>0$ is a given constant and $\mu=\mu(t)$ is a dimensionless up-regulation factor which is initialised by $\mu_{0}=1$ and approaches $\mu_{\operatorname{Max}}$ (see below) upon initiation of rho up-regulation in the rear compartment.

Note that in order to keep the model simple we neglect the exchange of myosin between the two compartments as a consequence of the compartment boundary shifting while the nucleus is moving past the pillars.

\section{Cytoplasm flux}

The total volumes of the nucleus and of the cytoplasm are assumed to be constant and given by $V_{0}^{N}$ and $V_{0}^{C}$. In situations when the nucleus occludes the passage between the micro-pillars dividing the cytoplasm into a front and rear compartment we explicitly distinguish between the volumes of the rear and front compartments, $V^{R}$ and $V^{F}$ in a way such that the total volume of the cytoplasm is conserved (Figure 2), $V^{R}+V^{F}=V_{0}^{C}$.
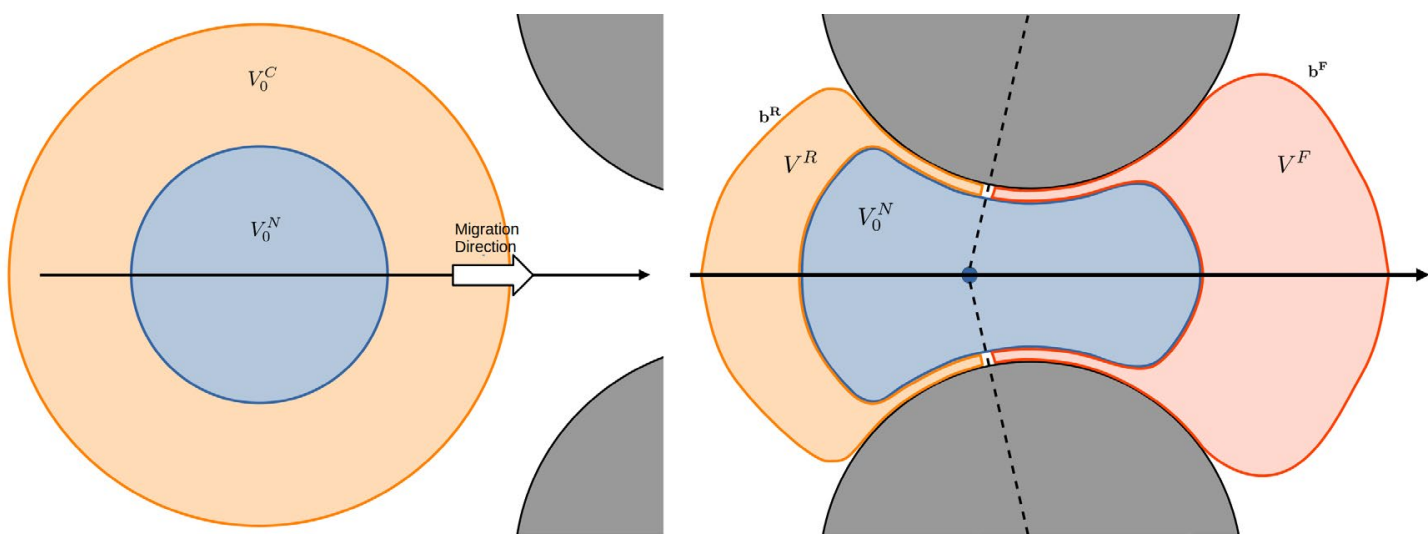

Figure 2: We use a heuristic to identify occlusion of the passage between the two micro-pillars (grey) and to find the boundary points between front and rear (see below). This allows to split the volume of the cytoplasm $V_{0}^{C}$ into rear and front components $V^{R}$ and $V^{F}$.

The redistribution of actomyosin triggers a difference in cortical tension and, subsequently, in intracellular pressure between the front and rear compartments. In agreement with the observations shown in Fig. 1 (main text), we assume that even after the nucleus occludes the space between the two pillars some cytoplasm still flows at a slow rate permeating the nucleus 
bioRxiv preprint doi: https://doi.org/10.1101/2022.02.08.479516; this version posted February 9, 2022. The copyright holder for this preprint (which was not certified by peer review) is the author/funder. All rights reserved. No reuse allowed without permission.

or else flowing beneath or above the nucleus. We model the flux of cytoplasm, typically from the rear into the front compartment, as proportional to the pressure difference between the two compartments,

$$
\dot{V}^{R}=-\dot{V}^{F}=\alpha\left(P^{R}-P^{F}\right)
$$

for a given constant $\alpha>0$.

\section{Microtubule Cushion}

We also model a dense microtubule network in the rear compartment of the cell acting as a mechanical cushion with initial volume $V_{\mathrm{MT}}(t=0)=V_{0, \mathrm{MT}}$, asserting a non-zero volume to this compartment.

This is designed to have no effect when the volume in the rear cytoplasmic compartment, $V^{R}$, is greater than the volume of the MT cushion, but will inhibit the volume of the rear compartment from shrinking below the volume of the MT cushion. We model this mechanical effect by stopping the decrease of $V^{R}$ when $V^{R}$ reaches the threshold value $V_{\mathrm{MT}}$.

We also model a mechanochemical effect assuming that once the pressure acting on the microtubule cushion (i.e. in the rear compartment) reaches the threshold level $P_{\mathrm{MT} \text { disassembly }}$ it gradually undergoes disassembly according to

$$
\dot{V}_{\mathrm{MT}}=-\eta\left(V_{\mathrm{MT}}-V_{\min }^{R}\right)
$$

and simultaneously triggers an increase in Rho activity (Rho burst) up-regulating actomyosin contraction in the rear compartment of the cell. This is modeled as a gradual increase of the dimensionless up-regulation factor $\mu$ in the expressions for $\sigma^{R}$ and $\sigma^{F}$ according to

$$
\dot{\mu}=\eta\left(\mu_{\mathrm{Max}}-\mu\right) .
$$

\begin{tabular}{|c|l|l|l|}
\hline Symbol & Description & Value & Source \\
\hline$V_{0}^{N}$ & volume (area) of the nucleus & $50.3 \mu \mathrm{m}^{2}$ & $\begin{array}{l}\text { Heyden and Ortiz } \\
2017[30]\end{array}$ \\
\hline$V_{0}^{C}$ & volume (area) of the cytoplasm & $706.9 \mu \mathrm{m}^{2}$ & $\begin{array}{l}\text { Heyden and Ortiz } \\
2017[30]\end{array}$ \\
\hline$V_{\mathrm{MT}}$ & $\begin{array}{l}\text { volume (area) occupied by rear } \\
\text { MT network }\end{array}$ & $30 \mu \mathrm{m}^{2}$ & \\
\hline$V_{\mathrm{min}}^{R}$ & $\begin{array}{l}\text { minimal volume (area) occupied } \\
\text { by rear cytoplasm compartment }\end{array}$ & $6 \mu \mathrm{m}^{2}$ & $\begin{array}{l}\text { Nambiar, McConnell, } \\
\text { and Tyska 2009 [31] }\end{array}$ \\
\hline$\sigma^{N}$ & nuclear envelope stiffness & $5000{\mathrm{pN} \mu \mathrm{m}^{-1}}^{\text {Tlili et al. 2018 [32] }}$ \\
\hline$\eta^{C}$ & surface friction & $10000{\mathrm{pN} \mathrm{min} \mu \mathrm{m}^{-1}}^{2}$ & \\
\hline
\end{tabular}


bioRxiv preprint doi: https://doi.org/10.1101/2022.02.08.479516; this version posted February 9, 2022. The copyright holder for this preprint (which was not certified by peer review) is the author/funder. All rights reserved. No reuse allowed without permission.

\begin{tabular}{|c|c|c|c|}
\hline $\mathbf{F}_{\text {migration }}$ & active migratory force & $(5000,0)^{T} \mathrm{pN}$ & $\begin{array}{l}\text { Lomakin et al. } 2020 \\
\text { [33] }\end{array}$ \\
\hline$\alpha$ & $\begin{array}{l}\text { cytoplasm flow rate during } \\
\text { occlusion }\end{array}$ & $0.01 \min ^{-1}$ & \\
\hline$\beta$ & actomyosin re-localization rate & $0.1 \mathrm{~min}^{-1}$ & $\begin{array}{l}\text { Venturini et al. } 2020 \\
\text { [29] }\end{array}$ \\
\hline $\bar{\beta}$ & random exchange of myosin & $0.1 \min ^{-1}$ & estimated \\
\hline$\kappa^{N}$ & $\begin{array}{l}\text { elastic force for nucleus } \\
\text { centering }\end{array}$ & $0.1 \mathrm{pN} \mu \mathrm{m}^{-1}$ & estimated \\
\hline$\eta^{N}$ & $\begin{array}{l}\text { drag coefficient for nucleus } \\
\text { centering }\end{array}$ & $0.5 \mathrm{pN} \min \mu \mathrm{m}^{-1}$ & estimated \\
\hline$\gamma$ & coefficient for cortical tension & $5000 \mathrm{pN} \mu \mathrm{m}^{-1}$ & Winklbauer 2015 [34] \\
\hline$\mu_{\operatorname{Max}}$ & $\begin{array}{l}\text { maximal coefficient for } \\
\text { actomyosin up-regulation } \\
\text { through Rho protein }\end{array}$ & 1.5 & main text, Fig. $5 \mathrm{~F}$ \\
\hline$\eta$ & $\begin{array}{l}\text { rate of gradual MT cushion } \\
\text { disassembly }\end{array}$ & $0.2 \min ^{-1}$ & main text, Fig. 4I \\
\hline
\end{tabular}

This finalizes the formulation of the mathematical model for the dependent quantities (degrees of freedom) $\mathbf{m}=\mathbf{m}(t, s), \mathbf{n}=\mathbf{n}(t, s), M^{R}(t)$ which also determines $M^{F}(t)=1-M^{R}(t)$ and $V^{R}(t)$ which determines $V^{F}(t)=V_{0}^{C}-V^{R}(t)$.

\section{Area and center of mass of regions enclosed by contour lines}

In this section we detail how the area enclosed by a closed contour line and its center of mass can be computed as path integrals and integrated into our mathematical model which is solely based on describing the surrounding contours of cell and nucleus. We denote the area of the region $\Omega$ enclosed by the closed curve $\partial \Omega=\left\{\mathbf{g}(s)=\left(g_{x}(s), g_{y}(s)\right), 0 \leq s \leq 1\right\}$ parametrised in anti-clockwise direction by $A[\mathbf{g}]$ and use the divergence theorem to compute it according to

$$
A[\mathbf{g}]=\int_{\Omega} 1 d x d y=\frac{1}{2} \int_{\Omega} \nabla \cdot\left(\begin{array}{l}
x \\
y
\end{array}\right) d x d y=\frac{1}{2} \int_{\partial \Omega}\left(\begin{array}{l}
x \\
y
\end{array}\right) \cdot \hat{n} d \ell=\frac{1}{2} \int_{0}^{1}\left(x g_{y}{ }^{\prime}(s)-y g_{x}{ }^{\prime}\right) d s,
$$

where $d \ell=\left|\mathbf{g}^{\prime}(s)\right| d s$ is the arc-length element and $\hat{n}=\left(g_{y}{ }^{\prime}(s),-g_{x}{ }^{\prime}(s)\right) /\left|\mathbf{g}^{\prime}(s)\right|$ is the unit outward normal.

Furthermore, we denote the center of mass in the $x$ direction of an area enclosed by the closed curve $\mathbf{g}(s)$ by $\boldsymbol{\Gamma}[\mathbf{g}]=\left(\Gamma_{x}[\mathbf{g}], \Gamma_{y}[\mathbf{g}]\right)$ and compute it according to 
bioRxiv preprint doi: https://doi.org/10.1101/2022.02.08.479516; this version posted February 9, 2022. The copyright holder for this preprint (which was not certified by peer review) is the author/funder. All rights reserved. No reuse allowed without permission.

$$
\begin{gathered}
\Gamma_{x}[\mathbf{g}]=\frac{1}{A[\mathbf{g}]} \int_{\Omega} x d x d y=\frac{1}{A[\mathbf{g}]} \frac{1}{2} \int_{\Omega} \nabla \cdot\left(\begin{array}{c}
x^{2} \\
0
\end{array}\right) d x d y= \\
=\frac{1}{2} \frac{1}{A[\mathbf{g}]} \int_{\partial \Omega}\left(\begin{array}{c}
x^{2} \\
0
\end{array}\right) \cdot \hat{n} d \ell=\frac{1}{2} \frac{1}{A[\mathbf{g}]} \int_{0}^{1} x^{2} g_{y}{ }^{\prime}(s) d s,
\end{gathered}
$$

and an analogous expression for $\Gamma_{y}[\mathbf{g}]$.

\section{Determining occlusion}

We treat the passage between the micro-pillars as occluded when the distances between the center of mass of the nucleus and the micro-pillars are shorter than a threshold value (see Figure 2).

When the passage is occluded the intersections of the circular surfaces of the pillars with the straight lines connecting the center of mass of the nucleus and the center points of the pillars are considered the boundaries between the rear and the front compartments.

We use these boundary points to split the plasma membrane/cortex located at $\mathbf{m}(s)$ and the nuclear envelope located at $\mathbf{n}(s)$ into rear and front parts. Then we glue the rear parts of $\mathbf{m}$ and $\mathbf{n}$ together to obtain a closed contour written as $\mathbf{b}^{R}$ line enclosing the rear cytoplasm compartment and an analogous contour line written as $\mathbf{b}^{F}$ enclosing the front compartment.

Finally, we find the areas of the rear and front compartments using evaluating $A\left[\mathbf{b}^{R}\right]$ and $A\left[\mathbf{b}^{F}\right]$. Note that when the passage is not occluded the volume of the cytplasm can be computed evaluating the difference $A[\mathbf{m}]-A[\mathbf{n}]$.

\section{Numerical scheme}

We simulate the model sketched above using a splitting scheme to compute a time-discrete approximation to the solution $\mathbf{m}^{n}(s), \mathbf{n}^{n}(s), M^{R, n}, V^{R, n}$ with timestep $\Delta t$ and where we use $n$ as a discrete index for time. Note that for the contour lines of membrane/cortex and nuclear envelope we use a spatially discrete approximation of the functions $\mathbf{m}^{n}(s), \mathbf{n}^{n}(s)$, but we omit this detail in the following presentation.

1. In every timestep we update the closed contours for membrane/cortex and nuclear envelope, $\mathbf{m}^{n}(s)$ and $\mathbf{n}^{n}(s)$ according to an implicit Euler scheme for the force balance equations.

2. Then we compute separate updates for the amounts of actomyosin $M^{R, n}$ and $M^{F, n}$, namely an Euler step of their evolution equations and

3. an Euler step for the volume (area) of the rear compartment $V_{0}^{R, n}$ and utilizing that the volume of the front compartment is given by $V_{0}^{F, n}=V_{0}^{C}-V_{0}^{R, n}$.

The numerical treatment of the force balance equations is peculiar in that we compute an implicit Euler step by minimizing an associated energy functional which itself depends on the solution at the previous point in time,

$$
\left(\mathbf{m}^{n}, \mathbf{n}^{n}\right)=\operatorname{argmin}_{\mathbf{m}, \mathbf{n}} E_{\text {total }}\left(\mathbf{m}^{n-1}, \mathbf{n}^{n-1}, M^{R, n-1}, V_{0}^{R, n-1}\right) .
$$

Note that for a minimizer $\left(\mathbf{m}^{n}, \mathbf{n}^{n}\right)$ the variation of $E_{\text {total }}$ vanishes. Indeed, this energy functional is formulated in such a way that its variations with respect to $\mathbf{m}$ and $\mathbf{n}$ correspond 
bioRxiv preprint doi: https://doi.org/10.1101/2022.02.08.479516; this version posted February 9, 2022. The copyright holder for this preprint (which was not certified by peer review) is the author/funder. All rights reserved. No reuse allowed without permission.

to implicit Euler schemes for the force balance equations. Details about the variational formulation of a system of over-damped equations of motions can be found as previously published [35].

The energy functional

$$
E_{\text {total }}=E_{\text {nucleus }}+E_{\text {cell }}+E_{\text {nucleus entering }}+E_{\text {steric }}
$$

contains several components which refer to potential energies (corresponding to conservative forces), pseudo-energies (corresponding to drag forces) and penalizing potentials (corresponding to constraints). They are given by

$$
\begin{aligned}
& E_{\text {nucleus }}= \frac{1}{\varepsilon}\left(A\left[\mathbf{n}^{n}\right]-V_{0}^{N}\right)^{2}+E_{\text {tension }}^{\mathrm{N}}[\mathbf{n}]-v^{N} \mathbf{F}_{\text {migration }} \cdot \Gamma[\mathbf{n}], \\
& E_{\text {cell }}= \frac{1}{\varepsilon} \Theta[\mathbf{m}, \mathbf{n}]+E_{\text {tension }}^{\mathrm{C}}\left[\mathbf{m}^{R}, \mathbf{m}^{F}\right]+ \\
& \quad \quad \quad \frac{\eta^{C}}{2 \Delta t}\left|\Gamma[\mathbf{m}]-\Gamma\left[\mathbf{m}^{n-1}\right]\right|^{2}-v^{C} \mathbf{F}_{\text {migration }} \cdot \Gamma[\mathbf{m}], \\
& E_{\text {nucleus centering }=}=\frac{\kappa^{N}}{2}|\Gamma[\mathbf{n}]-\Gamma[\mathbf{m}]|^{2}+\frac{\eta^{N}}{2 \Delta t}\left(|\Gamma[\mathbf{n}]-\Gamma[\mathbf{m}]|-\left|\Gamma\left[\mathbf{n}^{n-1}\right]-\Gamma\left[\mathbf{m}^{n-1}\right]\right|\right)^{2}, \\
& E_{\text {steric }}=\frac{1}{\varepsilon} \int_{0}^{1}(R-|\mathbf{c}-\mathbf{m}(s)|)_{+}^{2} d s+\frac{1}{\varepsilon} \int_{0}^{1}\left(-d_{\mathbf{m}}(\mathbf{n}(s))\right)_{+}^{2} d s .
\end{aligned}
$$

Note that friction with coefficient $\eta^{C}$ is acting on the center of mass of the cell, whereas the migratory force $\mathbf{F}_{\text {migration }}$ acts partially on the center of mass of the cell and of the nucleus according to the coefficients $v^{C}=0.9$ and $v^{N}=0.1$. This is to avoid un-physical negative pressure in the front compartment.

Constraints were implemented using steep penalization potentials whose coefficient written as $1 / \varepsilon$ can be chosen arbitrarily large (though taking into account numerical stability).

Specifically, $\Theta[\mathbf{m}, \mathbf{n}]$ is a penalizing potential that enforces $V_{0}^{C}$ as the total volume occupied by cytoplasm and $V^{R, n}$ and $V^{F, n}=V_{0}^{C}-V^{R, n}$ as volumes of the rear and front compartments during occlusion,

$$
\Theta[\mathbf{m}, \mathbf{n}]= \begin{cases}\frac{1}{2}\left(A\left[\mathbf{b}^{R}\right]-V^{R}\right)^{2}+\frac{1}{2}\left(A\left[\mathbf{b}^{F}\right]-V^{F}\right)^{2} & \text { channel is occluded } \\ \frac{1}{2}\left(A[\mathbf{m}]-A[\mathbf{n}]-V_{0}^{C}\right)^{2} & \text { otherwise. }\end{cases}
$$

Also note that the first component in $E_{\text {steric }}$ penalizes overlap of plasma membrane and pillars according to a square potential. Here $(\ldots)+$ refers to the positive part of the expression enclosed in brackets. The second component penalizes intersections of nuclear envelope and membrane by evaluating the signed minimal distance $d_{\mathbf{m}}(\mathbf{x})$ of $x$ towards the closed curve representing the membrane $\mathbf{m}(s)$ (positive if $\mathbf{x}$ is inside, negative if it is outside).

Finally, the square penalization terms for the volume constraints in $E_{\text {cell }}$ and $E_{\text {nucleus }}$ deserve special mention. They are not only used to enforce the volumes of the nucleus and the cytoplasm, but also to compute the pressure in the rear and in the front compartment when the passage is occluded. These govern the flow of cytoplasm between compartments. They are computed as the (negative) variation of the penalization term $\Theta[\mathbf{m}, \mathbf{n}]$ with respect to the compartment volumes 
bioRxiv preprint doi: https://doi.org/10.1101/2022.02.08.479516; this version posted February 9, 2022. The copyright holder for this preprint (which was not certified by peer review) is the author/funder. All rights reserved. No reuse allowed without permission.

$$
P_{R}=\frac{1}{\varepsilon}\left(V^{R}-A\left[\mathbf{b}^{R}\right]\right) \text { and } P^{F}=\frac{1}{\varepsilon}\left(V^{F}-A\left[\mathbf{b}^{F}\right]\right) .
$$

\section{Simulations}

In our simulations the two micro-pillars correspond to two circles with radius $R=14 \mu \mathrm{m}$ centered at $\mathbf{c}^{1}, \mathbf{c}^{2}$. For simplicity we assume that they are aligned vertically and symmetrically with respect to the $\mathrm{x}$-axis, at a distance of $2.5 \mu \mathrm{m}$. We also assume that the migratory force is horizontal, $\mathbf{F}_{\text {migration }}=\left(f_{\text {migration }}, 0\right)$, and that the nuclear envelope and the cell membrane are initially circular sharing a centre point on the horizontal axis. As a consequence, in simulations the cell approaches the micro-pillars horizontally. Indeed, with these choices of parameters and initial conditions, the simulation is symmetric with respect to the $x$ axis of the coordinate system. Exploiting this symmetry in simulations allows us to reduce the degrees of freedom by half.

\section{Acknowledgements}

Julia [36] was used to implement the numerical scheme and the Optim.jl package was used for its optimization part. 
bioRxiv preprint doi: https://doi.org/10.1101/2022.02.08.479516; this version posted February 9, 2022. The copyright holder for this preprint (which was not certified by peer review) is the author/funder. All rights reserved. No reuse allowed without permission.

Captions for Movies S1 to S19

Movie S1. Microtubules Form a Dynamic Cage in Cells Moving Through Complex 3D Environments. Time-lapse Light Sheet Fluorescence Microscopy (LSFM) of 1205Lu CRISPR edited cells expressing eGFP- $\alpha$-tubulin (orange heatmap LUT) embedded into 2.5 $\mathrm{mg} / \mathrm{ml}$ collagen I hydrogels within a custom-made sample holder. Collagen I was labelled and visualised using CNA35-mScarlet-I (cyan heatmap LUT). Microtubules surround the nucleus in a single migrating cell, dynamically reorganising as the cell routes through collagen I fibres. Images were acquired every 30 seconds for a total duration of 2 hours, at each time interval $126 \mathrm{Z}$-slices were acquired at $0.4 \mu \mathrm{m}$ steps totalling $50.4 \mathrm{um}$ total. Images are Maximum Intensity Projections. Scale bar $10 \mu \mathrm{m}$.

Movie S2. Contrasting Microtubule Organisation in 2D vs. 3D Migrating Cells. Spinning disc confocal microscopy of 1205Lu CRISPR edited cells expressing eGFP- $\alpha$-tubulin (orange heatmap LUT) migrating on 2D glass coverslips and migrating within $2.5 \mathrm{mg} / \mathrm{ml}$ collagen I hydrogels. Collagen I was labelled and visualised using CAN35-Halotag-JF549 (cyan heatmap LUT). Images of 2D cell migration was acquired every 1 minute for a total duration of 2 hours and 9 minutes. Images of 3D cell migration was acquired every 5 minutes for a total duration of 10 hours and 45 minutes, at each time interval, 3 Z-slices were acquired at $3 \mu \mathrm{m}$ spacing, totalling $9 \mu \mathrm{m}$ total. Z-slices were Maximum Intensity Projected. Scale bar $10 \mu \mathrm{m}$.

\section{Movie S3. CLASP Depletion Perturbs Cell Motility and Survival in 3D Environments.}

Time-lapse phase contrast and wide-field fluorescence microscopy of control (non-targeting shRNA) and CLASP1 depleted 1205Lu cells expressing mCherry-H2B (magenta heatmap LUT) embedded within $2.5 \mathrm{mg} / \mathrm{ml}$ Collagen I hydrogels. Control cells exhibit invasive 3D motility. CLASP1 depleted cells fail to migrate and subsequently rupture when they attempt to migrate. TrackMate overlay of spots and tracks overlayed onto individual cells (pink). Images were acquired at 5-minute intervals for a total duration of 24 hours. Scale bar $50 \mu \mathrm{m}$.

Movie S4. A Microtubule Cage Assembles in Cells Undergoing Constricted Migration. 3D-Structured Illumination Microscopy (3D-SIM) of cells undergoing constricted migration in microchannels, fixed and stained for acetylated (magenta heatmap LUT)/tyrosinated (grey) atubulin and nuclei (cyan heatmap LUT). The microtubule cage structure can be seen to envelope the nucleus, lining the entire cell. Notably, in areas where the cell experiences active constriction, microtubules organise in parallel bundles surrounding the nucleus. During early constriction timing acetylated- $\alpha$-tubulin is predominately polarised to a posterior microtubule pool behind the nucleus (opposing the direction of migration) and interspaced between breaks of tyrosinated- $\alpha$-tubulin. Rotating 3D-projection. Scale bar $5 \mu \mathrm{m}$.

Movie S5. CLASP-Depleted Cells Rupture in Constriction Microchannels. Time-lapse phase contrast and wide-field fluorescence microscopy of non-targeting control and CLASP1 (shRNA \#33) depleted 1205Lu cells with nuclei (cyan heatmap LUT) labelled with Hoechst 33342 migrating within constriction microchannels. Images were acquired at 5-minute intervals for a total duration of 24 hours. Scale bar $10 \mu \mathrm{m}$.

Movie S6. CLASP Depletion Results in Cell Rupture During Confined Migration. 1205Lu CRISPR edited cells co-expressing eGFP- $\alpha$-tubulin (grey) and SNAPtag-H2B-JF549 (magenta heatmap LUT). Control cells (non-targeting shRNA) successfully navigate constrictions between micropillars by deforming the nucleus and cell body. CLASP1 depleted cells rupture 
bioRxiv preprint doi: https://doi.org/10.1101/2022.02.08.479516; this version posted February 9, 2022. The copyright holder for this preprint (which was not certified by peer review) is the author/funder. All rights reserved. No reuse allowed without permission.

at varying stages of constriction challenge. Images were acquired at 10-minute intervals for a total duration of 24 hours. Scale bar $10 \mu \mathrm{m}$.

Movie S7. Acetylated-a-tubulin Polarizes to the Cell Rear During Active Confinement. 3D-Structured Illumination Microscopy (3D-SIM) of cells undergoing constricted migration at varying stages (early, mid, post) of confinement, fixed and stained for acetylated (magenta heatmap LUT), tyrosinated (grey) $\alpha$-tubulin and nuclei (cyan heatmap LUT). Acetylated- $\alpha-$ tubulin polarizes to a rear pool in cells undergoing early constriction. During mid-constriction acetylated- $\alpha$-tubulin exhibits localisation to the parallel bundles of microtubules alongside the nucleus and resolves to peri-cellular accumulation, post-constriction. Rotating 3D-projections. Scale bar $5 \mu \mathrm{m}$.

Movie S8. CLASP-depletion Results in Cortical Blebbing. Nested, time-lapse spinning disc microscopy of membrane (LCK-mScarlet-I, grey inverted LUT) and F-actin (eGFP-LifeAct, magenta inverted LUT) dynamics in non-targeting control and CLASP1 depleted 1205Lu cells migrating within constriction microchannels. Control cells exhibit polarised blebbing at the rear cortico-membrane region during early- and mid-confinement stages. CLASP1-depletion evokes uncontrolled blebbing at anterior and posterior cortico-membrane regions. At every hour interval for a total duration of 24 hours, nested acquisition of images were acquired at 1 second intervals for a total duration for 1 minute. Scale bar $5 \mu \mathrm{m}$.

Movie S9. CLASP-depletion Disrupts the Proximal Enrichment of Myosin During Confined Migration. Time-lapse spinning disc microscopy of non-targeting control and CLASP1 depleted 1205Lu CRISPR edited cells expressing eGFP-a-Tubulin (grey), and lentivirally transduced with mTurqoise2-MLC (myosin, cyan heatmap LUT) and SNAPtagH2B-JF549 (magenta heatmap LUT). Control cells exhibit polarised proximal enrichment of myosin during early to mid-confinement stages. CLASP1-depletion perturbs polarised proximal myosin enrichment during confinement stages. Images were acquired at 15-minute intervals for a total duration of 24 hours. Scale bar $10 \mu \mathrm{m}$.

Movie S10. Timed GEF-H1 Activation Upon Microtubule Depolymerisation Precedes Nuclear Transmigration. Time-lapse spinning disc microscopy showing ratiometric FRET/Donor images of non-targeting control and CLASP1 depleted 1205Lu cells lentivirally transduced with the GEF-H1-FLARE212 biosensor (Black-Purple-Yellow Heatmap LUT). Active GEF-H1 (high FRET/Donor ratio) can be visualised by yellow LUT colour and inactive (low FRET/Donor ratio) GEF-H1 in black-purple LUT colours. Active GEF-H1 polarises proximally in control cells during early to mid-constriction stages. CLASP1 depletion disrupts the proximal polarisation of active GEF-H1 causing cells to fail constricted migration and rupture. Images were acquired at 10-minute intervals for a total duration of 24 hours. Scale bar $10 \mu \mathrm{m}$.

Movie S11. A Timed Rho-burst at the Cell-Rear Progresses Nuclear Transmigration During Confined Migration. Time-lapse spinning disc microscopy of eGFP-RhoA (BlackPurple-Yellow Heatmap LUT) dynamics in non-targeting control and CLASP1 depleted 1205Lu cells. A polarised accumulation of proximal RhoA (yellow LUT colours) prior to nuclear translocation is associated with successful transmigration between constriction microchannels. CLASP1 depletion perturbs the polarised accumulation of RhoA, cells instead accumulate RhoA at both anteriorly and posteriorly leading to a static phenotype. Images were acquired at 10-minute intervals for a total duration of 24 hours. Scale bar $10 \mu \mathrm{m}$. 
bioRxiv preprint doi: https://doi.org/10.1101/2022.02.08.479516; this version posted February 9, 2022. The copyright holder for this preprint (which was not certified by peer review) is the author/funder. All rights reserved. No reuse allowed without permission.

Movie S12. The simulation of nuclear passage and simultaneous build-up of rear pressure (Fig.

6C) for a control cell.

Movie S13. Simulation of failed nuclear passage (Fig. 6D) for a cell lacking the rear microtubule network ("cushion"). 
bioRxiv preprint doi: https://doi.org/10.1101/2022.02.08.479516; this version posted February 9, 2022. The copyright holder for this preprint (which was not certified by peer review) is the author/funder. All rights reserved. No reuse allowed without permission.

\section{References}

1. Uphoff, C.C. and H.G. Drexler, Detecting Mycoplasma Contamination in Cell Cultures by Polymerase Chain Reaction, in Cancer Cell Culture: Methods and Protocols, I.A. Cree, Editor. 2011, Humana Press: Totowa, NJ. p. 93-103.

2. Uphoff, C.C. and H.G. Drexler, Comparative PCR analysis for detection of mycoplasma infections in continuous cell lines. In Vitro Cellular \& Developmental Biology - Animal, 2002. 38(2): p. 79-85.

3. Aper, S.J., et al., Colorful protein-based fluorescent probes for collagen imaging. PLoS One, 2014. 9(12): p. e114983.

4. Boyle, S.T., et al., Acute compressive stress activates RHO/ROCK-mediated cellular processes. Small GTPases, 2020. 11(5): p. 354-370.

5. Nobis, M., et al., A RhoA-FRET Biosensor Mouse for Intravital Imaging in Normal Tissue Homeostasis and Disease Contexts. Cell Rep, 2017. 21(1): p. 274-288.

6. Timpson, P., et al., Spatial regulation of RhoA activity during pancreatic cancer cell invasion driven by mutant p53. Cancer Res, 2011. 71(3): p. 747-57.

7. $\quad$ Yusa, K., et al., Generation of transgene-free induced pluripotent mouse stem cells by the piggyBac transposon. Nat Methods, 2009. 6(5): p. 363-9.

8. Yusa, K., et al., A hyperactive piggyBac transposase for mammalian applications. Proc Natl Acad Sci U S A, 2011. 108(4): p. 1531-6.

9. Campeau, E., et al., A versatile viral system for expression and depletion of proteins in mammalian cells. PLoS One, 2009. 4(8): p. e6529.

10. Chertkova, A.O., et al., Robust and Bright Genetically Encoded Fluorescent Markers for Highlighting Structures and Compartments in Mammalian Cells. bioRxiv, 2020: p. 160374.

11. Azoitei, M.L., et al., Spatiotemporal dynamics of GEF-H1 activation controlled by microtubule- and Src-mediated pathways. J Cell Biol, 2019. 218(9): p. 3077-3097.

12. Coleman, J.E., et al., Efficient large-scale production and concentration of HIV-1based lentiviral vectors for use in vivo. Physiological Genomics, 2003. 12(3): p. 221228.

13. Stehbens, S.J., et al., FGFR2-activating mutations disrupt cell polarity to potentiate migration and invasion in endometrial cancer cell models. J Cell Sci, 2018. 131(15).

14. Stehbens, S., et al., Imaging Intracellular Protein Dynamics by Spinning Disk Confocal Microscopy. Vol. 504. 2012. 293-313.

15. Stehbens, S.J., et al., CLASPs link focal-adhesion-associated microtubule capture to localized exocytosis and adhesion site turnover. Nat Cell Biol, 2014. 16(6): p. 561-73.

16. Grimm, J.B., et al., A general method to improve fluorophores for live-cell and singlemolecule microscopy. Nat Methods, 2015. 12(3): p. 244-50, 3 p following 250.

17. Khan, A.O., et al., CRISPR-Cas9 Mediated Labelling Allows for Single Molecule Imaging and Resolution. Scientific reports, 2017. 7(1): p. 8450-8450.

18. Khan, A.O., et al., Optimised insert design for improved single-molecule imaging and quantification through CRISPR-Cas9 mediated knock-in. Scientific Reports, 2019. 9(1): p. 14219.

19. Haubert, K., T. Drier, and D. Beebe, PDMS bonding by means of a portable, low-cost corona system. Lab on a Chip, 2006. 6(12): p. 1548-1549.

20. Dean, K.M., et al., Deconvolution-free Subcellular Imaging with Axially Swept Light Sheet Microscopy. Biophys J, 2015. 108(12): p. 2807-15. 
bioRxiv preprint doi: https://doi.org/10.1101/2022.02.08.479516; this version posted February 9, 2022. The copyright holder for this preprint (which was not certified by peer review) is the author/funder. All rights reserved. No reuse allowed without permission.

21. Dean, K.M., et al., Diagonally Scanned Light-Sheet Microscopy for Fast Volumetric Imaging of Adherent Cells. Biophys J, 2016. 110(6): p. 1456-65.

22. Schindelin, J., et al., Fiji: an open-source platform for biological-image analysis. Nature Methods, 2012. 9(7): p. 676-682.

23. Goedhart, J., PlotTwist: A web app for plotting and annotating continuous data. PLoS Biol, 2020. 18(1): p. e3000581.

24. Tinevez, J.Y., et al., TrackMate: An open and extensible platform for single-particle tracking. Methods, 2017. 115: p. 80-90.

25. Ershov, D., et al., Bringing TrackMate into the era of machine-learning and deeplearning. bioRxiv, 2021: p. 2021.09.03.458852.

26. Lee, K., et al., Functional hierarchy of redundant actin assembly factors revealed by fine-grained registration of intrinsic image fluctuations. Cell Syst, 2015. 1(1): p. $37-$ 50.

27. Wickham, H., ggplot2-Elegant Graphics for Data Analysis. Springer International Publishing. Cham, Switzerland, 2016.

28. Mary, H. and G.J. Brouhard, Kappa (\&lt;em\&gt; \&\&lt;/em\&gt;): Analysis of Curvature in Biological Image Data using B-splines. bioRxiv, 2019: p. 852772.

29. Venturini, V., et al., The nucleus measures shape changes for cellular proprioception to control dynamic cell behavior. Science, 2020. 370(6514).

30. Heyden, S. and M. Ortiz, Investigation of the influence of viscoelasticity on oncotripsy. Computer Methods in Applied Mechanics and Engineering, 2017. 314: p. 314-322.

31. Nambiar, R., R.E. McConnell, and M.J. Tyska, Control of cell membrane tension by myosin-I. Proceedings of the National Academy of Sciences, 2009. 106(29): p. 11972.

32. Tlili, S., et al., Collective cell migration without proliferation: density determines cell velocity and wave velocity. R Soc Open Sci, 2018. 5(5): p. 172421.

33. Lomakin, A.J., et al., The nucleus acts as a ruler tailoring cell responses to spatial constraints. Science, 2020. 370(6514): p. eaba2894.

34. Winklbauer, R., Cell adhesion strength from cortical tension - an integration of concepts. J Cell Sci, 2015. 128(20): p. 3687-93.

35. Oelz, Dietmar B., Boris Y. Rubinstein, and A. Mogilner, A Combination of Actin Treadmilling and Cross-Linking Drives Contraction of Random Actomyosin Arrays. Biophysical Journal, 2015. 109(9): p. 1818-1829.

36. Bezanson, J., et al., Julia: A Fresh Approach to Numerical Computing. SIAM Review, 2017. 59(1): p. 65-98. 